\author{
UNIVERSIDADE DE SÃO PAULO \\ FACULDADE DE FILOSOFIA CIÊNCIAS E LETRAS RIBEIRÃO PRETO \\ DEPARTAMENTO DE FÍSICA \\ PROGRAMA DE PÓS-GRADUAÇÃO EM CIÊNCIAS \\ ÁREA DE CONCENTRAÇÃO: FÍSICA APLICADA À MEDICINA E BIOLOGIA
}

GUSTAVO DE MENEZES PONTES DA COSTA O MÉTODO MONTE CARLO 


\section{ESTUDOS ESPECTRAIS APLICADOS À RADIOTERAPIA UTILIZANDO O MÉTODO MONTE CARLO}

Dissertação submetida ao programa de PósGraduação em Física Aplicada a Medicina e Biologia, da Faculdade de Filosofia, Ciências e Letras de Ribeirão Preto, da Universidade de São Paulo, como parte dos requisitos para a obtenção do título de Mestre em Ciências.

Área de Concentração: Física Aplicada à Medicina e Biologia.

Orientador: Prof. Dr. Thomaz Ghilardi Netto

RIBEIRÃO PRETO 
Autorizo a reprodução e divulgação total ou parcial deste trabalho, por qualquer meio convencional ou eletrônico, para fins de estudo e pesquisa, desde que citada a fonte.

PONTES DA COSTA, Gustavo de Menezes

Estudos espectrais aplicados à radioterapia utilizando o método de Monte Carlo - Ribeirão Preto - SP, 2013

115 p. : il. ; $30 \mathrm{~cm}$

Dissertação de Mestrado, apresentada à Faculdade de Filosofia, Ciências e Letras de Ribeirão Preto/USP. Área de concentração: Física Aplicada à Medicina e Biologia.

Orientador: Ghilardi Netto, Thomaz.

1. Radioterapia. 2. Controle da Qualidade.

3. Método de Monte Carlo. 4. Dosimetria. .5. Objeto simulador 


\section{ESTUDOS ESPECTRAIS APLICADOS À RADIOTERAPIA UTILIZANDO O MÉTODO MONTE CARLO}

Dissertação submetida ao programa de Pós-Graduação em Física Aplicada a Medicina e Biologia, da Faculdade de Filosofia, Ciências e Letras de Ribeirão Preto, da Universidade de São Paulo, como parte dos requisitos para a obtenção do título de Mestre em Ciências - Área de Concentração: Física Aplicada à Medicina e Biologia.

Aprovado em:

Banca Examinadora

Prof. Dr. Instituição:

Julgamento: Assinatura:

Prof. Dr. Instituição:

Julgamento: Assinatura:

Prof. Dr. Instituição:

Julgamento: Assinatura: 
"Os grandes de espírito sempre acharam a oposição violenta dos medíocres. Estes últimos não conseguem entender quando um homem não se submete aos preconceitos hereditários, mas honesta e corajosamente usa sua inteligência."

(Albert Einstein) 


\section{Dedicatória}

A meus pais, familiares, amigos e a minha namorada por estarem ao meu lado nos bons e nos maus momentos da vida. 


\section{AGRADECIMENTOS}

A Deus que sempre me protegeu nos momentos de distração.

A toda minha família pela compreensão e presença em minha vida, em especial, aos meus pais que tudo fizeram para que esse momento fosse possível, além dos tios, primos e avós e em memória ao meu avô Francisco Novais que acreditava em tudo isso muito antes de acontecer.

Aos professores Dra. Patrícia Nicolucci e Dr. Thomaz Ghilardi Netto pela orientação, ensino, incentivo e ao apoio nos momentos mais difíceis e que fizeram com que eu ingressasse na radioterapia.

Aos professores do Departamento de Física, especialmente aos professores doutores Martin Eduardo Poletti, louri Borissevitch, Ubiraci Pereira da Costa Neves e Eder Rezende Moraes pelo incentivo e auxílio no estudo da física aplicada.

Ao, também, paraibano André Miele pela amizade e compreensão.

Aos funcionários da USP, especialmente a Nilza pelas informações e a dedicação a cada aluno da instituição.

Ao hospital do câncer de Barretos, especialmente ao físico Marcelo pelo suporte, apoio, paciência e a postura de físico médico.

Ao físico Leonardo Lira do Amaral pelo apoio.

À Dra. Cassiana Viccari pelo apoio, amizade e pelas dúvidas esclarecidas.

À minha namorada Laize Nara pela compreensão e pela inspiração fornecida para a realização do trabalho.

Aos amigos do Departamento de física e do CIDRA (Vitor, Alex, Gislaine, Francyelli, Marcelo, Fernando, André Riul, Côco (Paulo), Antônio, Mirko, Thatiane, Jonatas, Cristiano, Fábio Takeda e Wender pelos momentos de descontração e pela amizade.

Aos professores do departamento de física da UFPB, em especial, ao meu orientador de iniciação científica Prof. Dr. Paulo César e ao Prof. Dr. Rubens Silva pela orientação e compreensão e ao Prof. Dr. Nilton Teruya pela disciplina de física nuclear.

Ao matemático Oswald Kerly pelo incentivo.

Aos professores de colégio que me ajudaram nos primeiros passos, em especial aos professores Tranquilino, Trajano e Helder.

Aos amigos de graduação Thiago e Gabriel.

Aos amigos de colégio Rodolfo, Josélio, Felipe Coutinho, Luighi, Wagner Lopes e Hugo Motta (deputado federal, não é fraco não).

Aos físicos do hospital Araujo Jorge: Flamarion, Valdeis, Milton e Katya pelo esclarecimento das dúvidas e pelo apoio.

As amigas Rafaela Freitas e Raquel Magalhães.

Aos técnicos do HAJ.

À CAPES pelo apoio financeiro. 


\section{RESUMO}

PONTES DA COSTA, G. M. Estudos espectrais aplicados à radioterapia utilizando o método de Monte Carlo. Dissertação (Mestrado). Ribeirão Preto: Faculdade de Filosofia, Ciências e Letras de Ribeirão Preto, Universidade de São Paulo; 2013,113 páginas.

O controle da qualidade é uma prática essencial em radioterapia para se garantir que a dose prescrita seja realmente entregue ao paciente. Essa etapa da radioterapia é fundamental para o sucesso do tratamento, pois sem executá-lo o paciente pode ser subdotado ou sobre dosado sem que o físico médico possa estimar o erro estabelecido entre a dose prescrita e dose recebida. Dentre os métodos para o controle da qualidade em radioterapia, as dosimetrias in vivo permitem determinar as doses recebidas pelo paciente durante o tratamento. Diferentes técnicas podem ser utilizadas em dosimetria in vivo, sendo uma das mais comuns a dosimetria por transmissão, que compreende a comparação entre os sinais de um dado dosímetro posicionado na entrada e na saída do paciente, nas condições de irradiação. Desta forma, o conhecimento dos espectros incidente e transmitido pelo paciente podem ser utilizados tanto para o cálculo das doses em profundidade no paciente quanto para a correção de resposta de dosímetros em dosimetrias in vivo por transmissão. O método Monte Carlo pode ser utilizado para reproduzir diversas situações desejadas em radioterapia, que pode ser tanto, em controle da qualidade como, em tratamentos, por ser uma ferramenta acurada e sem restrições físicas e financeiras. Esse trabalho se propõe a determinar a perturbação sofrida pelo feixe primário ao atravessar objetos simuladores por meio da determinação da fluência energética e da energia depositada em diferentes condições de irradiação, através do método Monte Carlo. Neste trabalho foram desenvolvidas situações utilizando-se o código PENELOPE para possibilitar a análise do comportamento de fluências energéticas e energias depositadas. Os parâmetros clínicos que sofreram variação para a analise foram a espessura do objeto simulador, o tamanho de campo e a distância fonte-superfície (DFS). Os resultados deste trabalho mostram que a dependência em relação a cada parâmetro clínico(espessura do objeto simulador, tamanho de campo e DFS) é diferente, como é o caso da DFS, que influência mais na resposta do que o tamanho de campo, por exemplo. Portanto, esse trabalho pode ser uma ferramenta para trabalhos posteriores no estabelecimento de protocolos de relação entre fluência e dose, bem como, de armazenamento ou aplicação de dose em pacientes.

Palavras-chave: Radioterapia, controle da qualidade, método Monte Carlo. 


\begin{abstract}
PONTES DA COSTA, G. M. Spectral studies applied to radiation therapy using the Monte Carlo method. Dissertation. Ribeirão Preto: Faculdade de Filosofia, Ciências e Letras de Ribeirão Preto, Universidade de São Paulo; 2013,113 páginas.

Quality control is an essential practice in radiation oncology in order to ensure that the prescribed dose is delivered to the patient. This step of radiation therapy is very important to successful treatment, because without it the patient may receive bellow dose or over dose without the physical doctor can estimate the error established between the prescribed dose and dose received. One of the methods for quality control in radiotherapy, the in vivo dosimetry let you determine the doses received by the patient during the treatment. Different techniques can be used in vivo dosimetry, being one of the most common dosimetry for transmission, which includes the comparison of the signs of a dosimeter placed on the entrance and exit of patient irradiation conditions. In this way, the knowledge of incident spectra and transmitted by the patient can be used for both the calculation of doses in depth in the patient as to the dosimeter response in vivo dosimetry for transmission. The Monte Carlo method can be used to make a variety of situations you want in radiotherapy, and may be as much in quality as in control treatments for being a tool accurately and without physical and financial constraints. This work aims to determine the disturbance suffered by primary beam across objects simulators through determination of energy flow and energy deposited in different irradiation conditions through the Monte Carlo method. This work was developed a number of situations using the PENELOPE code to enable the analysis of the behavior of energy deposited energies and skills. The clinical parameters that have suffered the assess variation ranges were the thickness of the object Simulator, the field size and source surface distance (SSD). The results show that the dependence on each clinical parameter is different, as is the case of DFS, which most influence on response than the field size, for example. Therefore, this work can be a tool for further work on the establishment of relationship between fluency and protocols, as well as dose, dose storage in patients.
\end{abstract}

Key-words: Radiation Therapy, Control Quality, Monte Carlo Method. 


\section{SIGLAS E ABREVIATURAS}

AL: $\quad$ Acelerador linear

ACR: $\quad$ American College of Radiology

AAPM: $\quad$ American Association of Physics in Medicine

ACMP: $\quad$ American College of Medical Physics

NCRP: National Council on Radiation Protection and Measurement

ICRP: International Commission Radiological Protection

IEC: International Electrotechnical Commission

IAEA: International Atomic Energy Agency

TRS: $\quad$ Technical Reports Series

EPIDs: $\quad$ Electronic Portal Imaging Devices

DFS: $\quad$ Distância Fonte-Superfície

MMC: $\quad$ Método Monte Carlo

PENELOPE: PENetration and Energy LOss of Positrons and Electrons in matter

PDP: $\quad$ Porcentagem de Dose em profundidade

TCP: $\quad$ Probabilidade de Controle tumoral local

NTCP: $\quad$ Probabilidade de complicações em tecidos normais

PET: $\quad$ Positron Emission Tomography

IMRT: Intensity Modulated Radiation Therapy

MLC: $\quad$ Colimadores Multilâminas

CRT: Radioterapia Conformacional

DFP: $\quad$ Distância Foco-Pele

SSD: $\quad$ Source Surface Distancie

SAD: $\quad$ Source Axis Distancie

DFE: $\quad$ Distância Fonte Eixo

ICRU: International Commission on Radiation and Measurements

HIV: $\quad$ Vírus da Imunodeficiência Humana

OMS: $\quad$ Organização Mundial de Saúde 


\section{LISTA DE FIGURAS}

Figura 1 - Representação da ocorrência do efeito fotoelétrico ( P. Mayles, A.

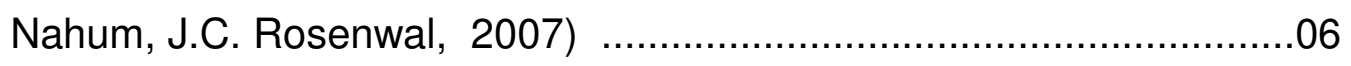

Figura 2 - Valores de seção de choque para efeito fotoelétrico para o chumbo em função da energia (TAHUATA, SALATI, DI PRONZIO, 2003) ........07

Figura 3 - Representação da ocorrência do efeito Compton (KHAN, 2003)...........08

Figura 4 - Representação da ocorrência da produção de (KHAN, 2003) ..............09

Figura 5 - Probabilidade de ocorrência dos efeitos Compton, fotoelétrico e produção de pares em função da energia do fóton incidente e do número atômico do átomo absorvedor (ATTIX, 1986)..........................10

Figura 6 - Arranjo experimental que mostra a atenuação de feixe estreito ...........11

Figura 7 - Intensidade relativa em função do decaimento exponencial ..............12

Figura 8 - Funcionamento de um dosímetro gasoso com os íons e elétrons produzidos no gás pela radiação coletados no ânodo e no cátodo

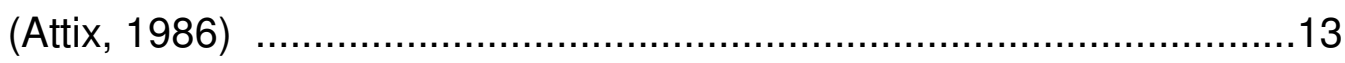

Figura 9 - Vista seccional de uma câmara cilíndrica..........................................15

Figura 10 - Curvas de PDP em água um campo $10 \times 10 \mathrm{~cm}^{2}$ e uma DFS de $100 \mathrm{~cm}$ para feixes de fótons de megavoltagem desde $0{ }^{60} 60$ até 0 feixe de $25 \mathrm{MeV}$ de energia

Figura 11 - Caracterização do campo de radiação em um ponto $\mathrm{P}$ em termos da radiação atravessando uma esfera centrada no ponto $P$ (Attix,1986)

Figura 12 - Uma ilustração do conceito de energia transmitida pela radiação em um volume elementar pela radiação (Attix, 1986)

Figura 13 - Gráfico que mostra a correspondência entre as porcentagens da probabilidade de controle tumoral e do dano ao tecido normal em função da dose

Figura 14 - Radiografias planares utilizadas em planejamentos $2 \mathrm{D}$ .23

Figura 15 - Comparação entre a conformação estabelecida no planejamento 3D e no IMRT 24

Figura 16 - Geração de trajetórias aleatórias usando simulação detalhada. Uma partícula proveniente do vácuo entra no material 1, após Múltiplas interações atravessa a interface entre os materiais 1 e $2 . . .28$ 
Figura 17 - Visualização de um corte axial de um objeto simulador antropomórfico utilizando o método Monte Carlo (MMC) com o código PENELOPE através do gview 2D

Figura 18 - Representação da montagem das simulações envolvendo o objeto simulador homogêneo

Figura 19 - Representação da montagem das simulações envolvendo o objeto simulador antropomórfico

Figuras 20 e 21- Acelerador Linear Clinac 2100 produzido pela Varian com energia de 6 MV e as placas de água sólida utilizados na parte experimental

Figura 22 - Esquema da câmara de ionização utilizada nos experimentos realizados

Figura 23 - Os pontos vermelhos representam a PDP fornecida pelo sistema de planejamento do HC de Barretos - Fundação Pio XII e os pontos pretos representam a PDP obtida por meio de simulação Monte Carlo

Figura 24 - Energias depositadas em detectores virtuais para diferentes espessuras do objeto simulador

Figura 25 - Energia depositada normalizada em função da espessura do objeto simulador para $01^{\circ}$ detector virtual .48

Figura 26 - Energia depositada normalizada em função da espessura do objeto simulador para o $4^{\circ}$ detector virtual

Figura 27 - Energia depositada normalizada em função da espessura do objeto simulador para o $9^{\circ}$ detector virtual .50

Figura 28 - Espetros de entrada e de saída da fluência energética normalizada para um objeto simulador de $1 \mathrm{~cm}$ de espessura.

Figura 29 - Espectros de entrada e de saída da fluência energética normalizados para um objeto simulador de $5 \mathrm{~cm}$ de espessura. .52

Figura 30 - Espectros de entrada e saída normalizados para um objeto simulador de $10 \mathrm{~cm}$ de espessura. 53

Figura 31 - Espectros de entrada e saída normalizados para um objeto simulador de $16 \mathrm{~cm}$ de espessura. 54 
Figura 32 - Espectros de entrada e saída normalizados para um objeto simulador de $20 \mathrm{~cm}$ de espessura

Figura 33 - Apresenta o esquema de diferentes tamanhos de campo mantendo-se fixos a espessura do objeto simulador e a DFS.

Figura 34 - Energias depositadas de todos os detectores virtuais em função do tamanho do campo

Figura 35 - Energia depositada normalizada em função da espessura do objeto simulador para o $1^{\circ}$ detector virtual em função do raio do tamanho de campo

Figura 36 - Energia depositada normalizada em função da espessura do objeto simulador para o $4^{\circ}$ detector virtual em função do raio do tamanho de campo

Figura 37 - Espectros de entrada e de saída normalizados para tamanho de campo $1 \times 1$

Figura 38 - Espectros de entrada e de saída normalizados para tamanho de campo $5 \times 5$

Figura 39 - Espectros de entrada e de saída normalizados para tamanho de campo $10 \times 10$

Figura 40 - Espectros de entrada e de saída normalizados para tamanho de campo $15 \times 15$

Figura 41 - Espectros de entrada e de saída normalizados para tamanho de campo $20 \times 20$

Figura 42 - Apresenta o esquema de uma fonte de radiação colocada a diferentes DFSs mantendo-se fixos a espessura do objeto simulador e o tamanho de campo

Figura 43 - Apresenta estudos da resposta de nove detectores virtuais, para diferentes distâncias fonte-superfície utilizando o objeto simulador homogêneo

Figura 44 - Energia depositada normalizada em função da espessura dfs para $01^{\circ}$ detector virtual

Figura 45 - Energia depositada normalizada em função da espessura dfs para $\circ 4^{\circ}$ detector virtual 68 
Figura 46 - Energia depositada normalizada em função da espessura dfs espectro, para o $9^{\circ}$ detector virtual.

Figura 47 - Comparação entre o espectro primário e a fluência energética secundário mais o transmitido, normalizados, respectivamente para respectivamente para uma DFS $=70 \mathrm{~cm}$

Figura 48 - Comparação entre o espectro primário e a fluência energética espectro, secundário mais o transmitido, normalizados, respectivamente para uma DFS $=90 \mathrm{~cm}$ .70

Figura 49 - Comparação entre o espectro primário e a fluência energética espectro, secundário mais o transmitido, normalizados respectivamente para uma DFS $=110 \mathrm{~cm}$

Figura 50 - Comparação entre o espectro primário e a fluência energética espectro, secundário mais o transmitido, normalizados respectivamente, para uma DFS $=130 \mathrm{~cm}$

Figura 51 - Resposta da carga em nC obtida com a câmara de ionização colocada dentro do objeto simulador de água sólida em função da sua espessura. .73

Figura 52 - Fator de conversão da espessura do objeto simulador. .74

Figura 53 - Resposta obtida em nC, utilizando a câmara de ionização dentro do objeto simulador de água sólida em função do tamanho de campo.....75

Figura 54 - Resposta obtida em nC, utilizando a câmara de ionização, em função do tamanho de campo, para os nove detectores estudados....76

Figura 55 - Resposta obtida da carga em nC em função da dfs, com câmara de ionização

Figura 56 - Fator de conversão em pC/eV em função da distância fonte-superfície

Figura 57 - Energias depositadas para os 9 diferentes detectores virtuais em do tamanho do campo de exposição. .79

Figura 58 - Energias depositadas normalizadas para o $1^{\circ}$ detector virtual para diferentes tamanhos de campo 80

Figura 59 - Energias depositadas normalizadas para o $4^{\circ}$ detector virtual para diferentes tamanhos de campo. 
Figura 60 - Energias depositadas normalizadas para o $9^{\circ}$ detector virtual para diferentes tamanhos de campo em que o objeto simulador antropomórfico é exposto

Figura 61 - Comparação entre os espectros de entrada e de energia e de saída normalizados para o tamanho de campo 1 x 1 utilizando objeto simulador antropomórfico.

Figura 62 - Comparação entre os espectros de entrada e de saída normalizados para o tamanho de campo $5 \times 5$ utilizando objeto simulador antropomórfico

Figura 63 - Comparação entre os espectros de entrada e de saída normalizados para o tamanho de campo $10 \times 10$ utilizando objeto simulador antropomórfico.

Figura 64 - Comparação entre os espectros de entrada e de saída normalizados para o tamanho de campo $15 \times 15$ utilizando objeto simulador antropomórfico. .86

Figura 65 - Comparação entre os espectros de entrada e de saída normalizados para o tamanho de campo $20 \times 20$ utilizando objeto simulador antropomórfico.

Figura 66 - Energias depositadas em detectores virtuais para diferentes dfs. 88

Figura 67 - Energias depositadas no $1^{\circ}$ detector virtual para diferentes dfs .89

Figura 68 - Energias depositadas no $9^{\circ}$ detector virtual para diferentes dfs 90

Figura 69 - Comparação entre o espectro primário e a fluência energética do espectro secundário mais o transmitido, normalizados, respectivamente, para uma DFS $=70 \mathrm{~cm}$

Figura 70 - Comparação entre o espectro primário e a fluência energética do espectro, secundário mais o transmitido, normalizados, respectivamente, para uma DFS $=90 \mathrm{~cm}$ .92

Figura 71 - Comparação entre o espectro primário e a fluência energética espectro, secundário mais o transmitido, normalizados, respectivamente, para uma DFS $=110 \mathrm{~cm}$

Figura 72 - Comparação entre o espectro primário e a fluência energética espectro, secundário mais o transmitido, normalizados, respectivamente, para uma $\mathrm{DFS}=130 \mathrm{~cm}$ 


\section{LISTA DE TABELAS}

Tabela 1 - A tabela apresenta as quádricas reduzidas e seus respectivos coeficientes.

Tabela 2 - Valores utilizados nas simulações envolvendo objetos simuladores homogêneos.

Tabela 3 - Valores utilizados nas simulações envolvendo objetos simuladores antropomórficos.

Tabela 4 - Espectro de entrada utilizado no trabalho nas simulações com o código PENELOPE. 


\section{SUMÁRIO}

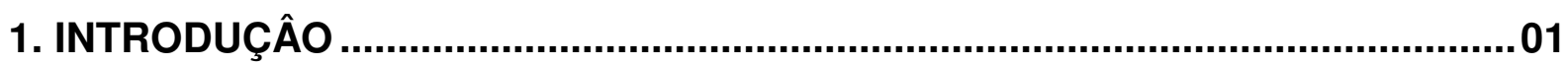

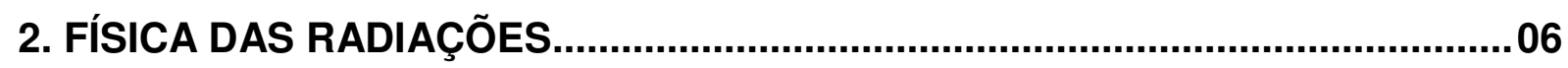

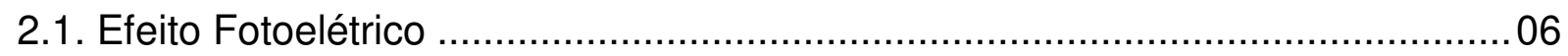

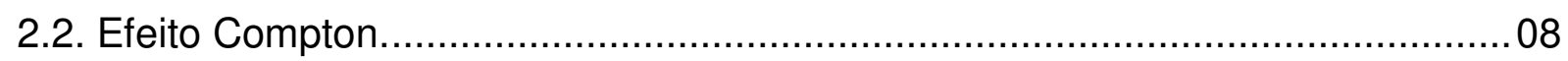

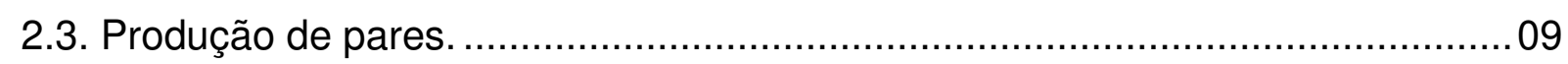

2.4. Importância relativa da interação da radiação com a matéria........................... 10

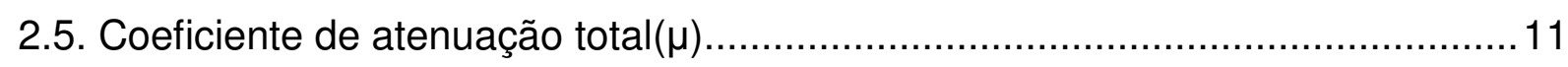

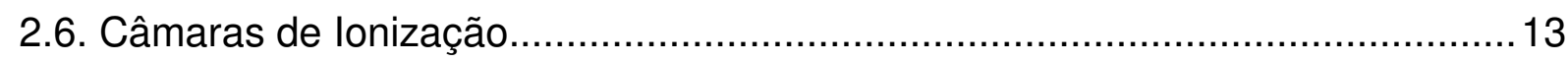

2.6.1. Câmaras de lonização esférica e cilíndrica.................................................. 14

2.7. Porcentagem de dose profunda e lei do inverso do quadrado da distância. .....15

2.8. Grandezas quantificadoras da radiação................................................... 17

2.8.1. Fluência Energética........................................................................ 17

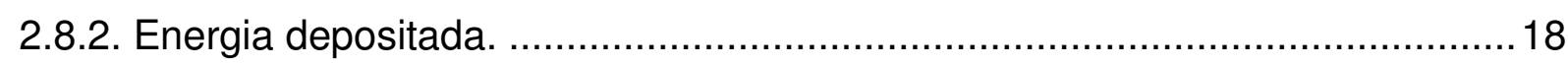

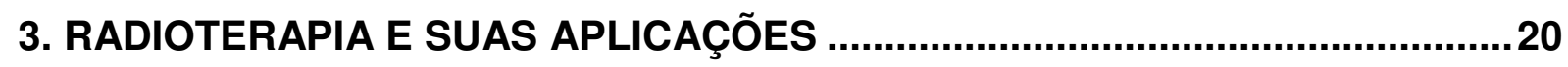

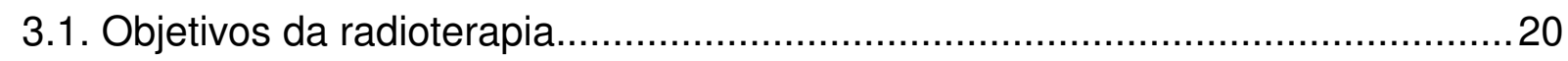

3.2. Planejamento de tratamentos radioterápicos..............................................22

4. SIMULAÇÃO MONTE CARLO COM O CÓDIGO PENELOPE ............................27

4.1. Aspectos fundamentais do método Monte Carlo...........................................2 27

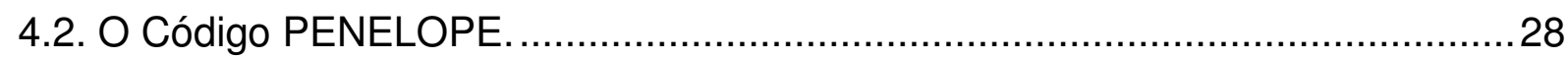

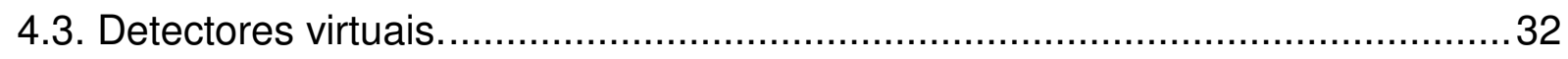

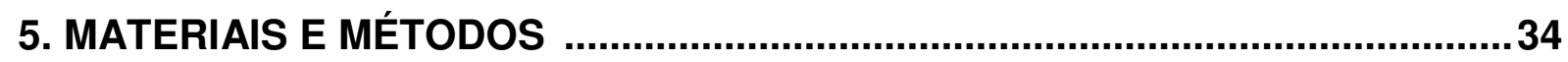

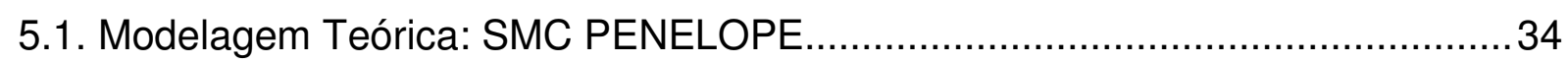

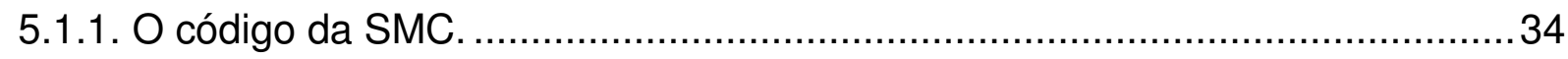

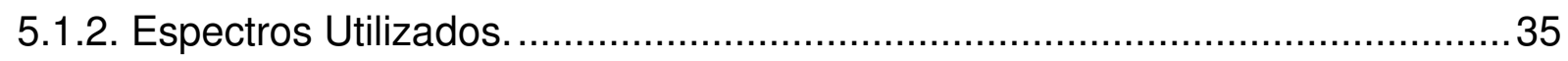

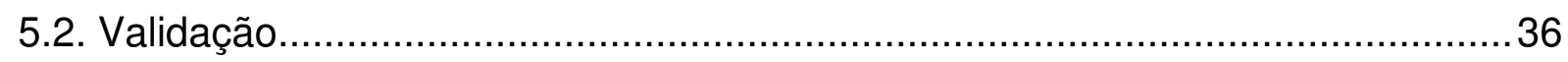

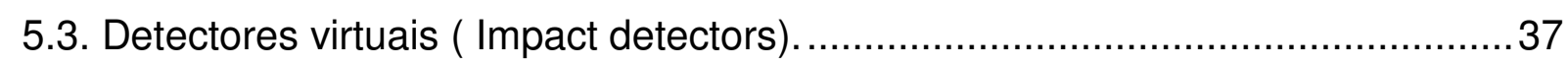

5.4. Intervalo de variação dos parâmetros clínicos nas SMC .....................................38

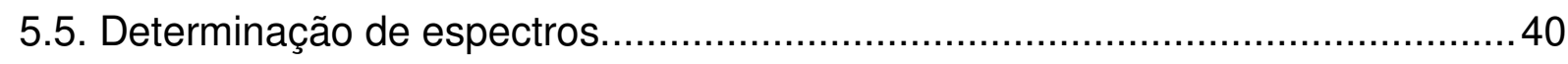

5.6. Doses em profundidade por meio da simulação Monte Carlo............................41 
5.7. Experimentos realizados.

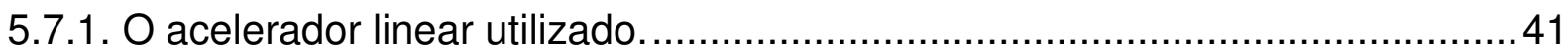

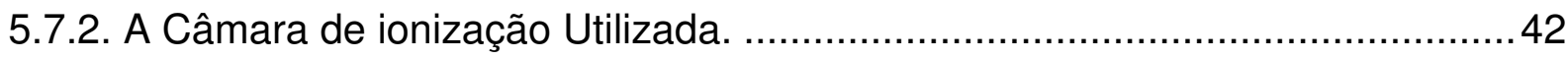

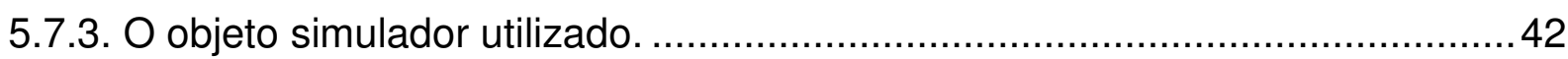

5.8. Determinação da Energia depositada em profundidade através da relação entre simulação Monte Carlo e a câmara de ionização............................................. 43

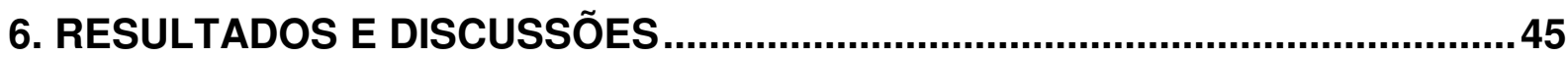

6.1. Simulação Monte Carlo para objetos simuladores homogêneos........................ 45

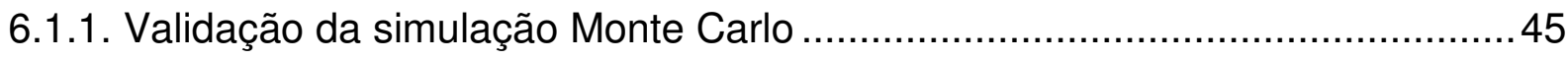

6.1.2. Estudo da energia depositada com a variação das espessuras do objeto simulador.

6.1.3. Estudo das fluências energéticas com a variação das espessuras do objeto simulador. 50

6.1.4. Estudo da energia depositada com a variação do tamanho de campo. ...........55

6.1.5. Estudo da fluência energética com a variação do tamanho de campo. 58

6.1.6. Estudo da energia depositada com a variação da distância fonte-superfície...63 6.1.7. Estudo da fluência energética com a variação da distância fonte superfície...67 6.2. Medidas realizadas com câmara de ionização............................................... 70

6.3. Medidas utilizando objeto simulador antropomórfico ..................................... 76

6.3.1. Variação da energia depositada em função do tamanho de campo ...............77

6.3.2. Variação da fluência energética em função do tamanho de campo .................. 80

6.3.3. Variação da energia depositada em função da distância fonte-superfície........86

6.3.2. Variação da fluência energética em função da dfs........................................ 89

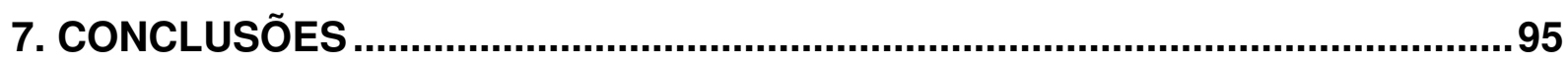

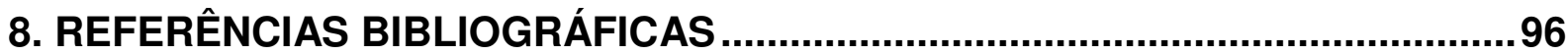




\section{INTRODUÇÃO}

Em países com grande volume de recursos financeiros, predominam os cânceres de pulmão, mama, próstata e cólon. Em países de recursos baixos e médios, os cânceres predominantes são os de estômago, fígado, cavidade oral e colo do útero. Mesmo na tentativa de se criar padrões mais característicos de países ricos em relação aos de rendas baixa e média, padrão este que está mudando rapidamente, e que vem sendo observado um aumento progressivo nos cânceres de pulmão, mama, cólon e reto, os quais, historicamente, não apresentavam essa importância e magnitude ( Inca, 2012).

Mortes causadas por câncer em todo o mundo deverão continuar crescendo com uma estimativa que deve alcançar neste ano, 13,1 milhõesde mortes (World Health Organization, 2012).

No Brasil, as estimativas veem apontando a ocorrência de aproximadamente 518.510 casos novos de câncer por ano incluindo os casos de pele não melanoma. Sem esses casos, estima-se um total de 385 mil casos novos (Inca, 2012).

Os tratamentos de câncer são realizados utilizando-se as modalidades de radioterapia, quimioterapia e cirurgia. A radioterapia consiste na utilização de radiação ionizante para o tratamento do câncer, onde o seu grande objetivo é atingir o tecido tumoral poupando o tecido sadio e levando-se em conta o dano biológico no tumor.

Assim, deve-se levar em conta que apesar do aumento da dose recebida pelo tecido tumoral melhorar o controle local, essa dose é limitada pela sensibilidade à radiação de tecidos sadios adjacentes. Na forma convencional a radioterapia normalmente é realizada com feixes de fótons de raios $X$ de energias altas(acima de $6 \mathrm{MeV}$ ) produzidos por aceleradores lineares $(A L)$, com feixes de raios gama de unidades de cobalto, com raios $X$ de energias menores, bem como, feixes de elétrons de energias acima de $6 \mathrm{MeV}$. Os principais serviços de radioterapia no Brasil utilizam esse tipo de acelerador, cujos tratamentos são realizados atendendo condições pré-estabelecidas em protocolos clínicos.

Os tratamentos de radioterapia devem ser realizados após os equipamentos serem devidamente calibrados e submetidos ao controle da qualidade que são 
propostos por organizações como American College of Radiology (ACR), American Association of Physics in Medicine (AAPM) e a American College of Medical Physics (ACMP). Esses programas de controle da qualidade incorporam regras e critérios desenvolvidos pelas agências: International Council on Radiation Protection and Measurements (NCRP), International Comisson Radiological Protection (ICRP) e International Electrotechinical Commission (IEC) (KHAN, 2003).

Os protocolos de controle da qualidade recomendam uma dose administrada ao volume alvo com precisão de $5 \%$ para a erradicação do tumor (ICRU REPORT 62, 1999). No Brasil, segue-se o protocolo da IAEA ( International Atomic Energy Agency), TRS 398, que estabelece medidas de dose absorvida por calibração em água, que indica as taxas de dose de referência, em unidades de terapia, que devem ser adotadas para proporcionar um padrão de dose com a maior acurácia e com a mais alta precisão possível (BERDAKY e CALDAS, 2001).

A radioterapia moderna tem a necessidade de se utilizar novas técnicas de alta exatidão na aplicação da dose, incluindo identificação de dose em radioterapia conformacional 3D. Novas tecnologias aplicadas em radioterapia utilizam ferramentas modernas de diagnóstico para determinação do volume alvo, sistemas de planejamento de tratamento em radioterapia TPS, do Inglês Treatment Planning Systems, somados a aceleradores de última geração, podem ser amplamente utilizados preservando sempre a alta exatidão na determinação e entrega de dose (IAEA, 2001). Ainda, deve-se observar que, embora planos de tratamento utilizando IMRT (Intensity Modulated Radiation Therapy) se apresentem como um importante procedimento em radioterapia, esses métodos não comprovam a verdadeira dose aplicada ao paciente durante o tratamento, devido aos altos gradientes de dose entregues ao volume alvo, por isso existe uma grande necessidade de controle da qualidade na aplicação do tratamento.

Para medidas dosimétricas são necessários dispositivos adequados para que se possa verificar, a fluência correta durante um tratamento IMRT (sabe et al, 2012).

Diante desse panorama, a percepção da estrutura interna do paciente é fundamental para o aumento da qualidade dos tratamentos radioterápicos, pois possibilita a localização de órgãos críticos nas adjacências do tumor e as diferenças de homogeneidade presentes no organismo. Atualmente, isso é possível devido as 
inovações tecnológicas que são evidenciadas por alguns dispositivos, tais como, tomografia, ressonância magnética, ultrassom e os EPIDs.

O acesso à clínica, a disponibilidade de detectores e os custos experimentais são algumas das dificuldades enfrentadas para a realização desses estudos. Uma alternativa para minimizar as necessidades e as problemáticas descritas acima é a aplicação do Método Monte Carlo-MMC, que consiste em um modelo implementado para descrever o transporte de partículas.

O Método Monte Carlo é amplamente utilizado para resolver problemas físicos e matemáticos complexos.

A simulação de tratamentos clínicos baseada no método Monte Carlo vem sendo, amplamente utilizada em radioterapia devido, principalmente, à uma maior exatidão associada ao seu uso.

O MMC é uma ferramenta que não representa custos experimentais elevados, por isso, os dados fornecidos pelo MMC podem ser utilizados como um instrumento, para interpolar esses dados com os já existentes clinicamente, pois possibilita extrapolar o estudo para situações que sejam difíceis ou impossíveis de serem realizadas no hospital.

Uma partícula, na simulação Monte Carlo de transporte de radiação, segue uma sequência, constituída de três possibilidades, que se encerram com a interação, onde as partículas mudam sua direção de movimento, perdem energia e ocasionalmente geram partículas secundárias (SALVAT, FERNÁNDEZ-VAREA e SEMPAU, 2008).

Assim, o Método Monte Carlo apresenta vários códigos com que o usuário pode interagir e resolver diferentes tipos de problemas.

O código que foi utilizado neste trabalho é o PENELOPE que simula a penetração e perda de energia de fótons, elétrons e pósitrons na matéria. Sua sigla é proveniente da própria função do código salientada pelas letras maiúsculas em destaque (PENetrationand Energy LOss of Positrons and Electrons in matter). $O$ código de simulação Monte Carlo PENELOPE se apresenta como uma ferramenta bem estabelecida e eficiente para estudos de espectrometria e dosimetria de feixes 
clínicos, permitindo a representação geométrica fiel de diversos tipos de aparelhos radioterápicos.

Após a simulação ser realizada pelo código PENELOPE são geradas várias pastas com aspectos associados a situação representada. Dentre elas as que irão nos interessar são os arquivos que geram dados de fluência energética e da energia depositada.

O estudo das grandezas citadas acima permite realizar o controle de qualidade de detectores para o eixo central do feixe, com uma metodologia que abranja diferentes espessuras do objeto simulador, tamanhos de campo e distâncias fonte superfície (DFS).

A relevância do trabalho está associada à determinação de fluências energéticas e energias depositadas, para auxiliar no controle da qualidade de um tratamento radioterápico e que foi estudado nessa etapa no eixo central do feixe, com uma abordagem que utilizou simulação Monte-Carlo e câmara de ionização, como ferramentas para o seu desenvolvimento.

A entrega correta da dose em radioterapia se enquadra no contexto do tratamento do câncer que apresenta magnitudes diferentes conforme a região geográfica e o poder socioeconômico da população que o adquire.

O aumento do número de casos de câncer de pulmão revela a importância de se fazer estudos relacionados a esse órgão. Portanto pretende-se realizar um estudo de controle da qualidade utilizando um objeto simulador antropomórfico e tomando a região do pulmão, como referência nas simulações Monte Carlo a serem desenvolvidas nesse trabalho.

Além disso, utilizando simulação Monte Carlo pretende-se obter curvas de resposta de energia depositada para detectores virtuais que simulem uma determinada região, como também se propõe a determinar espectros de fluências energéticas utilizando o método Monte Carlo variando alguns parâmetros como: espessura do objeto simulador; tamanho de campo e distância fonte-superfície (DFS).

A sequência a ser utilizada para a abordagem deste trabalho será a seguinte: 
No capítulo 2 são apresentados os tópicos referentes a física das radiações abordando o efeito fotoelétrico, o efeito Compton, produção de pares, importância relativa da interação da radiação com a matéria, coeficiente de atenuação total $(\mu)$, câmaras de ionização, bem como as grandezas quantificadoras da radiação.

O capítulo 3 trata da Radioterapia e suas aplicações e é subdividido em objetivos da radioterapia, planejamento de tratamentos radioterápicos, tipos de tratamento radioterápicos.

No capítulo 4 é discutido o conceito da simulação Monte Carlo com o código PENELOPE e está subdividido nos seguintes tópicos: Aspectos fundamentais do método Monte Carlo, o código PENELOPE e detectores virtuais.

Os materiais e métodos envolvidos nas simulações utilizadas neste trabalho são descritos no capítulo 5, onde é apresentada a forma em que serão implementadas, além de ser explicitada a metodologia empregada nos experimentos utilizando câmara de ionização.

No capítulo 6 são apresentados os resultados obtidos de espectros de energia, as curvas de fluência energética e a dependência com os parâmetros clínicos que iremos variar nesse trabalho além da discussão e resultados alcançados.

O capítulo 7 apresenta as conclusões dos resultados alcançados com o trabalho.

No capítulo 8 são apresentadas as referências bibliográficas utilizadas nessa dissertação. 


\section{FÍSICA DAS RADIAÇÕES}

\subsection{Efeito fotoelétrico}

No efeito fotoelétrico, um fóton de energia $E$ é absorvido por um átomo e um elétron em sua estrutura faz a transição para um estado excitado, conforme mostra a figura 1.

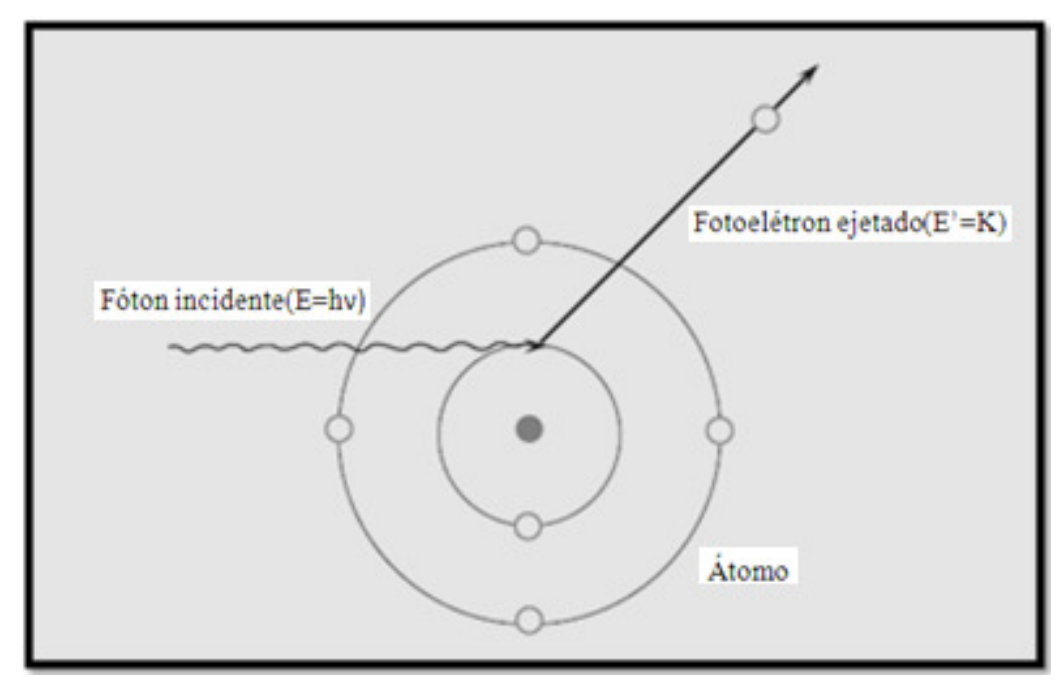

Figura 1 - Representação da ocorrência do efeito fotoelétrico (P Mayles, A Nahum, J C Rosenwald, 2007)

A equação que descreve o efeito fotoelétrico é dada por:

$$
h v=\Phi+K
$$

Onde:

- $h$ é a constante de Planck.

- $v$ é a frequência do fóton incidente.

- $\Phi$ é a função trabalho, ou energia mínima exigida para remover um elétron de sua ligação atômica.

- K é a energia cinética máxima dos elétrons expelidos.

A direção de saída do fotoelétron em relação à de incidência do fóton varia com a energia. $O$ efeito fotoelétrico é predominante para baixas energias e para elementos químicos de elevados números atômicos $Z$. 


$$
\sigma_{\text {fotoelétrico }}=\frac{k Z^{2}}{(h v)^{3}}
$$

A probabilidade de ocorrência é diretamente proporcional a $Z^{2}$ e inversamente proporcional ao cubo da energia, pois ela é proporcional a seção de choque, conforme mostra a figura 2 .

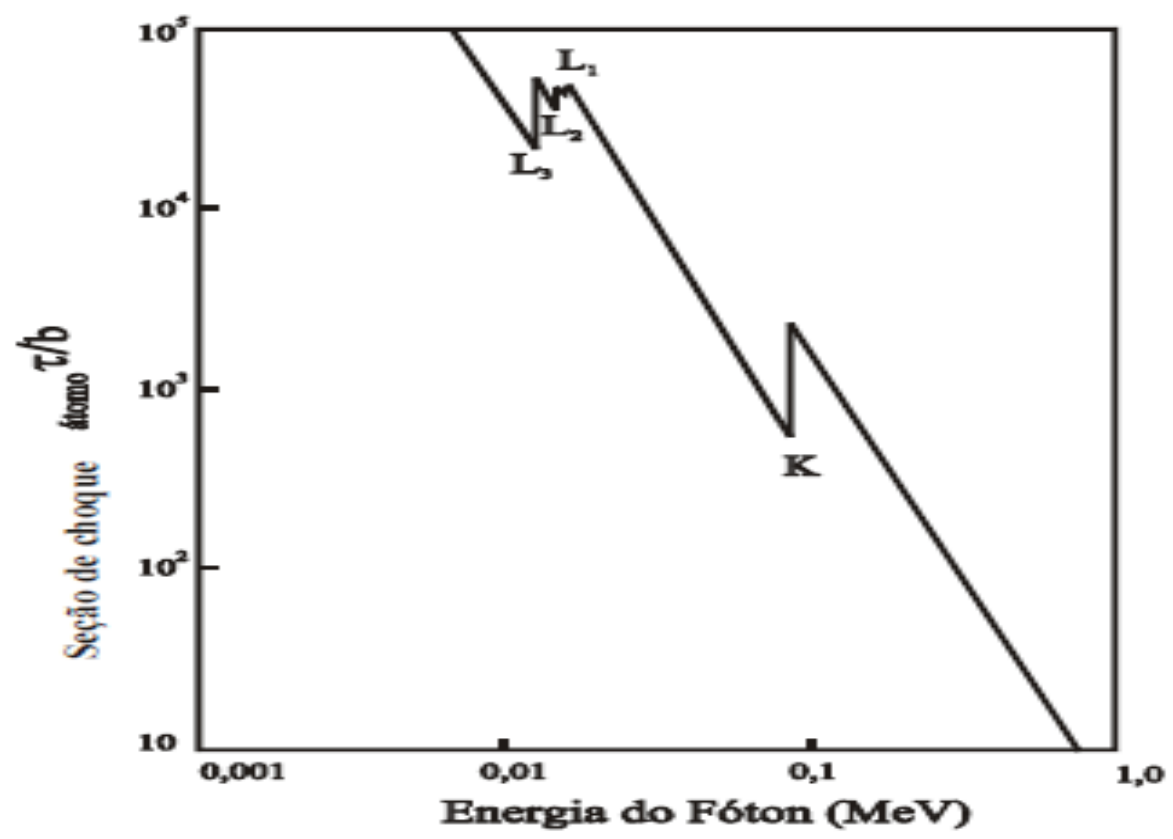

Figura 2 - Valores de seção de choque para efeito fotoelétrico para o chumbo em função da energia (TAHUATA, SALATI, DI PRINZIO, 2003).

O comportamento apresentado na figura 2 é de decréscimo com a energia conforme aumenta a energia dos fótons incidentes, porém existem descontinuidades nos picos de absorção que ocorrem quando os fótons incidentes atingem a energia de ligação de uma determinada camada. A figura 2 mostra as energias de ligação atingidas para as camadas $L$ e $K$, sendo o chumbo o material absorvedor.

\subsection{Efeito Compton}

A importância científica da descoberta desse efeito está associada ao fato de Compton ter provado que a radiação $X$ não apresenta um caráter meramente ondulatório. 
No efeito Compton, o fóton é espalhado por um elétron que recebe somente parte de sua energia, continuando dentro do material em outra direção, representado na figura 3.

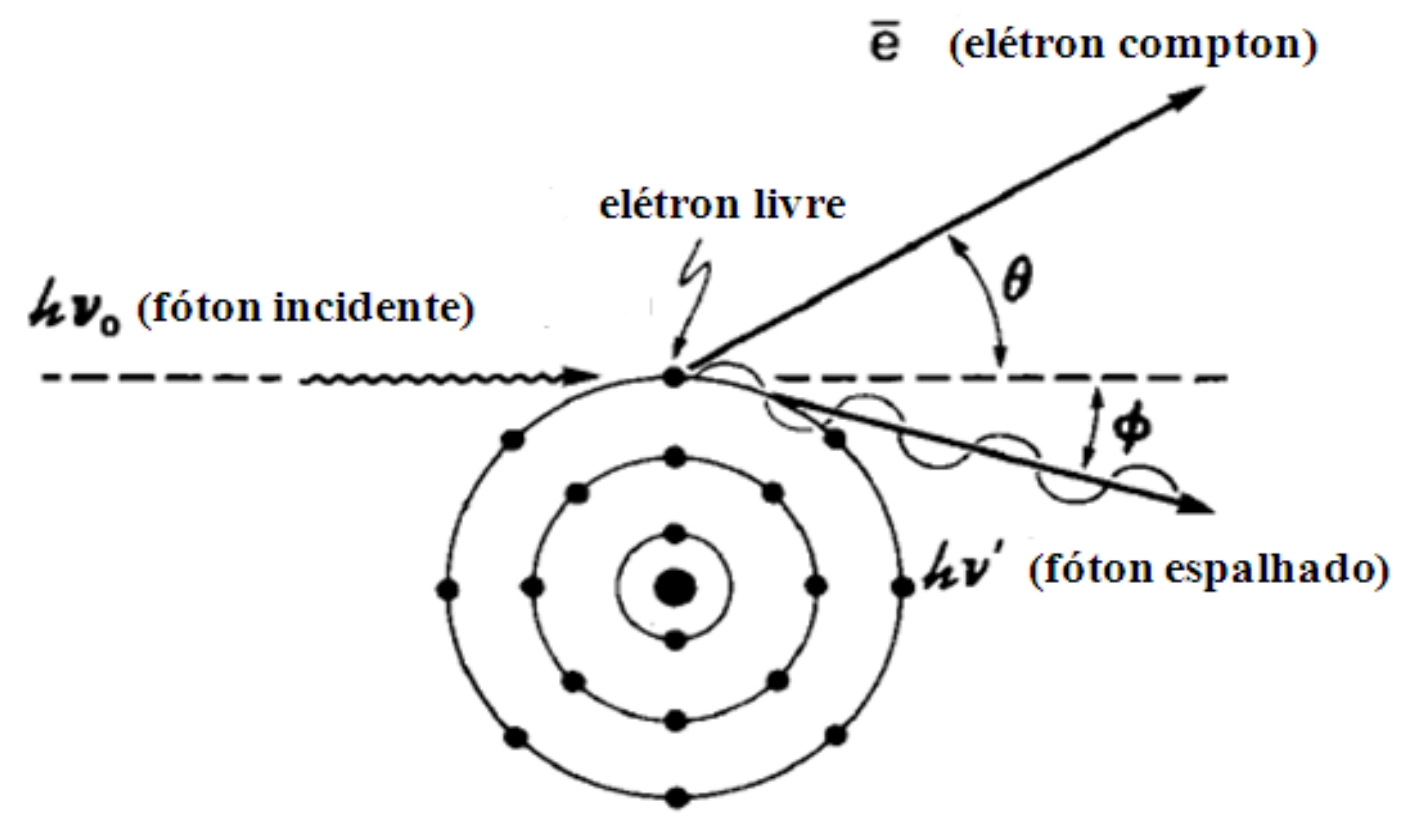

Figura 3 - Representação da ocorrência do efeito Compton (KHAN, 2003).

No espalhamento Compton, um fóton de energia $E$ interage com um elétron, que absorve e reemite um fóton secundário de energia E' em relação ao fóton inicial. No código PENELOPE, O espalhamento Compton é descrito por meio da seção de choque obtida pela aproximação do impulso relativístico (Ribberfors, 1983).

A equação que evidencia a diferença entre os comprimentos de onda do fóton após e antes do espalhamento está associada ao ângulo de espalhamento após a interação, conforme descrito em abaixo, vejamos:

$$
\lambda_{2}-\lambda_{1}=\frac{h}{m_{e} c}(1-\cos \theta)
$$

onde,

- $\lambda_{2}$ é o comprimento de onda do fóton depois do espalhamento.

- $\lambda_{1}$ é o comprimento de onda do fóton antes do espalhamento.

- $m_{e}$ é a massa do elétron.

- $\frac{h}{m_{e} c}$ é o comprimento de onda compton. 
- $\theta$ é o ângulo pelo qual a direção do fóton muda.

- h é a constante de Planck.

- c é a velocidade da luz no vácuo.

\subsection{Produção de pares}

Pares elétron-pósitron pode ser criados pela absorção de um fóton na vizinhança de uma partícula massiva, um núcleo ou um elétron, que absorve a energia e impulso para que estes dois valores sejam conservados, conforme mostra a figura 4. A energia limiar para a produção de pares no campo de um núcleo (assumido de massa infinita) é $2 m_{e} c^{2}$.

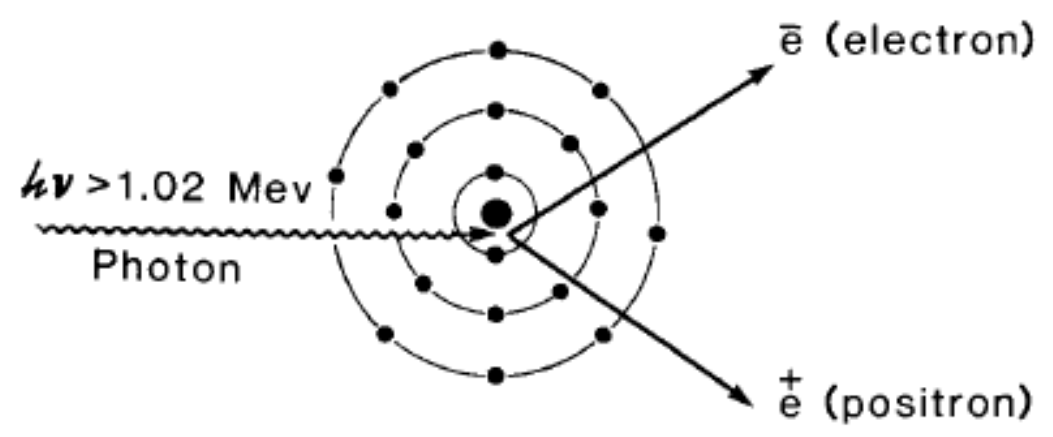

Figura 4 - Representação da ocorrência da produção de pares (KHAN, 2003)

A equação representativa da produção de pares está mostrada abaixo:

$$
\gamma \rightarrow e^{-}+e^{+}+E_{\mathrm{c}}
$$

Onde:

$\gamma$ é o fóton incidente próximo do núcleo atômico.

$e^{-}$é o elétron formado após a interação.

$e^{+}$é o pósitron formado após a interação.

$E_{c}$ é a energia cinética do par formado. 
As duas partículas transferem energia cinética para o meio material, sendo que o pósitron volta a se combinar com um elétron do meio e dá origem a dois fótons, cada um com energia de $511 \mathrm{keV}$.

\subsection{Importância relativa dos efeitos de interação da radiação com a matéria}

O efeito fotoelétrico, Compton e formação de pares apresentam uma importância relativa, pois a probabilidade de ocorrência depende da energia do fóton incidente e do número atômico do material absorvedor, o gráfico representativo desses efeitos é apresentado na figura 5.

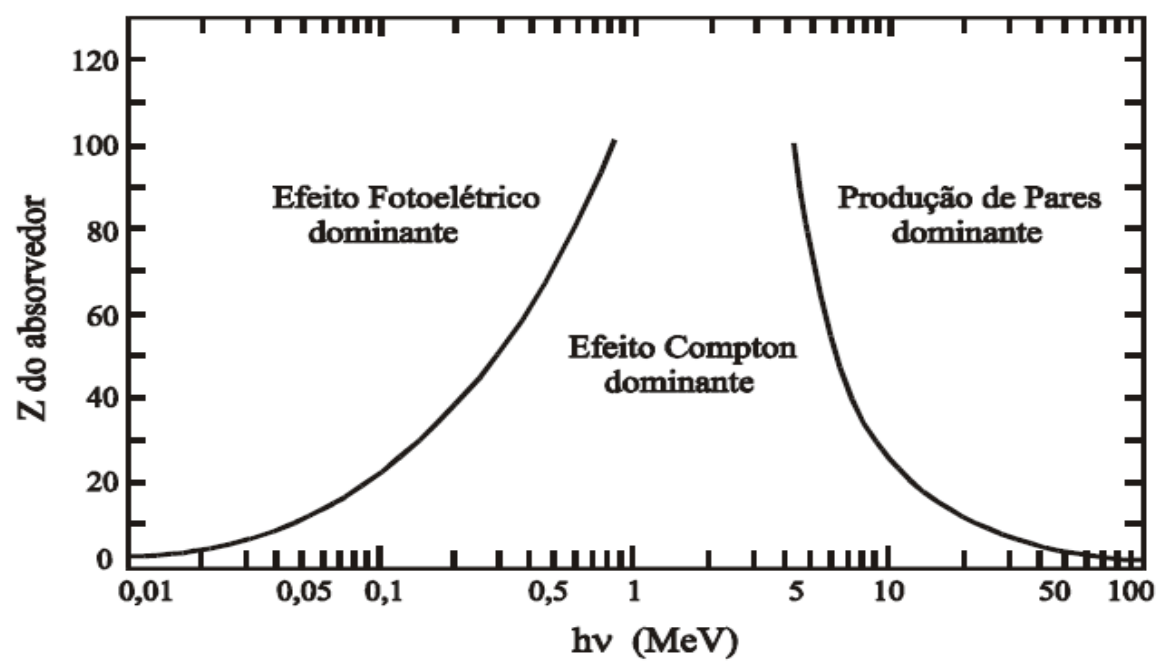

Figura 5 - Probabilidade de ocorrência dos efeitos Compton, fotoelétrico e produção de pares em função da energia do fóton incidente e do número atômico do átomo absorvedor (ATTIX, 1986).

\subsection{Coeficiente de atenuação linear total $(\mu)$}

O coeficiente de atenuação total $(\mu)$ depende da contribuição associada aos efeitos de interação da radiação da matéria, portanto:

$$
\mu=\sigma+\tau+\kappa
$$

Onde:

$\sigma$ é o coeficiente de atenuação linear compton. 
$\tau$ é o coeficiente de atenuação linear devido ao efeito fotoelétrico.

к é o coeficiente de atenuação linear devido a produção de pares.

Considere que um feixe estreito monoenergético constituído por um número $\mathrm{N}$ de fótons incidindo perpendicularmente em um material absorvedor de comprimento variável $x$, conforme mostra a figura 6 .

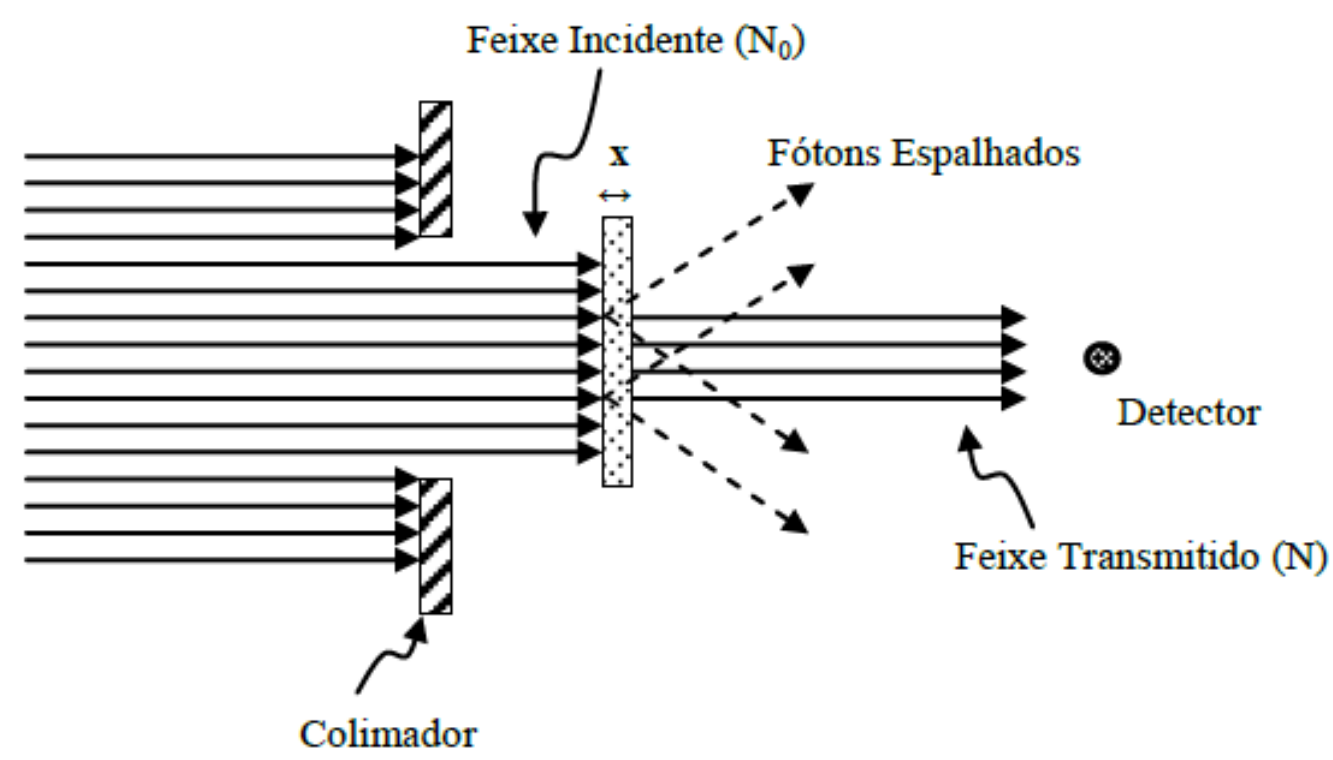

Figura 6 - Arranjo experimental que mostra a atenuação de feixe estreito

Nessa situação um detector é colocado em uma distância fixa da fonte e suficientemente distante do absorvedor para que as medidas do detector sejam apenas provenientes de fótons primários, conforme mostra a figura 6 . Portanto, se um fóton interage com o átomo, ele é completamente absorvido ou espalhado distante do detector, portanto sem atingi-lo. Dentro dessas condições, a redução do número de fótons $\mathrm{dN}$ é proporcional ao número de fótons incidente e à espessura do material absorvedor (KHAN, 2003).

Matematicamente, pode-se escrever essa relação da seguinte forma:

$$
\mathrm{dN}=-\mu \mathrm{Ndx}
$$

Essa equação pode ser escrita em termos da intensidade, ou seja:

$$
D I=-\mu I d x
$$


Dessa expressão segue que:

$$
\frac{d I}{I}=-\mu \mathrm{dx}
$$

Integrando os 2 membros:

$$
\int_{I_{0}}^{I} \frac{d I}{I}=\int_{0}^{x}-\mu \mathrm{dx}
$$

Portanto: $\quad \ln \left(\frac{I}{I_{0}}\right)=-\mu . x$

Aplicando a função exponencial em ambos os membros, temos:

$$
I=I_{0} e^{-\mu \mathrm{x}}
$$

onde:

$\mu$ é o coeficiente de atenuação total.

$I_{0}$ é a intensidade do feixe incidente.

A atenuação de um feixe de fótons descrita matematicamente pela função da intensidade $I=I_{0} e^{-\mu \mathrm{x}}$ em um material de espessura x é representada pela curva da figura 7 .

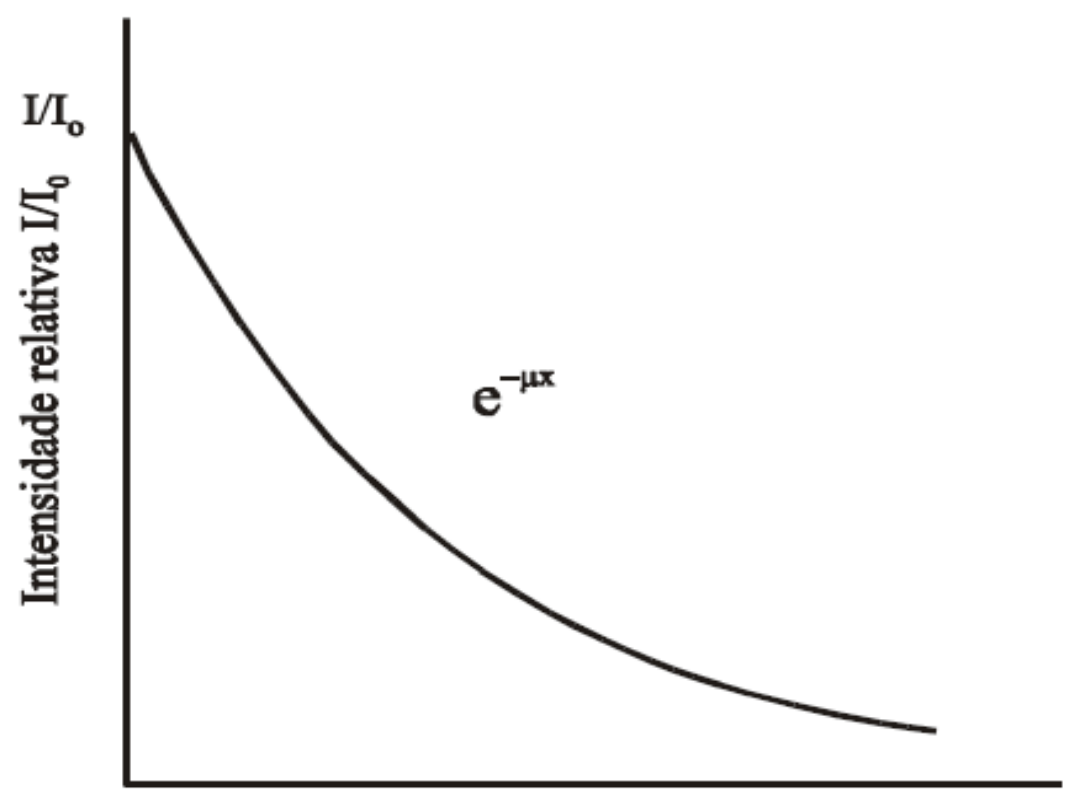

Espessura $\mathrm{X}$

Figura 7 - Intensidade relativa em função da espessura do material.

A figura 7 mostra a intensidade relativa em função do decaimento exponencial para um feixe monoenergético, entretanto para um feixe que apresenta $n$ 
componentes com energias diferentes, a intensidade apresentará uma combinação de $\mathrm{n}$ funções exponenciais.

\subsection{Câmaras de lonização}

Câmara de ionização é um dos tipos de dosímetros mais usados, sendo considerado um instrumento de referência em radioterapia e radiodiagnóstico. São constituídas por um volume preenchido por um gás sensível a radiação e eletrodos coletores conectados a um eletrômetro. A radiação incidente no volume sensível (o gás) cria pares de íons no campo elétrico estabelecido que pode ser medido com um dispositivo de medida elétrica (eletrômetro) mostrado na figura 8.

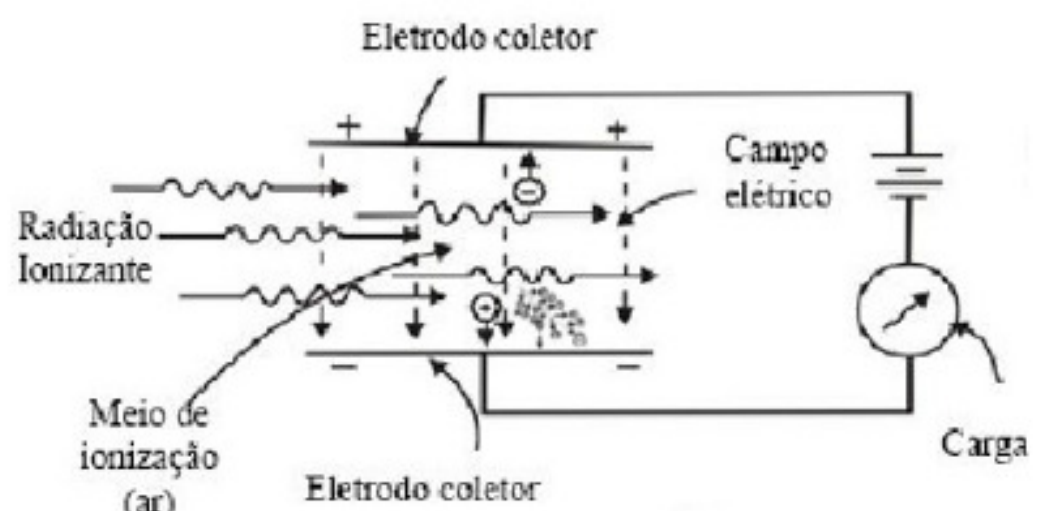

Figura 8 - Funcionamento de um dosímetro gasoso com os íons e elétrons produzidos no gás pela radiação coletados no ânodo e no catodo (Attix, 1986).

A ionização medida é aquela coletada a partir do volume V'(volume de origem dos elétrons secundários). A distância entre o volume e qualquer extremidade da câmara deve ser maior que o alcance dos elétrons. Além disso, para cada partícula que sai de $\mathrm{V}$, outra partícula similar deve entrar em $\mathrm{V}$ considerando-se o equilíbrio das partículas carregadas.

2.6.1. Câmaras de Ionização Esféricas e Cilíndricas

As características desse tipo de câmara são as seguintes: 
- Câmaras de ionização esféricas e cilíndricas apresentam volumes entre 0.1 e $2000 \mathrm{~cm}^{3}$.

- São constituídas por dois eletrodos: o ânodo e o catodo.

- A diferença de potencial (ddp) entre o ânodo e o catodo tem valores que variam na faixa de 100 a 500 volts.

- A voltagem apropriada depende de vários fatores como, por exemplo, o tamanho da câmara de ionização.

- Se as medidas forem feitas no simulador não precisa da capa de equilíbrio eletrônico, pois o próprio simulador garante a condição de equilíbrio eletrônico.

Esse tipo de câmara apresenta uma série de características úteis, ou seja:

a) São usadas para medidas dosimétricas rotineiras;

b) Apresentam fácil manuseio e transporte;

c) Versatilidade;

d) Possibilidade de uso em simuladores;

e) Não funcionam como padrão primário;

f) Apresentam dependência energética.

O eletrodo central e a parede são equivalentes ao ar, em relação à interação dos fótons e dos elétrons secundários. A parede é condutora e atua como uma camada de ar condensado, de forma que sua presença não perturbe a fluência e o espectro de energia dos fótons e dos elétrons secundários. A espessura da parede sempre deve ser maior que o alcance máximo dos elétrons secundários gerados fora da câmara. A figura 9 mostra um esquema de uma câmara. 


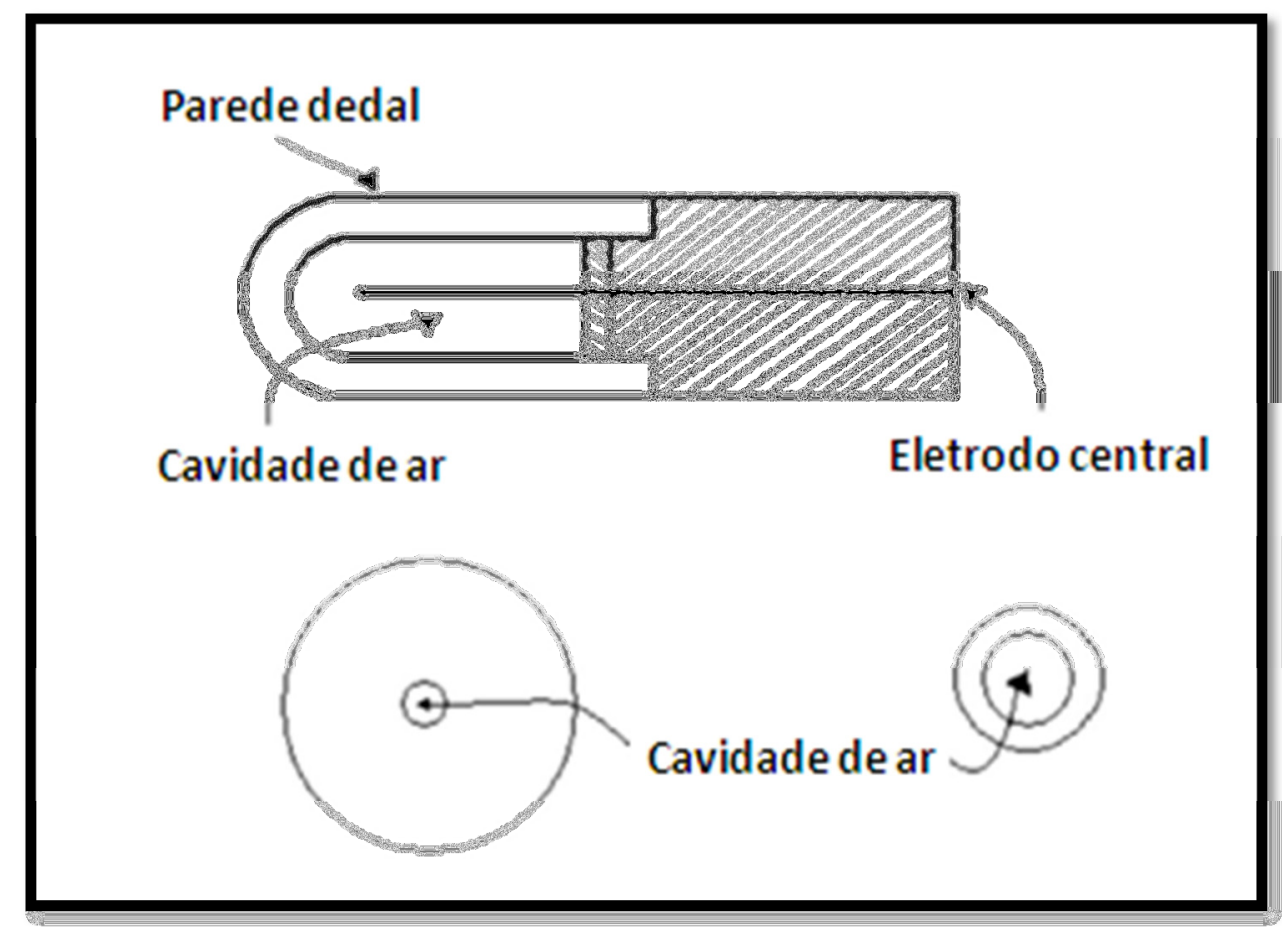

Figura 9 - Vista seccional de uma câmara cilíndrica

\subsection{A porcentagem de dose profunda e a lei do inverso do quadrado da distância}

A porcentagem de dose profunda (PDP) é o parâmetro dosimétrico em radioterapia que caracteriza a distribuição de dose em profundidade em relação a uma profundidade na qual a dose apresenta valor máximo. Portanto, a PDP é definida como a quantidade que expressa à porcentagem de dose absorvida em uma profundidade de interesse, $D_{d}$, em relação à dose absorvida em uma profundidade de dose máxima, $D_{m}$, como mostrado na equação abaixo:

$$
P D P(d)=\left(\frac{D_{d}}{D_{\text {máx }}}\right) \cdot 100 \%
$$

A porcentagem de dose profunda depende da largura do campo de radiação, da distância da fonte de radiação à superfície de tratamento e do feixe utilizado (JONHS CUNNINGHAM, 1983; ATTIX, 1986).

A figura 10 mostra que, a partir da superfície do material irradiado, a PDP, inicialmente, aumenta até alcançar o valor de 100\%, na profundidade de dose máxima (região de build up), onde o feixe de radiação alcança o equilíbrio eletrônico 
dento do material. A espessura de build up aumenta diretamente com a energia do feixe, além disso, a região de build up é menor para feixes de elétrons do que para feixes de fótons emitidos coma mesma energia. A partir da camada de build up, a PDP diminui com o aumento da profundidade devido à atenuação do feixe primário pelo material.

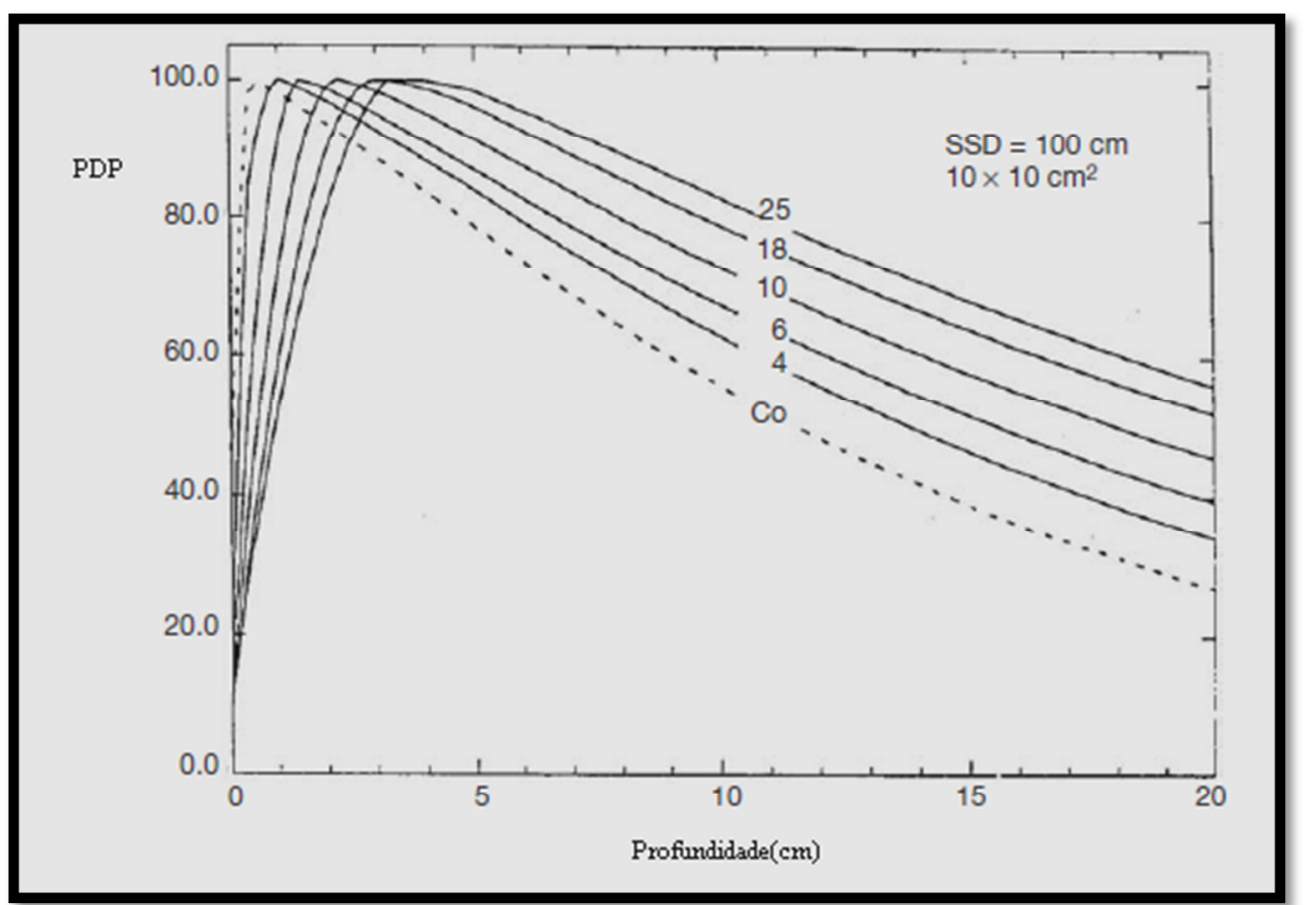

A lei do inverso do quadrado das distâncias define a variação da fluência dos Figura 10 - Curvas de PDP em água para um campo $10 \times 10 \mathrm{~cm}^{2}$ e uma DFS de $100 \mathrm{~cm}$ para feixes de fótons de megavoltagem desde ${ }^{60}{ }^{6} \mathrm{Co}$ até o feixe de $25 \mathrm{MeV}$ de energia (Khan 2003).

fótons de uma fonte de radiação conforme cresce a distância da fonte, sendo independente da energia da fonte e desconsiderando a atenuação do feixe.

Considerando-se a fonte de radiação como uma fonte pontual, a lei do inverso do quadrado da distância relaciona as doses nos pontos $X$ e $Y$ no espaço livre (JOHNS, 1983), como é mostrado na equação 14:

$$
D_{Y}=D_{X}\left(\frac{d_{Y}}{d_{X}}\right)^{2}(G y)
$$

Onde $D_{Y}$ e $D_{X}$ são as doses nos pontos $\mathrm{X}$ e $\mathrm{Y}$, localizados a uma distância $d_{Y}$ e $d_{X}$ em relação à fonte de radiação, respectivamente. 
O Fator de Mayneord apresenta uma formulação, baseada na lei do inverso do quadrado das distâncias, para a correção das PDPs em diferentes DFSs sem considerar variações de espalhamento. Para a PDP a uma determinada profundidade, d, o Fator de Mayneord é descrito conforme a equação abaixo:

$$
F=\left(\frac{f_{2}+d_{m}}{f_{2}+d}\right)^{2} \cdot\left(\frac{f_{1}+d}{f_{1}+d_{m}}\right)^{2}
$$

Onde $\mathrm{F}$ é o Fator de Mayneord, $f_{1}$ e $f_{2}$ são duas distâncias fonte-superfície diferentes e $d_{m}$ e d são as profundidades de máxima dose e do ponto avaliado no objeto simulador, respectivamente.

\subsection{Grandezas quantificadoras da radiação.}

\subsubsection{Fluência energética}

A fluência de partículas é uma grandeza importante envolvendo número de partículas por unidade de área. Considere que $\mathrm{N}$ seja o valor esperado do número de partículas colidindo em uma esfera finita que circunda o ponto $\mathrm{P}$, durante um intervalo de tempo finito. Imagine que a esfera se torne um elemento infinitesimal ao redor de $\mathrm{P}$ com uma seção de choque de área $\mathrm{dA}$, conforme mostra a figura 11:

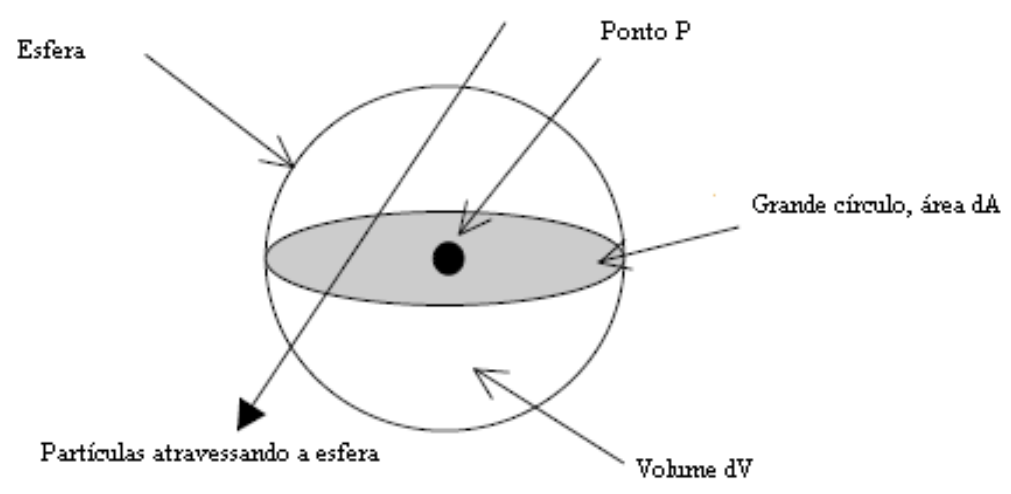

Figura 11 - Caracterização do campo de radiação em um ponto $\mathrm{P}$ em termos da radiação atravessando uma esfera centrada no ponto P (Attix, 1986).

Portanto a fluência é definida por

$$
\Phi=\frac{d N}{d A}
$$


que é usualmente expressa nas unidades $\mathrm{m}^{-2}$ ou $\mathrm{cm}^{-2}$ (ICRU 1980, 1998). A fluência é uma grandeza escalar, pois a direção da radiação não é levada em conta. A fluência pode ser diferenciada em relação a energia da radiação utilizada, nesse caso ela é expressa por:

$$
\Phi_{e}=\frac{d \Phi}{d E}
$$

A fluência total é mostrada pela integral em todo o espectro, portanto:

$$
\Phi=\int_{0}^{E_{\operatorname{máx}}} \Phi_{e} d E
$$

A fluência energética é a grandeza física não estocástica que representa energia, por unidade de área, excluindo os fenômenos de conversão de massa em energia:

Onde: $R=E N_{e}$.

$$
\Psi=\frac{d R}{d a}=E \Phi
$$

A fluência energética é uma grandeza que leva em conta a soma das energias de todos os raios de energia somados, onde $\mathrm{R}$ representa o valor esperado da energia total do feixe (Attix, 1986).

\subsubsection{Energia depositada}

A energia depositada pela radiação ionizante na matéria de massa $\mathrm{m}$ em um finito volume $V$ é definida como:

$$
\epsilon=\left(R_{\text {in }}\right)_{u}-\left(R_{\text {out }}\right)_{u}+\left(R_{\text {in }}\right)_{c}-\left(R_{\text {out }}\right)_{c}+\sum Q
$$

Onde:

$\left(R_{i n}\right)_{u}$ é a energia radiante das partículas não carregadas entrando em um volume $\mathrm{V}$. $\left(R_{\text {out }}\right)_{u}$ é a energia radiante das partículas não carregadas saindo de um volume $\mathrm{V}$.

$\left(R_{i n}\right)_{c}$ é a energia radiante das partículas carregadas entrando em um vol. V. 
$\left(R_{\text {out }}\right)_{c}$ é a energia radiante das partículas carregadas saindo de um vol. V.

$\sum Q$ é a energia derivada da massa de repouso em $\mathrm{V}(\mathrm{m} \rightarrow \mathrm{E}$ positiva, $\mathrm{E} \rightarrow \mathrm{m}$ negativa) (Attix, 1986).

Os sinais mostrados na equação acima representam ganho de energia no caso do sinal positivo e a perda de energia é representada pelo sinal negativo.

Os termos positivos representam energias radiantes de partículas carregadas ou não carregadas que entram em um volume $V$, já os termos negativos são provenientes da energias radiantes que saem de um volume $V$. A conversão de massa em energia representa um ganho de energia depositada, portanto $\Sigma Q$ apresenta valor positivo nessa situação, já a conversão de energia em massa representa perda de energia, logo $\sum Q$ é negativo. A figura 12 ilustra o conceito de energia transmitida pela radiação em um volume elementar.
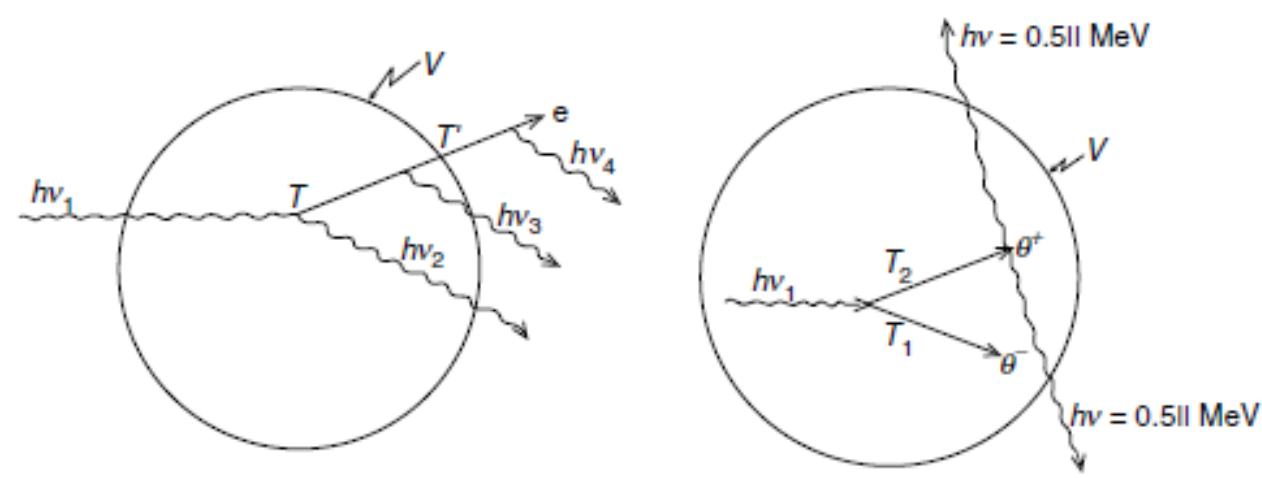

Figura 12 - Uma ilustração do conceito de energia transmitida pela radiação em um volume elementar (Attix, 1986). 


\section{RADIOTERAPIA E SUAS APLICAÇÕES}

A radioterapia é uma técnica de tratamento de neoplasias, mais especificamente o câncer, seja utilizando apenas radiação ionizante ou combinando com outras modalidades, como cirurgia ou quimioterapia.

\subsection{Aspectos gerais da radioterapia}

A utilização das radiações ionizantes em radioterapia se baseia na destruição das células tumorais provocadas pela absorção da energia incidente.

O termo câncer abrange um grupo de doenças que ocorrem quando as células se tornam anormais, dividindo-se e formando mais células, sem controle ou ordem mais especificamente é o resultado de uma série de alterações nos genes, que controlam o crescimento e o comportamento celular.

Qualquer tipo de radiação que tenha energia suficiente para causar a liberação de um ou mais elétrons de um átomo é denominada radiação ionizante. Esse tipo de radiação pode ionizar diretamente ou indiretamente a matéria. Quando isso acontece, no interior da estrutura celular, pode inviabilizar biologicamente a célula ou levá-la a morte.

A radiação diretamente ionizante tem energia cinética suficiente para produzir ionização quando penetra na matéria e é constituída de partículas carregadas: elétrons, prótons e íons pesados.

A radiação indiretamente ionizante libera partículas diretamente ionizantes quando interage com a matéria, as quais são constituídas de partículas não carregadas, tais como, o nêutron e o fóton.

A diferença de sensibilidade à radiação entre o tecido tumoral e os tecidos normais permite que se estabeleça um intervalo de dose, que maximiza o controle tumoral minimizando a probabilidade de danos em tecidos normais.

As doses aplicadas no volume tumoral são limitadas pela tolerância dos tecidos sadios adjacentes. 
O processo de um tratamento radioterápico envolve uma série de etapas e uma equipe formada por profissionais de diversos ramos do conhecimento são necessários para a execução desse tratamento.

O ciclo completo associado à radioterapia envolve as seguintes etapas: o diagnóstico da doença; aquisição de imagens do paciente; o planejamento do tratamento e a execução do tratamento.

A execução eficiente do tratamento pressupõe que os equipamentos utilizados estejam funcionando adequadamente e devidamente calibrados, para que a dose prescrita corresponda a dose a ser liberada durante 0 tratamento e isso somente será possível se o serviço mantiver um controle da qualidade adequado.

Os métodos usados para calcular a distribuição de dose em pacientes irradiados com feixes de fótons e de elétrons levam em consideração a superfície irregular do paciente e as inomogeneidades no corpo com graus de sucesso variáveis. Esses cálculos que fazem parte do planejamento radioterápico e que serão discutidos na próxima seção são diretamente responsáveis pela qualidade do tratamento radioterápico.

Com a introdução de novos conceitos e de novas tecnologias associadas à radioterapia, nota-se que essas inovações técnicas de tratamento têm por objetivo a maximização do controle tumoral local (TCP) e a minimização da probabilidade de complicações em tecidos normais (NTCP). O Gráfico da figura 13 mostra as correspondências entre as porcentagens da probabilidade de controle tumoral e do dano ao tecido normal em função da dose. 


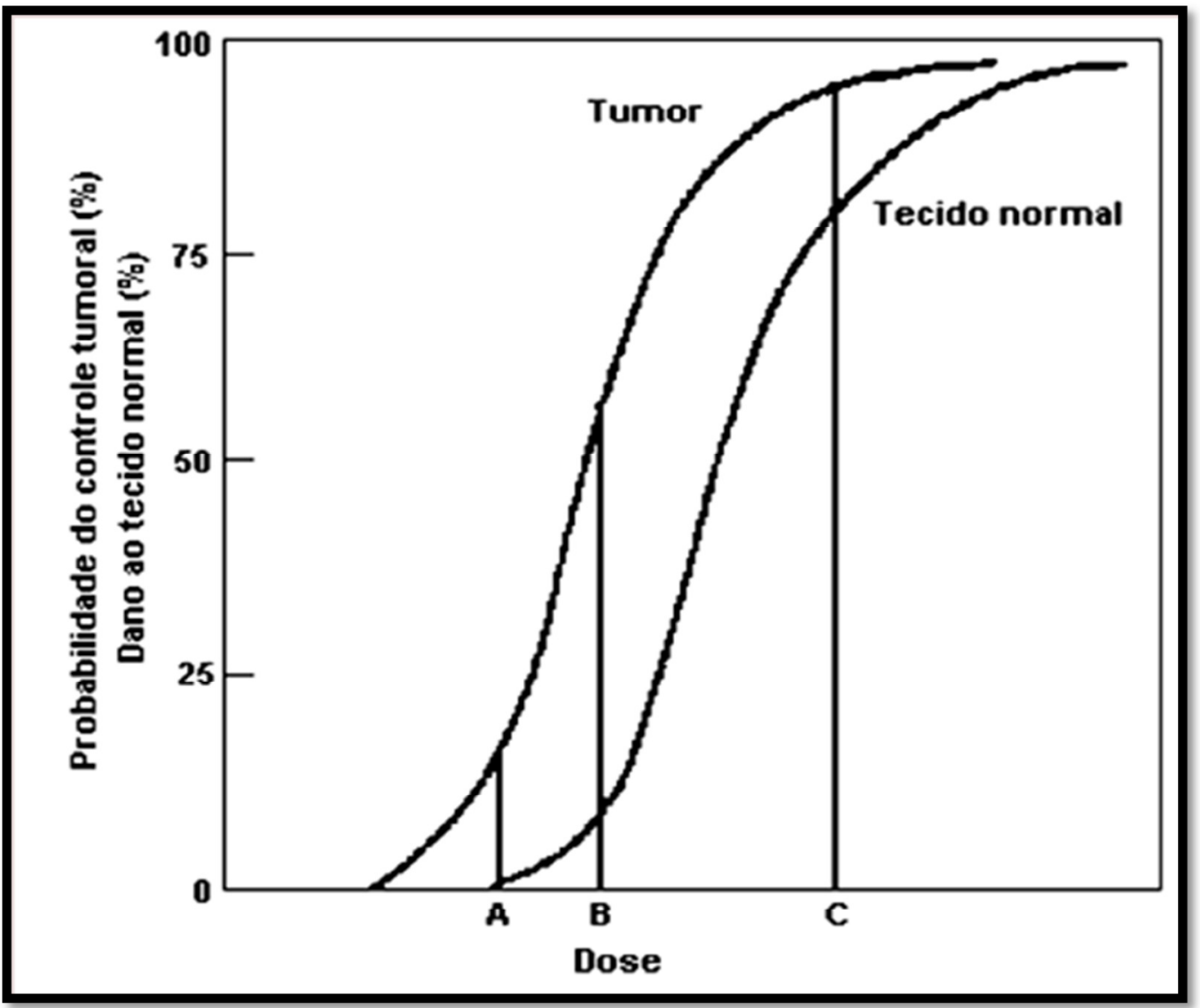

Figura 13 - Gráfico que mostra as correspondências entre as porcentagens da probabilidade de controle tumoral e do dano ao tecido normal em função da dose.

O gráfico da Figura 13 mostra que o tumor e o tecido normal respondem de maneira diferente a radiação durante a aplicação de um tratamento radioterápico e que a escolha da dose deve se basear na maximização da probabilidade do controle tumoral minimizando o dano ao tecido normal, entretanto satisfazendo o máximo de dose que o tecido sadio deve receber. Essa dose está representada pelo ponto B.

\subsection{Planejamento de tratamentos radioterápicos}

O planejamento radioterápico é uma das etapas do tratamento que envolve uma série de atividades, tais como, o cálculo do tempo de exposição para aplicação da dose de radiação exata que o volume a ser tratado receberá, além das estruturas sadias adjacentes e dos órgãos de risco. O planejamento radioterápico pode ser executado através das técnicas 2D e 3D. 
Por exemplo, planejamento 2D é executado através da delimitação do volume tumoral em radiografias planares conforme mostram as radiografias da figura14.

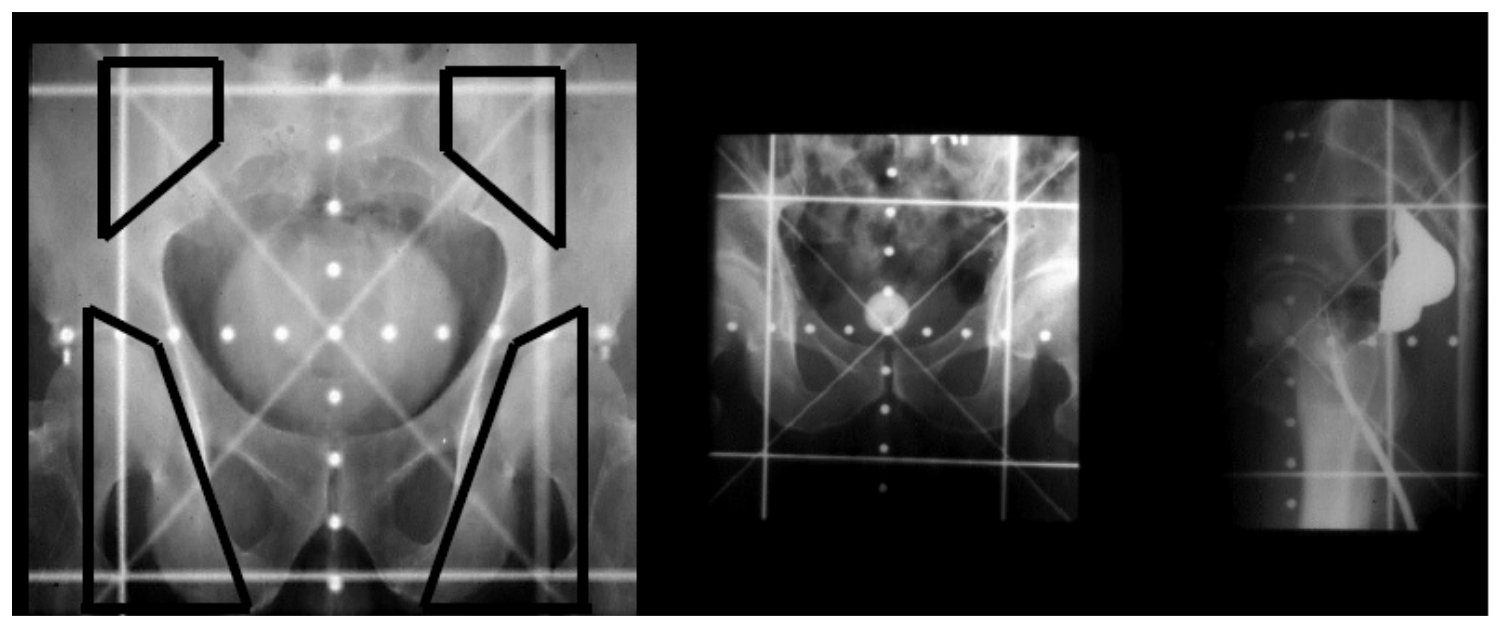

Figura14 - Radiografias planares utilizadas em planejamentos 2D.

As desvantagens desse tipo de tratamento são a impossibilidade de se avaliar a dose no volume a ser tratado e nos órgãos sadios adjacentes, bem como a impossibilidade da visualização completa, do volume alvo e dos órgãos de risco e grandes volumes irradiados, com maior possibilidade de complicações além da impossibilidade de se aumentar a dose prescrita.

A Radioterapia 3D é baseada em uma série de características, dentre as quais, o planejamento é realizado com base em exames de imagem dos órgãos do paciente a serem irradiados, através de tomografia, ressonância magnética, PET, etc., que permitem a possibilidade de visualização do volume alvo e dos órgãos de risco, além disso, essa técnica permite uma proteção maior dos órgãos sadios adjacentes em comparação com a radioterapia 2D. É importante observar que nos planejamentos 2D e conformacional 3D os parâmetros associados ao tratamento como, tamanho, posicionamento, quantidade de campos, ângulo de gantry, colimador e mesa são propostos para que as distribuições de dose no tumor e nos órgãos de risco sejam satisfeitas na forma desejada.

O IMRT surgiu com o objetivo de superar algumas limitações provenientes do 3D, a figura 15 mostra a comparação da distribuição de dose entre o 3D e o IMRT em uma imagem proveniente de um sistema de planejamento. 


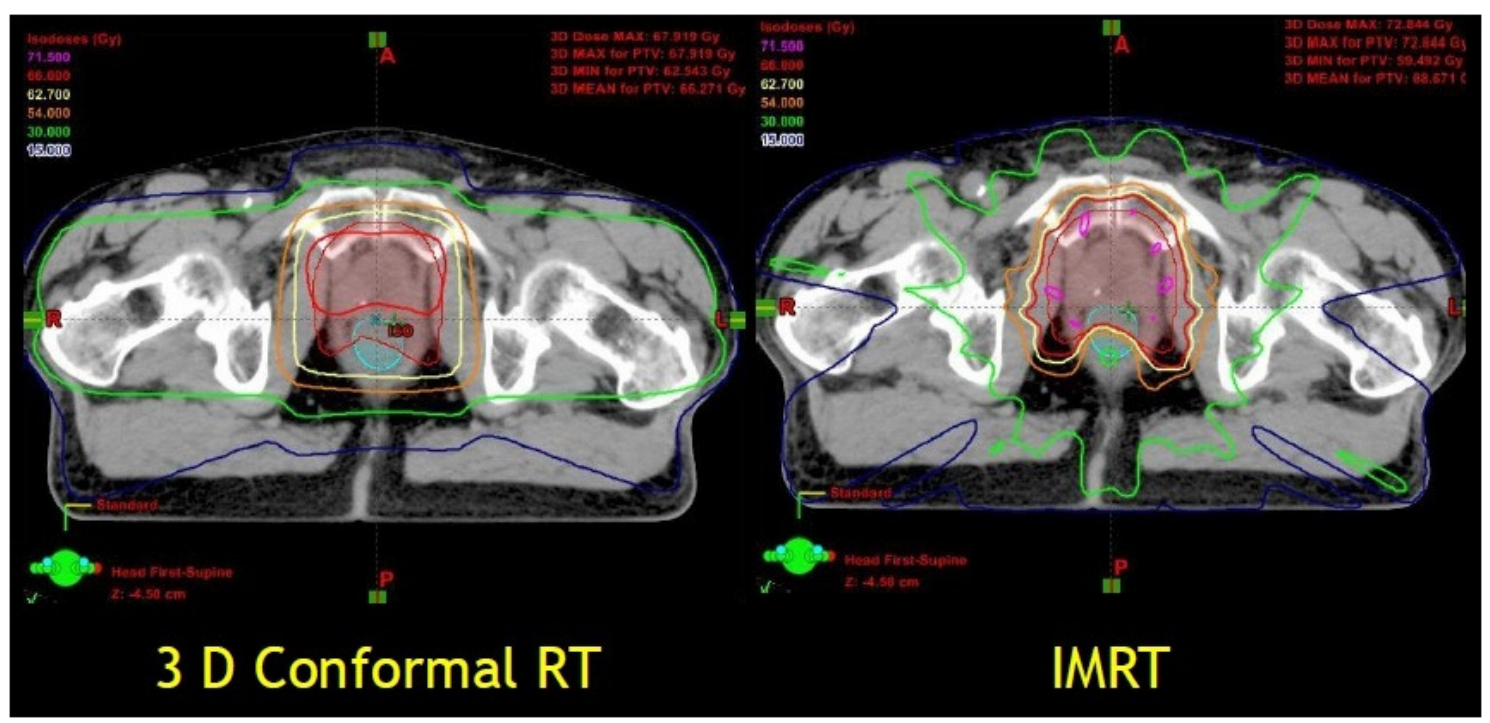

Figura 15 - Comparação entre a conformação estabelecida no planejamento 3D e no IMRT.

O IMRT permite aplicação da dose de radiação com maior precisão no formato tridimensional (3D) do tumor, modulando ou controlando a intensidade do feixe de radiação em volumes diminutos. A IMRT também permite a aplicação de doses mais intensas de radiação no interior do tumor, minimizando a dose ao redor de estruturas críticas normais. O tratamento é cuidadosamente planejado utilizando tomografia computadorizada (3D-CRT), ou imagens de ressonância magnética (IMR) do paciente, juntamente com os cálculos computadorizados de dose para determinar o padrão de intensidade de dose, que se adaptar melhor à forma de tumor. Normalmente, combinações de vários campos de intensidade modulada com feixes originários de várias direções, para produzirem a dose de radiação devida, que maximize a dose no tumor e a minimize nos tecidos adjacentes normais. O IMRT também utiliza sistema de planejamento aplicando algoritmo com lógica inversa de cálculo.

Nos planejamentos com lógica inversa de cálculo, as condições de tratamento, como o tamanho, o posicionamento, a quantidade de campos, ângulo de gantry, colimador, a intensidade de radiação modulada, a angulação da mesa e a quantidade de unidades monitoras, são propostas com a finalidade de se obter as distribuições de dose no tumor e nos órgãos de risco para satisfazer os limites sugeridos pelos protocolos. 
Os planejamentos que utilizam IMRT necessitam de aceleradores lineares com colimadores multilâminas (MLC) controlados por computador, além de um sistema de controle da qualidade e acessórios específicos para dosimetria.

Dentre as especificações de controle da qualidade do IMRT, pode-se destacar uma das primeiras publicações sobre esse tema para sistemas convencionais com MLC que descreve uma metodologia em seis etapas para o QA (Quality Assurance) específico para cada paciente: a) verificação do limite de campo do feixe modulado com o limite de campo do planejamento, que normalmente é feito no 3D-CRT; b) verificação dos dados das lâminas da máquina para que elas possam gerar a dose absorvida prevista, mediante um cálculo independente; c) comparação da distribuição de dose absorvida em um objeto simulador nas mesmas condições de irradiação; d) comparação do movimento das lâminas planejado com o registrado nos arquivos MLC log; e) confirmação das posições iniciais e finais do MLC para cada campo no sistema de registro e verificação; f) medidas de dose absorvida in vivo (Burman C. et. al, 1997)

Esta série de procedimentos de QA dificilmente se repetirá, pois normalmente será necessária quando se inicia um programa de IMRT. Normalmente, são utilizados testes de QA específicos para cada paciente, de um ou mais dos seguintes métodos que são usados, para verificar se o padrão de intensidade irá liberar a dose absorvida desejada:

a) medidas do padrão de intensidade (fluência) dos feixes individuais para cada paciente específico;

b) medidas da dose absorvida no objeto simulador do padrão de intensidade dos feixes planejados para cada paciente específico;

c) cálculos independentes da dose absorvida para o padrão de intensidade dos feixes planejados para cada paciente específico;

d) dosimetria in vivo.

A aplicação de um campo de tratamento em radioterapia, seja qual for a técnica de planejamento, pode ser realizada através das técnicas dfp e da técnica isocêntrica. 
A técnica da distância Foco-Pele-DFP que também pode ser chamada de distância Fonte-Superfície-DFS ou "Source Skin Distance"-SSD representa a distância da fonte de radiação até a pele do paciente.

A técnica isocêntrica que também pode ser chamada de "Source Axis Distance"- SAD ou Distância Fonte Eixo-DFE representa a distância da fonte de radiação até o eixo de rotação do aparelho. Na prática clínica, consiste na determinação de um ponto em uma determinada profundidade no paciente, ao redor do qual o aparelho irá girar, que é denominado isocentro. O Isocentro é definido como um ponto virtual localizado no volume tumoral que é colocado na profundidade desejada no interior do paciente. 


\section{SIMULAÇAO MONTE CARLO COM O CÓDIGO PENELOPE}

O Método Monte Carlo é amplamente utilizado para resolver problemas físicos e matemáticos complexos (James, 1980; Rubinstein, 1981; Kalosand, Whitlock, 1986). A lógica utilizada por esse método é fornecer uma solução numérica em conformidade com o problema de interesse.

Nesse capítulo serão abordados os aspectos fundamentais do método Monte Carlo, o Código PENELOPE e os detectores virtuais.

\subsection{Aspectos fundamentais do método Monte Carlo}

O método Monte Carlo desenvolve uma solução numérica para a equação de transporte de Boltzmann, assim como para aplicações em radioterapia e dosimetria no transporte de radiação que emprega diretamente leis fundamentais microscópicas da física de interações átomo-elétron e fóton-átomo. Esse método é útil na análise de problemas físicos relacionados aos feixes de fótons e de elétrons, pois eles tratam da incidência de partículas de baixa energia, da ordem de quilovoltagem $\left(10^{3} \mathrm{keV}\right)$, ou de alta energia, da ordem megavoltagem $\left(10^{6} \mathrm{MeV}\right)$, utilizada em teleterapia, em um meio material, na teleterapia, com a possibilidade de interação por diversos mecanismos. Através do método monte Carlo pode-se simular o decaimento de elementos radiativos, que é altamente relevante para estudos em braquiterapia.

Uma partícula, na simulação Monte Carlo de transporte de radiação segue uma sequência com três possibilidades que se encerram com a interação, onde as partículas mudam sua direção de movimento, perdem energia e ocasionalmente geram partículas secundárias (SALVAT, FERNÁNDEZ-VAREA e SEMPAU, 2008).

A figura 16 mostra a interação de uma partícula ao atravessar um material. Uma partícula proveniente do vácuo entra no material 1, após múltiplas interações atravessa a interface entre os materiais 1 e 2 . 


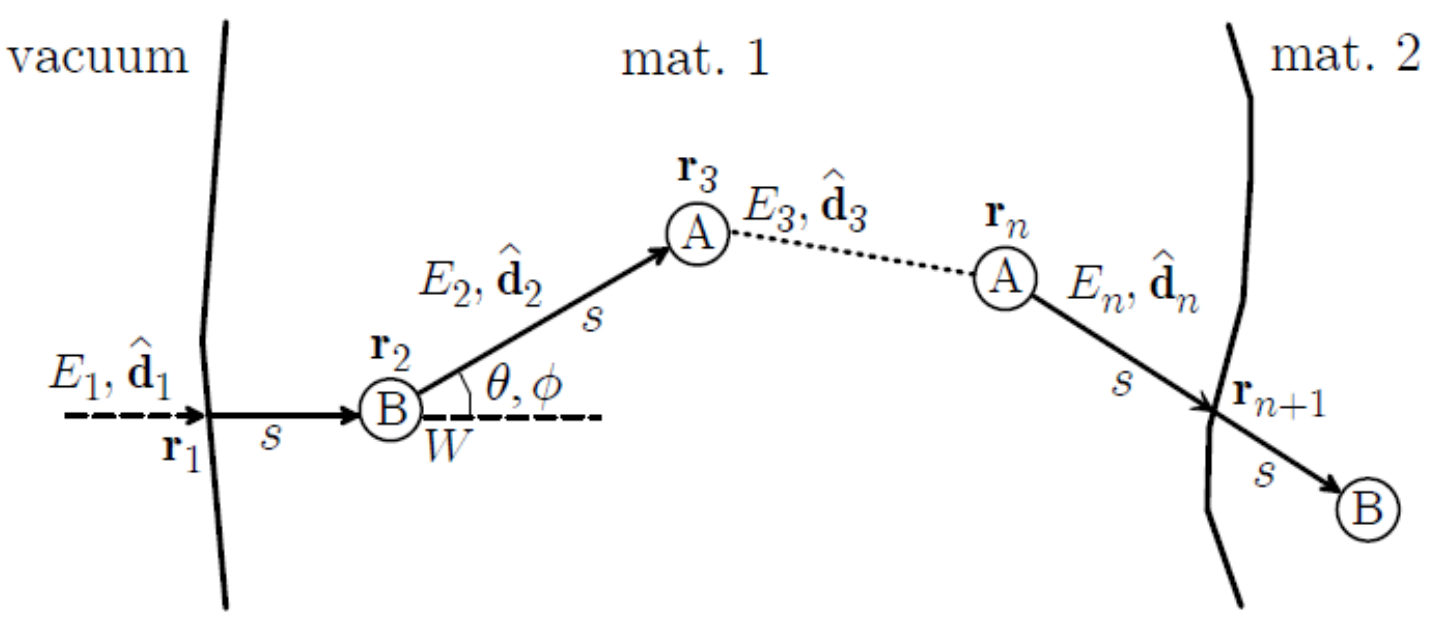

Figura 16 - Geração de trajetórias aleatórias usando simulação detalhada. Uma partícula proveniente do vácuo entra no material 1, após múltiplas interações atravessa a interface entre os materiais 1 e 2 .

A simulação de tratamentos clínicos baseada em método Monte Carlo tem sido largamente utilizada em radioterapia, devido principalmente à exatidão associada ao seu uso. O método Monte Carlo pode também ser utilizado para reproduzir diversas situações desejadas em radioterapia, podendo ser tanto em controle de qualidade como em tratamentos. O método Monte Carlo em estudos de radioterapia apresenta uma série de códigos com os quais, o usuário pode interagir na realização das suas pesquisas, onde pode ser destacado o Código PENELOPE que será adotado nesse trabalho.

\section{2. $O$ Código PENELOPE}

O pacote de simulação Monte Carlo PENELOPE (PENetration and Energy LOss of Positrons and Electrons) realiza a simulação em diversos materiais na geometria desejada baseado no transporte de fótons, elétrons e pósitrons. No pacote PENELOPE encontram-se diversas sub-rotinas escritas em linguagem FORTRAN, distribuídas em diferentes arquivos, aplicativos e uma base de dados com características de materiais de interesse em física radiológica (ICRU, 1989). O transporte de partículas é reproduzido pelo código PENELOPE de maneira que todas as interações sejam realizadas. O PENELOPE distribui suas sub-rotinas nos quatro arquivos FORTRAN: PENELOPE.f, que refere-se ao transporte de partículas; PENGEON.f, que refere-se à geometria da simulação; PENVARED.f, que refere-se às sub-rotinas que executam os métodos de redução variacional e TIMER.f, que 
refere-se às sub-rotinas de controle do tempo de simulação. O código possui, ainda, uma biblioteca de grandezas de interação da radiação com a matéria, como secções de choque e coeficientes de atenuação para diversos elementos e materiais, em função da energia e do tipo de radiação (SALVAT, FERNÁNDEZ-VAREA e SEMPAU, 2005). O programa MATERIAL.f, que faz parte do pacote PENELOPE, gera arquivos de dados de interação dos materiais simulados em função da energia e do tipo de partícula, para utilização em simulações específicas.

Para se executar uma simulação, o usuário deve gerar um aplicativo usuário.exe e a partir da edição de um arquivo fonte usuário.f - com as chamadas sub-rotinas descritas nos programas do pacote - para o gerenciamento da simulação. O aplicativo gerado irá buscar informações da simulação nos arquivos de entrada - entrada.in - e de geometria - geometria.geo - fornecidas pelo usuário.

$\mathrm{O}$ arquivo de entrada (in) caracteriza as condições em que as simulações serão realizadas com dados fornecidos pelo usuário, dentre eles, estão a quantidade de partículas primárias envolvidas na simulação, o tipo de feixe de radiação, com apenas uma componente de energia ou com um espectro de componentes de energias, cada uma com sua probabilidade associada, o campo de radiação no que se refere a tamanho e formato, a abertura, a posição e o tipo da fonte de radiação.

A simulação pode ser encerrada por duas possibilidades que são: primeiro através do número de partículas primárias definidas na linha de comando NSIMSH que ocorre quando todas elas, bem como, as partículas secundárias originadas, descreverem as suas interações, e por tempo, que ocorre quando o tempo máximo de simulação escolhido pelo usuário em TIME chega ao final. O código PENELOPE encerra a simulação pelo evento que acontecer primeiro.

Dentre os parâmetros de controle da exatidão da simulação são definidos: o valor da energia mínima que uma partícula deve possuir antes de ser localmente absorvida $E_{A B S}$ : o parâmetro $C_{1}$, que se refere à deflexão angular média produzida por múltiplo espalhamento de partículas carregadas; o parâmetro $\mathrm{C}_{2}$, que se refere à perda fracional máxima de energia permitida entre eventos colisionais de uma partícula carregada, o parâmetro $\mathrm{W}_{\mathrm{CC}}$, que refere-se a energia máxima perdida por partículas carregadas em colisões fortes e o parâmetro $W_{C R}$ referente a energia 
máxima perdidas por partículas carregadas em perdas radioativas (SALVAT, FERNÀNDEZ-VAREA e SEMPAU, 2005).

O código PENELOPE lê as informações físicas requeridas sobre cada material colocado (que inclui tabelas de propriedades físicas, seção de choque de interação, dados de relaxação, etc.). Os dados do material são criados por meio de um programa de material que auxilia e extrai dados de interação atômica de uma base de dados, PENELOPE-2008.

Para estabelecer um arquivo material.mat é criado o aplicativo material.exe, gerado a partir dos arquivos MATERIAL.f e do PENELOPE.f

No código PENELOPE, o corpo consiste em uma superfície limitante composta por um determinado material. Por razões práticas todas as superfícies limitantes são assumidas quadráticas e obtidas pela equação implícita:

$$
\begin{gathered}
\mathrm{F}(\mathrm{x}, \mathrm{y}, \mathrm{z})=A_{X X} x^{2}+A_{X Y} x y+A_{X Z} x z+A_{Y Y} y^{2}+A_{Y Z} y z+A_{Z Z} z^{2}+ \\
A_{X} x+A_{Y} y+A_{Z} z+A_{0}=0
\end{gathered}
$$

As formas que são assumidas por essas superfícies são as mais diversas, dentre elas, podemos citar os planos, pares de planos, esferas, cilindros, cones, elipsoides, paraboloides, hiperboloides, etc. A definição dessas superfícies está associada ao valor assumido pelos coeficientes da equação.

A expressão reduzida de uma quádrica é definida por:

$$
F_{r}(x, y, z)=I_{1} x^{2}+I_{2} y^{2}+I_{3} z^{2}+I_{4} z+I_{5}
$$

Onde, os índices ou coeficientes podem assumir os valores -1,0 e 1 e as superfícies possíveis com seus respectivos coeficientes são mostradas na tabela 1 . 


\begin{tabular}{lrrrrrl}
\hline \hline Reduced form & \multicolumn{5}{c}{ Indices } & Quadric \\
\hline$z-1=0$ & 0 & 0 & 0 & 1 & -1 & plane \\
$z^{2}-1=0$ & 0 & 0 & 1 & 0 & -1 & pair of parallel planes \\
$x^{2}+y^{2}+z^{2}-1=0$ & 1 & 1 & 1 & 0 & -1 & sphere \\
$x^{2}+y^{2}-1=0$ & 1 & 1 & 0 & 0 & -1 & cylinder \\
$x^{2}-y^{2}-1=0$ & 1 & -1 & 0 & 0 & -1 & hyperbolic cylinder \\
$x^{2}+y^{2}-z^{2}=0$ & 1 & 1 & -1 & 0 & 0 & cone \\
$x^{2}+y^{2}-z^{2}-1=0$ & 1 & 1 & -1 & 0 & -1 & one sheet hyperboloid \\
$x^{2}+y^{2}-z^{2}+1=0$ & 1 & 1 & -1 & 0 & 1 & two sheet hyperboloid \\
$x^{2}+y^{2}-z=0$ & 1 & 1 & 0 & -1 & 0 & paraboloid \\
$x^{2}-z=0$ & 1 & 0 & 0 & -1 & 0 & parabolic cylinder \\
$x^{2}-y^{2}-z=0$ & 1 & -1 & 0 & -1 & 0 & hyperbolic paraboloid \\
$\ldots$ and permutations of $x, y$ and $z$ that preserve the central symmetry with respect \\
to the $z$-axis.
\end{tabular}

Tabela 1 - A tabela apresenta as quádricas reduzidas e seus respectivos coeficientes.

O material confinado dentro da superfície pertence aos arquivos do tipo material.mat e são gerados através do material.exe gerado a partir do MATERIAL.f e do PENELOPE.f

Exceto em casostriviais, a correção da geometria definida é difícil de verificar e, além disso, as estruturas 3D com corpos interpenetrantes são difícies de visualizar.

Os programas de visualização, chamados gview $2 d$ e gview $3 d$, foram escritos para exibir a geometria na tela do computador.

Portanto o giew $2 d$ e o gview $3 d$ são programas que fornecem imagens e que servem de auxílio ao usuário. O gview2d é responsável por fornecer um corte na imagem desejada, ou seja, uma imagem plana, já o gview 3d mostra o volume desejado, ou seja, imagens tridimensionais, conforme mostrado na figura 17. 


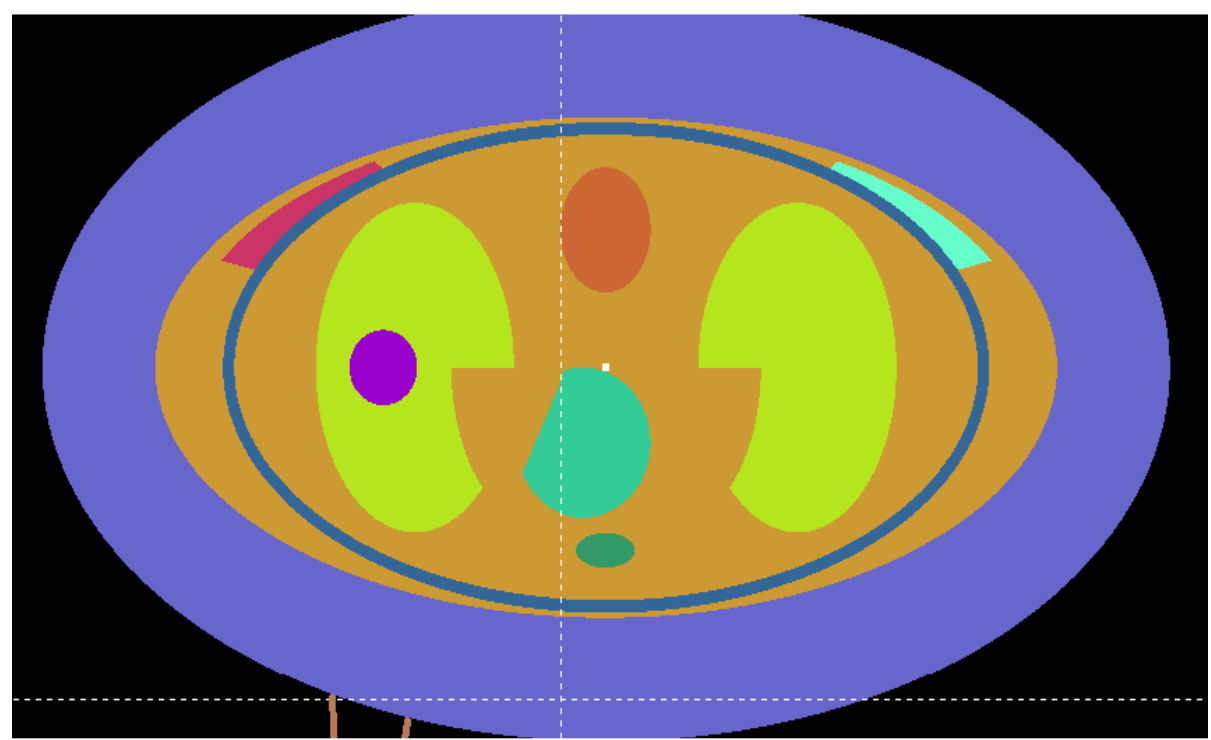

Figura 17 - Visualização de um corte axial de um objeto simulador antropomórfico utilizando o Método Monte Carlo (MMC) com o código PENELOPE através do gview2D.

\subsection{Detectores virtuais}

Os detectores virtuais são estruturas geométricas que são usadas para extrair informações sobre fluência de partículas dentro delas. Devido a sua definição descrita acima, é possível extrair a energia depositada e fluência energética das partículas que chegam à geometria.

Cada detector consiste em uma série de corpos ativos, que devem ter sido definidos como partes da geometria. O espectro de saída de um "impact detector" é a distribuição de energia de partículas que entram em um corpo ativo PENELOPE2008.

Os arquivos de saída da simulação são definidos como arquivos de dados, que possuem a estrutura penmain.dat, para fornecerem informações sobre a energia depositada em cada corpo da geometria e o seu respectivo erro associado, devido ao comportamento probabilístico das partículas primárias e espalhadas incidentes na geometria.

Além disso, esse arquivo fornece o número de eventos de interação de um determinado tipo que foram simulados, a transmissão e absorção fracional de radiação pela geometria e outras informações. 
Dentre os arquivos com esse tipo de estrutura pode ser destacado o "fln.dat" que mostra para o usuário, o espectro de fluência energética que chega a um determinado corpo solicitado pelo usuário. 


\section{MATERIAIS E MÉTODOS}

Neste capítulo são apresentados os materiais e métodos utilizados para a realização desse trabalho, onde foi utilizada uma abordagem mista na aquisição de dados através do uso de medidas clínicas, com a utilização de câmara de ionização e simulação Monte Carlo em diferentes condições de irradiação.

As simulações Monte Carlo utilizaram o código PENELOPE e as medidas envolvendo câmara de ionização foram executadas no Hospital do Câncer de Barretos - Fundação Pio XII.

\subsection{Modelagem Teórica: SMC PENELOPE}

\subsubsection{O código da SMC}

As simulações realizadas nesse trabalho foram definidas com o objetivo de reproduzir situações clínicas de forma que os resultados tenham uma estatística boa o suficiente para que seja possível observar fenômenos físicos associados com poucos ruídos, que dificultariam ou impossibilitariam a interpretação dos fatos envolvidos.

A outra variável que merece ser observada é o tempo de simulação que não deve ser muito longo sem que haja necessidade para isso.

Diante dessa problemática de custo-benefício, adotamos o valor de $10^{8}$ partículas primárias nas nossas simulações, pois ele permite uma boa estatística.

Além disso, adotamos valores padrões do código PENELOPE para $\mathrm{E}_{\mathrm{ABS}}, \mathrm{W}_{\mathrm{CC}}$, $W_{C R}, C_{1}$ e $C_{2}$ nas simulações envolvendo objeto simulador homogêneo.

Onde:

- $E_{A B S}$ é o limiar de energia para absorção da partícula.

- $\mathbf{W}_{\mathrm{Cc}}$ é o limiar para perda de energia em colisões inelásticas fortes.

- $\mathbf{W}_{C_{R}}$ é o limiar para perda de energia por "Bremmstrahlung".

$-\mathbf{C}_{1}$ é a deflexão angular média entre eventos elásticos fortes.

$-\boldsymbol{C}_{2}$ é a fração máxima de energia perdida em um evento.

Os valores utilizados nas simulações envolvendo simuladores homogêneos estão mostrados na tabela 2. 


\begin{tabular}{|l|l|l|l|l|l|l|}
\hline $\mathbf{E}_{\text {Abs1 }}(\mathbf{e V})$ & $\mathbf{E}_{\text {Abs2 }}(\mathbf{e V})$ & $\mathbf{E}_{\text {Abs3 }}(\mathbf{e V})$ & $\mathbf{W}_{\mathrm{CC}}$ & $\mathbf{W}_{\mathrm{CR}}$ & $\mathbf{C}_{1}$ & $\mathbf{C}_{2}$ \\
\hline $\mathbf{1 . 0 e 3}$ & $1.0 \mathrm{e} 3$ & $1.0 \mathrm{e} 5$ & 0.1 & 0.1 & $1 \mathrm{e} 4$ & $1 \mathrm{e} 3$ \\
\hline
\end{tabular}

Tabela 2 - Valores utilizados nas simulações envolvendo objetos simuladores homogêneos.

$\mathrm{Na}$ outra etapa do trabalho onde foi irradiado o objeto simulador antropomórfico da região pulmonar com um tumor localizado dentro desse órgão, adotamos outros valores para $\mathrm{E}_{\mathrm{ABS}}, \mathrm{W}_{\mathrm{CC}}, \mathrm{W}_{\mathrm{CR}}, \mathrm{C}_{1}$ e $\mathrm{C}_{2}$ devido a maior complexidade da geometria estudada. $\mathrm{Na}$ tabela 2 são apresentados os valores utilizados nesse trabalho.

Os valores utilizados nas simulações envolvendo simuladores antropomórficos estão mostrados na tabela 3.

\begin{tabular}{|l|l|l|l|l|l|l|}
\hline $\mathbf{E}_{\text {Abs1 } 1}(\mathbf{e V})$ & $\mathbf{E}_{\text {Abs2 }}(\mathbf{e V})$ & $\mathbf{E}_{\text {Abs3 }}(\mathbf{e V})$ & $\mathbf{W}_{\mathrm{CC}}$ & $\mathbf{W}_{\mathrm{CR}}$ & $\mathbf{C}_{1}$ & $\mathbf{C}_{\mathbf{2}}$ \\
\hline $\mathbf{1 . 0 e 5}$ & $1.0 \mathrm{e} 5$ & $1.0 \mathrm{e} 5$ & 0.05 & 0.05 & $1 \mathrm{e} 4$ & $1 \mathrm{e} 3$ \\
\hline
\end{tabular}

Tabela 3 - Valores utilizados nas simulações envolvendo objetos simuladores antropomórficos.

\subsubsection{Espectros Utilizados}

No caso presente nessa dissertação, os resultados clínicos foram obtidos por meio de irradiações com espectro primário de feixe de fótons proveniente de um acelerador Linear Clinac 2100 da Varian, com energia máxima de $6 \mathrm{MeV}$.

Como o espectro de energia não é fornecido pelo fabricante do equipamento utilizou-se, uma tabela reconstruída, por Sheikh-Bagheri e Rogers mostrada na tabela2, na qual foram determinadas as componentes do espectro de um acelerador Varian de $6 \mathrm{MeV}$ de energia e as suas respectivas probabilidades de ocorrência.

A tabela 4 mostra o espectro primário, utilizado nessa dissertação, nas diferentes condições em que os objetos simuladores homogêneos e 0 antropomórfico foram irradiados. 


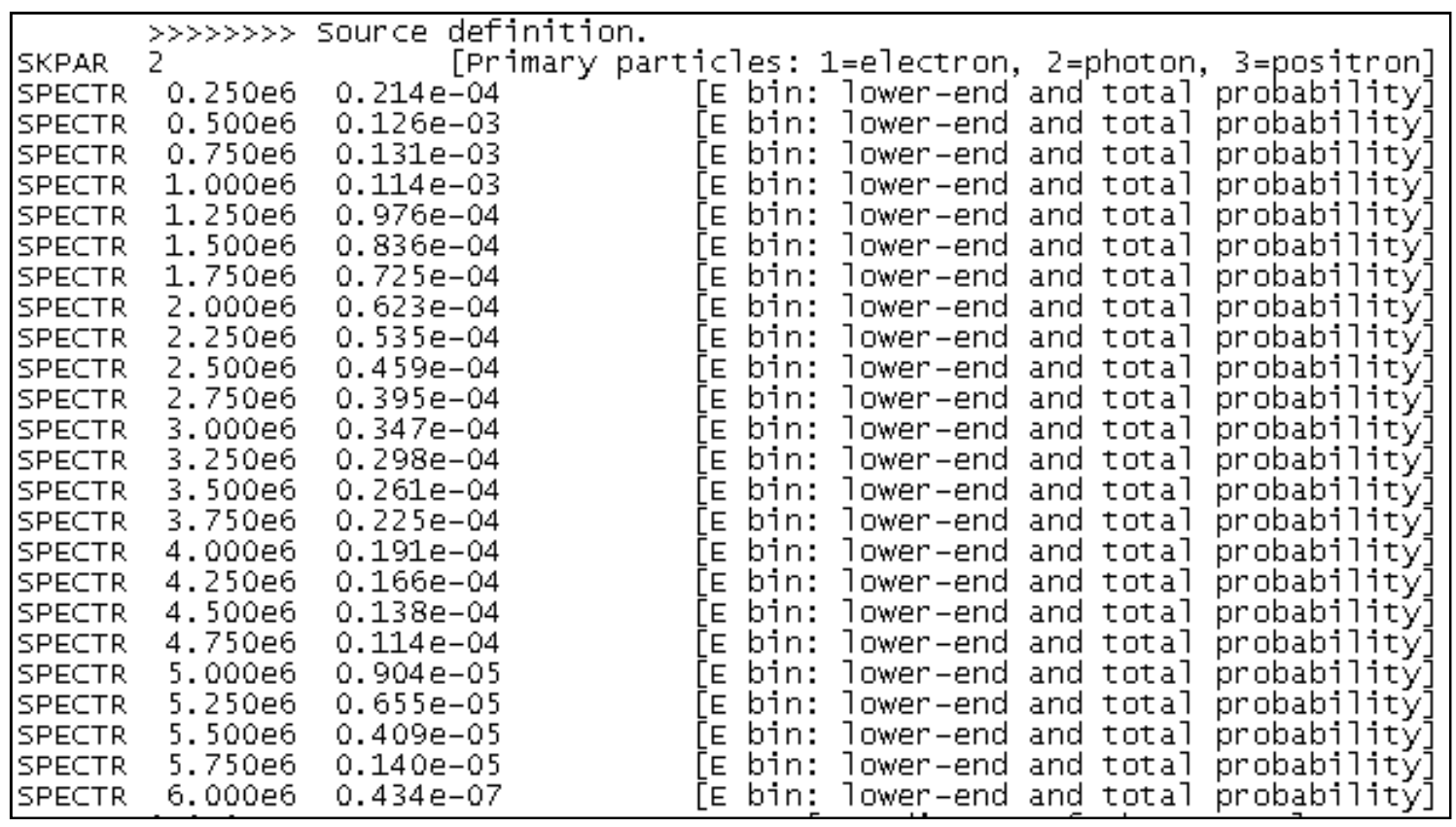

Tabela 4 - Espectro de entrada utilizado no trabalho nas simulações com o código PENELOPE.

\subsection{Validação das simulações}

Essa etapa do trabalho tem por objetivo verificar se as simulações reproduzem bem o que está acontecendo na clínica. Para isso foi utilizado o padrão das curvas de PDP (porcentagem de dose profunda), devido ao fato de estar relacionada com a dose.

A validação das simulações Monte Carlo utilizando o código PENELOPE foi realizada com base nas condições padrão do protocolo TRS-398 que são campo $10 \times 10 \mathrm{~cm}^{2}$ e dfs $=100 \mathrm{~cm}$, para feixes de fótons de alta energia incidentes, em um objeto simulador de água. Torna-se importante salientar que, o feixe de fótons espalha ao atingir um objeto simulador de água e a margem mínima para essa condição é de $5 \mathrm{~cm}$ em cada lado, logo o objeto simulador deve apresentar valor superior a $20 \mathrm{~cm}$ em cada lado.

Nestas condições foi realizada uma simulação considerando uma distância de $100 \mathrm{~cm}$ entre a fonte de acelerador da Varian de $6 \mathrm{MeV}$ de energia com o espectro mostrado na tabela 3 e a superfície de um objeto simulador de água com dimensões $30 \times 30 \times 30 \mathrm{~cm}^{3}$ e dela obtivemos uma curva de PDP (porcentagem de dose profunda). 
A curva de PDP obtida por meio da SMC foi comparada com a obtida no serviço de radioterapia do Hospital do câncer de Barretos- Fundação Pio XII.

\subsection{Detectores virtuais}

No experimento foram utilizados 9 detectores virtuais, que apresentavam dimensões cúbicas com lados iguais a meio centímetro simulando água, aplicadas nesse trabalho. Os detectores foram posicionados externamente ao objeto simulador sendo que, o $1^{\circ}$ foi posicionado imediatamente abaixo do objeto simulador, na direção central do feixe de radiação, sendo que os outros foram posicionados apresentando um espaçamento de $3 \mathrm{~cm}$ entre os seus centros de forma que, o $2^{\circ}$ foi colocado $3 \mathrm{~cm}$ abaixo do $1^{\circ}$ e assim, sucessivamente até o $9^{\circ}$ detector, conforme pode ser observado na figura 18 .

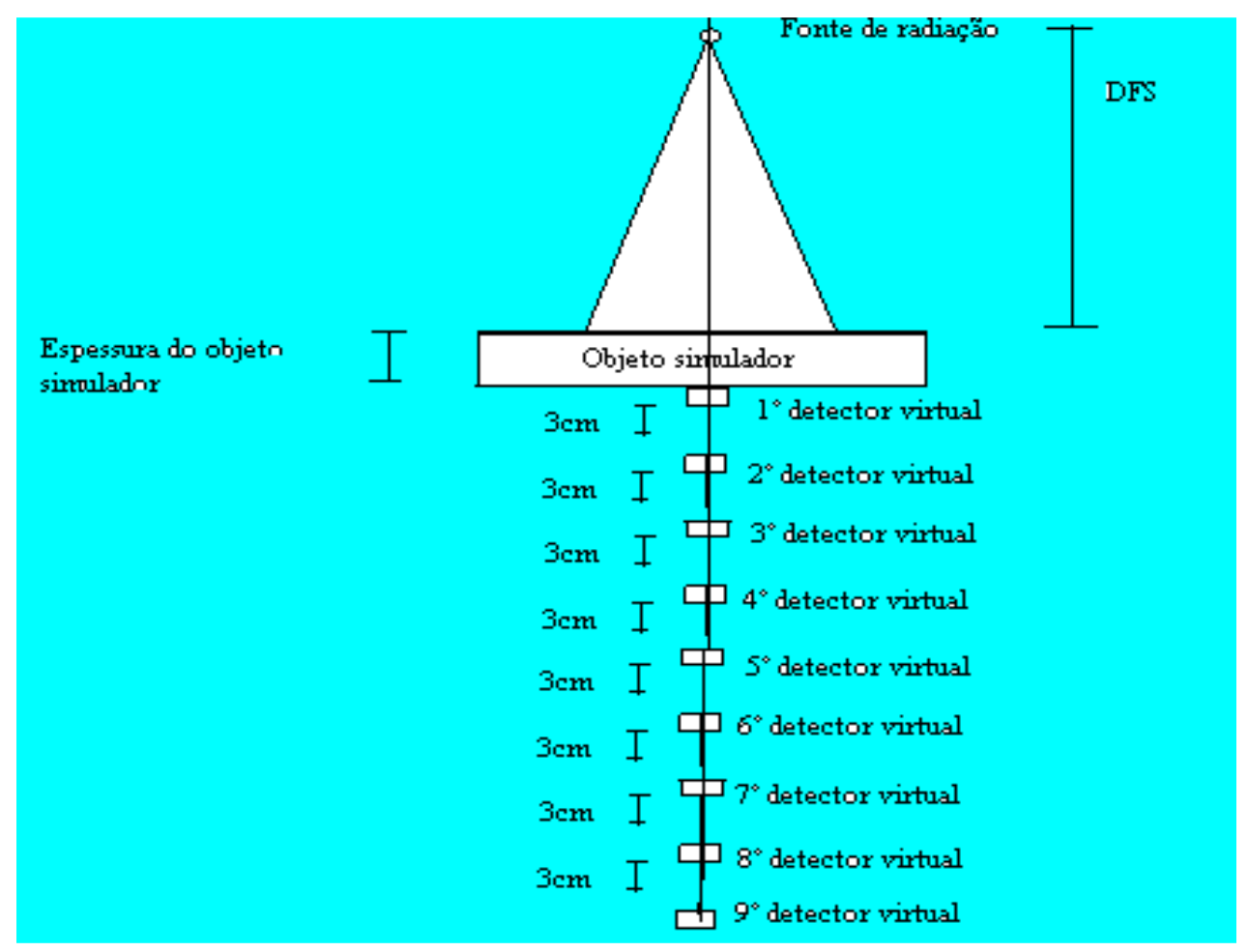

Figura 18: Representação da montagem das simulações envolvendo objeto simulador homogêneo.

As simulações envolvendo objetos simuladores antropomórficos foram realizadas de maneira que o posicionamento desses detectores foi externo ao objeto simulador, onde posicionamos o $1^{\circ}$ imediatamente atrás do objeto simulador na direção do eixo central do feixe que irradiou um tumor posicionado dentro do pulmão 
e os outros apresentaram espaçamento de $3 \mathrm{~cm}$ entre eles de forma que o $2^{\circ}$ ficou colocado imediatamente atrás do $1^{\circ}$ e assim sucessivamente até 0 9ํำ detector, conforme mostra a figura 19.

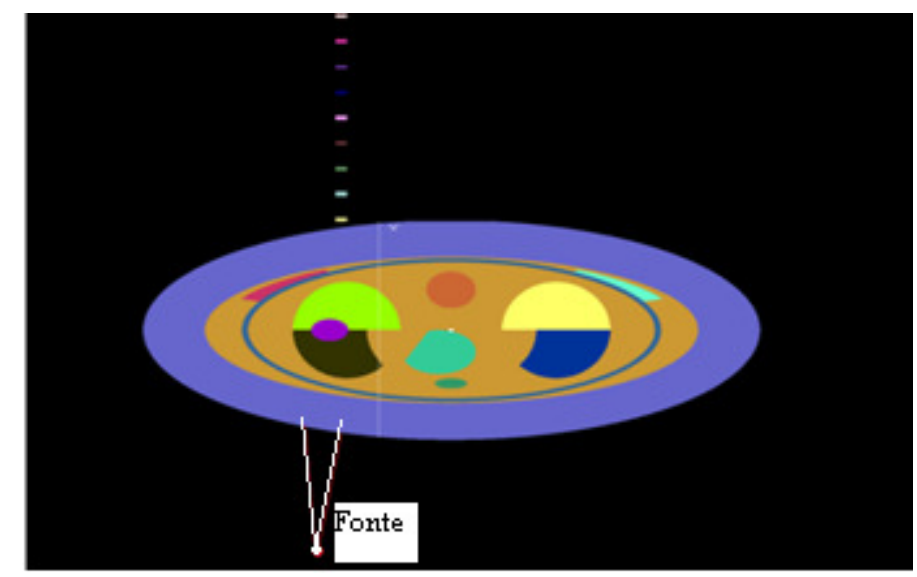

Figura 19 - Representação da montagem das simulações envolvendo objeto simulador antropomórfico.

\subsection{Intervalo de variação dos parâmetros clínicos nas SMC}

Os parâmetros clínicos que sofreram variação foram os seguintes: a espessura do objeto simulador, o tamanho de campo e a distância fonte superfície.

As espessuras do objeto simulador utilizadas variaram de 1 a $20 \mathrm{~cm}$ com variações de um centímetro entre as simulações realizadas.

Os resultados provenientes da variação da espessura do objeto simulador forneceram dados para a seção 6.1.2 que trata do estudo da energia depositada com a variação das espessuras do objeto simulador e da seção 6.1 .3 que trata do estudo das fluências energéticas com a variação das espessuras do objeto simulador.

$\mathrm{Na}$ seção 6.1.2 obteve-se as energias depositadas para cada espessura descrita acima nos nove detectores virtuais com arranjo experimental conforme descrito na seção 5.3 .

$\mathrm{Na}$ seção 6.1 .3 obteve-se os gráficos de fluência energética do espectro secundário mais o transmitido, captada pelo $1^{\circ}$ detector virtual, e do espectro 
primário, onde ambos estavam normalizados e sobrepostos para as espessuras de 1 $\mathrm{cm}, 5 \mathrm{~cm}, 10 \mathrm{~cm}, 16 \mathrm{~cm}$ e $20 \mathrm{~cm}$.

Os tamanhos de campos, em $\mathrm{cm}^{2}$ utilizados foram: $1 \times 1 ; 2 \times 2 ; 3 \times 3 ; 5 \times 5 ; 8 \times 8$; $10 \times 10 ; 12 \times 12 ; 15 \times 15 ; 18 \times 18$ e $20 \times 20$.

$\mathrm{Na}$ seção 6.1.4 fez-se o estudo da energia depositada com a variação do tamanho de campo para os nove detectores virtuais descritos conforme o arranjo experimental descrito em 5.3.

$\mathrm{Na}$ seção 6.1 .5 fez-se o estudo da fluência energética com a variação do tamanho de campo onde se obteve os gráficos de fluência energética do espectro secundário mais 0 transmitido, captada pelo $1^{\circ}$ detector virtual, e do espectro primário, onde ambos estavam normalizados e sobrepostos para os tamanhos de campo de $1 \times 1,5 \times 5,10 \times 10,15 \times 15$ e $20 \times 20 \mathrm{~cm}^{2}$.

Enquanto que, as distâncias fonte-superfície utilizadas sofreram incrementos de $5 \mathrm{~cm}$ entre elas, no intervalo de $70 \mathrm{~cm}$ a $130 \mathrm{~cm}$.

Os resultados utilizando diferentes dfs estão presentes na seção 6.1.6 que trata do estudo da energia depositada com a variação da distância fonte-superfície e na seção 6.1.7 que trata do estudo da fluência energética com a variação da distância fonte superfície.

Os resultados obtidos em 6.1.6 mostram os resultados referentes às energias depositadas para o intervalo de dfs descrito acima, considerando-se os nove detectores virtuais descritos em 5.3.

Na seção 6.1 .7 fez-se o estudo da fluência energética com a variação do tamanho de campo onde se obteve os gráficos de fluência energética do espectro secundário mais o transmitido, captada pelo $1^{\circ}$ detector virtual, e do espectro primário, onde ambos estavam normalizados e sobrepostos para as distâncias fonte superfície de $70 \mathrm{~cm}, 90 \mathrm{~cm}, 110 \mathrm{~cm}$ e $130 \mathrm{~cm}$.

Na seção 6.2 será obtida a resposta da câmara descrita em 5.7.2 para se obter a resposta para diferentes condições de irradiação, bem como, se determinar os fatores de conversão que será descrito em detalhes na seção 5.8. Em virtude das limitações do acelerador utilizado, descrito em 5.7.1, não será possível se obter as respostas para as distâncias fonte superfície de $70 \mathrm{~cm}$ e de $75 \mathrm{~cm}$, por isso, 0 
intervalo de distâncias fonte superfície dessa seção foi limitado de $80 \mathrm{~cm}$ a $130 \mathrm{~cm}$ com incrementos de $5 \mathrm{~cm}$ entre as mesmas.

$\mathrm{Na}$ seção 6.3 serão realizas simulações envolvendo um objeto simulador antropomórfico onde a região irradiada é a torácica e com o feixe de radiação atravessando o pulmão.

Na subseção 6.3.1 denominada variação da energia depositada em função do tamanho de campo serão apresentados os resultados referentes aos tamanhos de campo $1 \times 1 ; 2 \times 2 ; 3 \times 3 ; 5 \times 5 ; 8 \times 8 ; 10 \times 10 ; 12 \times 12 ; 15 \times 15 ; 18 \times 18$ e $20 \times 20 \mathrm{~cm}^{2}$ para nove detectores virtuais conforme descrito em 5.3.

Na seção 6.3.2 será realizado o estudo da fluência energética, com a variação do tamanho de campo, para se obter os gráficos de fluência energética do espectro secundário mais o transmitido, captada pelo $1^{\circ}$ detector virtual, e do espectro primário, sendo que ambos estarão normalizados e sobrepostos para os tamanhos de campo de $1 \times 1,5 \times 5,10 \times 10,15 \times 15$ e $20 \times 20 \mathrm{~cm}^{2}$.

Os resultados utilizando diferentes dfs para objeto simulador antropomórfico serão apresentados na seção 6.3.3 que trata do estudo da energia depositada com a variação da distância fonte-superfície e na seção 6.3.4 que trata do estudo da fluência energética com a variação da distância fonte superfície.

Os resultados que serão obtidos em 6.3.3 mostrarão os resultados referentes as energias depositadas para o intervalo de dfs descrito acima, considerando-se os nove detectores virtuais descritos em 5.3 .

Na seção 6.3.4 será feito o estudo da fluência energética com a variação do tamanho de campo onde será obtido os gráficos de fluência energética do espectro secundário mais o transmitido, captada pelo $1^{\circ}$ detector virtual, e do espectro primário, onde ambos estão normalizados e sobrepostos para as distâncias fonte superfície de $70 \mathrm{~cm}, 90 \mathrm{~cm}, 110 \mathrm{~cm}$ e $130 \mathrm{~cm}$.

\subsection{Determinação de espectros}

Uma das aplicações do código de Simulação Monte Carlo (SMC) PENELOPE utilizada nesse trabalho foi a obtenção de gráficos de espectros de fluência energética onde são determinados os gráficos das fluências energéticas de 
espectros secundários mais transmitidos para diferentes condições de irradiação e foram graficados por meio do programa orign8, de onde foram importados os arquivos do tipo fln-impdet.dat.

\subsection{Doses em profundidade por meio da simulação Monte Carlo}

O Método Monte Carlo, por meio do código PENELOPE através da simulação de eventos envolvendo partículas, faz o cálculo da energia depositada em detectores virtuais para a situação envolvida. Enquanto que, os dados de energia depositada foram retirados dos arquivos do tipo penmain-res.dat que fornece esse tipo de resposta no corpo que se tem interesse em determinar a energia depositada. A resposta fornecida pelo código PENELOPE no que se refere à energia depositada nos detectores virtuais é fornecida em eV.

\subsection{Experimentos realizados}

5.7.1. O acelerador linear utilizado

O acelerador utilizado na parte experimental desse trabalho foi um acelerador linear Clinac 2100 fabricado pela Varian com feixe de fótons com energia máxima de $6 \mathrm{MeV}$ pertencente ao hospital do câncer de Barretos - Fundação Pio XII.

As figuras 20 e 21 representam o acelerador linear e as placas de água sólida utilizados no experimento. 

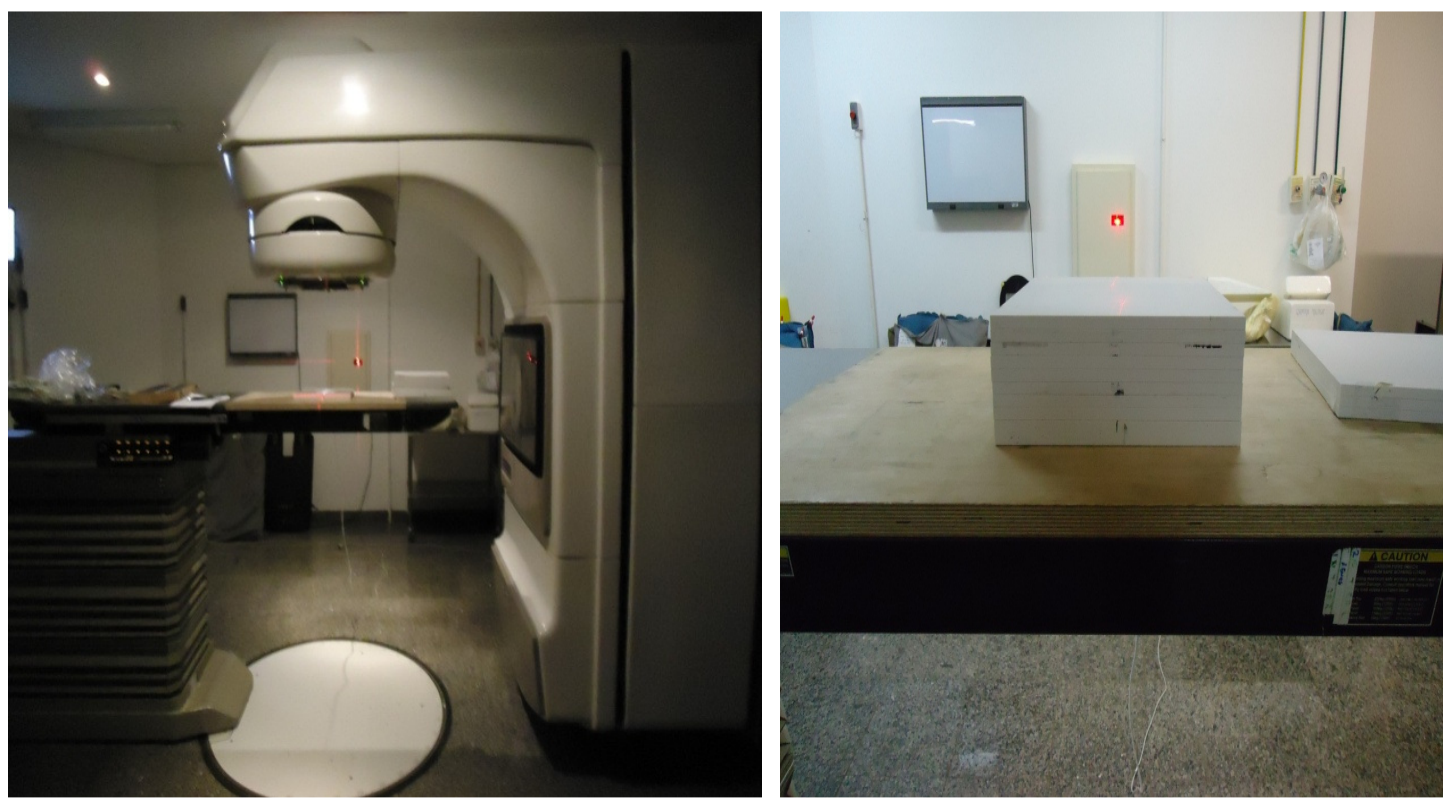

Figuras 20 e 21 - Acelerador Linear Clinac 2100 produzido pela Varian com energia de $6 \mathrm{MeV}$ e as placas de água sólida utilizados na parte experimental.

\subsubsection{A Câmara de ionização utilizada}

Nós utilizamos uma câmara de ionização cilíndrica tipo "farmer Exradin A12" que apresenta espessura da parede de $0,5 \mathrm{~mm}$ e um volume sensível de $0,64 \mathrm{~cm}^{3}$, mostrada na figura 22.

Figura 22 - Esquema da câmara de ionização utilizada nos experimentos realizados.

\subsubsection{O objeto simulador utilizado}

$\mathrm{Na}$ montagem experimental foram utilizadas placas de água sólida. Cada placa de água sólida apresenta dimensões de $30 \mathrm{~cm} \times 30 \mathrm{~cm} \times 1 \mathrm{~cm}$ onde uma delas foi acoplada a câmara de ionização ao objeto simulador. Esse acoplamento foi realizado através de um orifício de $7 \mathrm{~mm}$ de diâmetro existente na placa.

Além disso, o volume sensível da câmara foi posicionado no eixo central do feixe. 
Nesse trabalho, foram utilizados espessuras do objeto simulador de $1 \mathrm{~cm} \mathrm{a}$ $20 \mathrm{~cm}$ acima da câmara de ionização. Tendo em vista, a necessidade de se aumentar a espessura do objeto simulador foram acrescentadas placas de dimensões de $30 \times 30 \times 1 \mathrm{~cm}$ acima da placa na qual, a câmara de ionização estava acoplada até que fosse atingida a dimensão desejada.

\subsection{Determinação da Energia depositada em profundidade através da relação entre simulação Monte Carlo e a câmara de ionização}

A pesquisa desenvolvida nessa dissertação apresenta as respostas obtidas tanto na parte externa quanto na interna do objeto simulador homogêneo. As respostas obtidas na parte interna foram verificadas por meio da abordagem experimental utilizando uma câmara de ionização cilíndrica tipo Farmer sendo que, o seu volume sensível se localizava no centro do objeto simulador.

As respostas obtidas através de simulação monte Carlo foram realizadas de maneira que, os detectores virtuais se encontravam em posições externas ao objeto simulador.

Sabe-se que o grande objetivo da radioterapia é conseguir altas doses no tecido tumoral e baixas doses nas adjacências dos tecidos sadios. Assim, para satisfazer essa condição é importante calcular o quanto de energia se deposita no tumor.

A proposta dessa etapa do trabalho é determinar um fator que relacione essas duas medidas, de maneira que seja possível prever o quanto de energia está se depositando em um tumor através de uma medida externa a esse tumor realizada por meio de simulação Monte Carlo. Assim, o cálculo desse fator foi realizado utilizando a expressão matemática abaixo, vejamos:

$$
f_{c}=\frac{Q_{c}}{E_{d_{S M C}}}
$$

Onde:

$-f_{c}$ é o fator de conversão.

- $Q_{c}$ é a carga coletada pelo eletrômetro conectado a câmara de ionização colocada dentro do objeto simulador. 
- $E_{d_{S M C}}$ é a resposta obtida através de simulação Monte Carlo no detector virtual imediatamente abaixo do objeto simulador.

Através desses resultados consegue-se determinar os fatores de conversão nos intervalos clínicos considerados, tanto para objeto simulador homogêneo quanto para objeto simulador antropomórfico.

Os fatores de conversão têm a utilidade de se determinar a energia depositada na parte interna de um objeto simulador, algo que pode ser estendido para pacientes na determinação de dose no volume alvo. 


\section{RESULTADOS E DISCUSSÕES}

Nesse capítulo serão apresentados os resultados obtidos e desenvolvidos, envolvendo simulação monte Carlo e as medidas utilizando câmara de ionização, bem como serão discutidos os aspectos físicos relevantes associados com a pesquisa.

\subsection{Simulação Monte Carlo para objetos simuladores homogêneos.}

Essa seção mostra a validação da simulação e os resultados obtidos por meio de simulações Monte Carlo de fluências energéticas e energias depositadas se varia ou em função da espessura do objeto simulador, o tamanho de campo e a distância fonte-superfície.

\subsubsection{Validação da simulação Monte Carlo}

A PDP obtida no serviço de radioterapia do hospital do câncer de Barretos (Fundação Pio XII) foi comparada com a PDP obtida por meio de Simulação MonteCarlo nas mesmas condições, ou seja, com a utilização de um tamanho de campo $10 \times 10$ e uma dfs=100 cm em um objeto simulador com dimensões $30 \times 30 \times 30 \mathrm{~cm}$ composto por água.

A figura 23 representa a sobreposição das PDPs obtidas por meio da simulação Monte Carlo e a obtida através do sistema de planejamento do Hospital do Câncer de Barretos (Fundação Pio XII). 


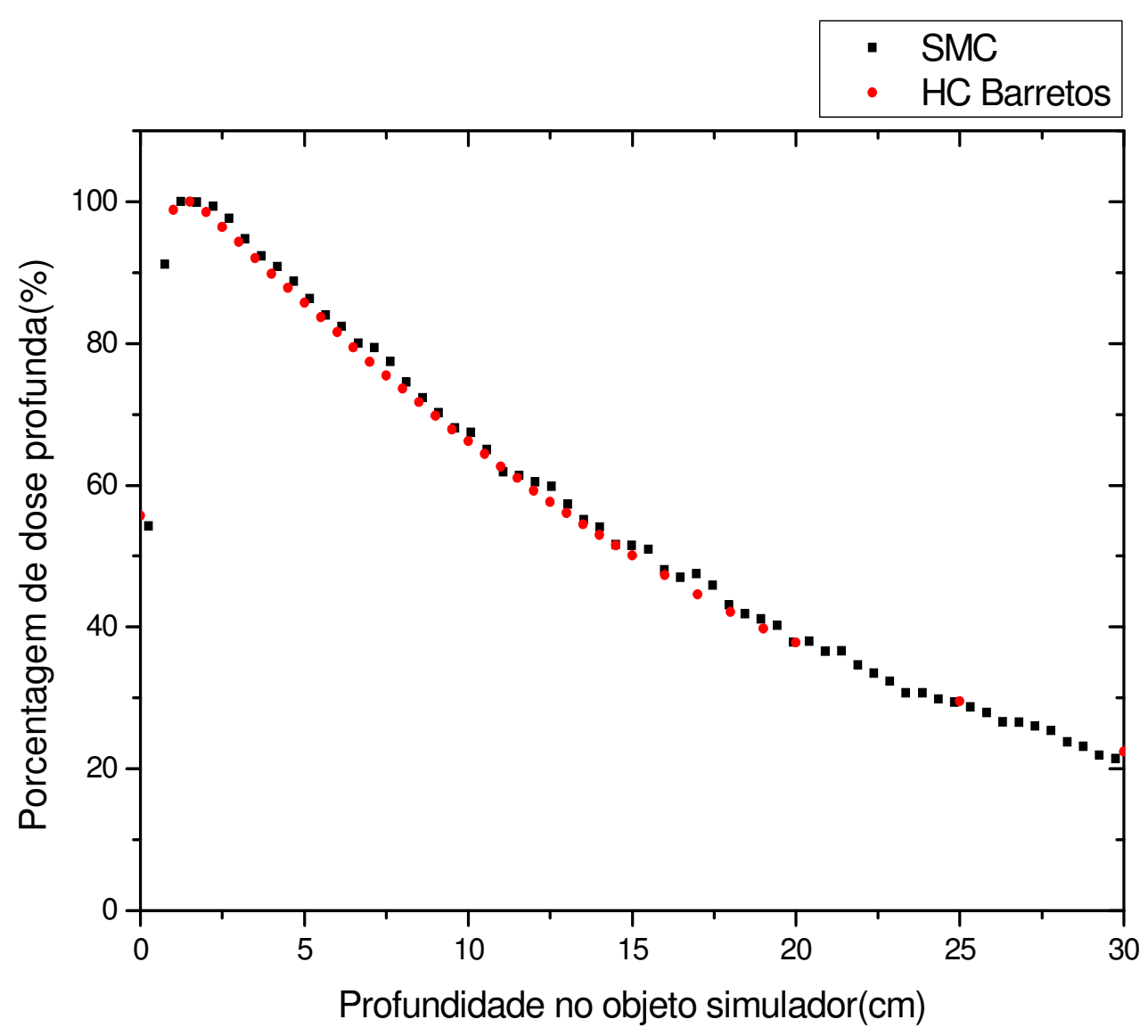

Figura 23 - Os pontos vermelhos representam a PDP fornecida pelo sistema de planejamento do HC de Barretos - Fundação Pio XII e os pontos pretos representam a PDP obtida por meio de simulação Monte Carlo.

A PDP fornecida pelo sistema de planejamento do hospital do câncer de Barretos (Fundação Pio XII) apresenta build up com valor de 1,498 cm enquanto que, o módulo desse mesmo parâmetro obtido por meio de simulação Monte Carlo apresenta o valor de $1,229 \mathrm{~cm}$.

A maior diferença de dose ocorreu na profundidade $16,97 \mathrm{~cm}$ e apresentou uma diferença percentual de $2,63 \%$. É importante observar que essa diferença percentual não ultrapassou o valor de 5\% (ICRU, 62).

6.1.2. Estudo da energia depositada com a variação das espessuras do objeto simulador

O estudo que será descrito nessa seção apresenta importância em controle de qualidade de tratamentos radioterápicos, porque cada paciente tratado apresenta 
uma anatomia própria e conforme o paciente seja mais espesso, o processo de deposição de energia será diferenciado.

Além disso, na realização do controle da qualidade pode posicionar o detector durante o controle mais próximo ou mais distante do paciente, por isso, foram posicionados nove detectores virtuais posicionados em diferentes distâncias para analisar a resposta obtida. O estudo realizado nessa seção contemplou as respostas obtidas para nove detectores virtuais posicionados abaixo de objetos simuladores com espessura variável, conforme descrito nos materiais e métodos. A resposta obtida da situação descrita anteriormente é apresentada na figura 24.

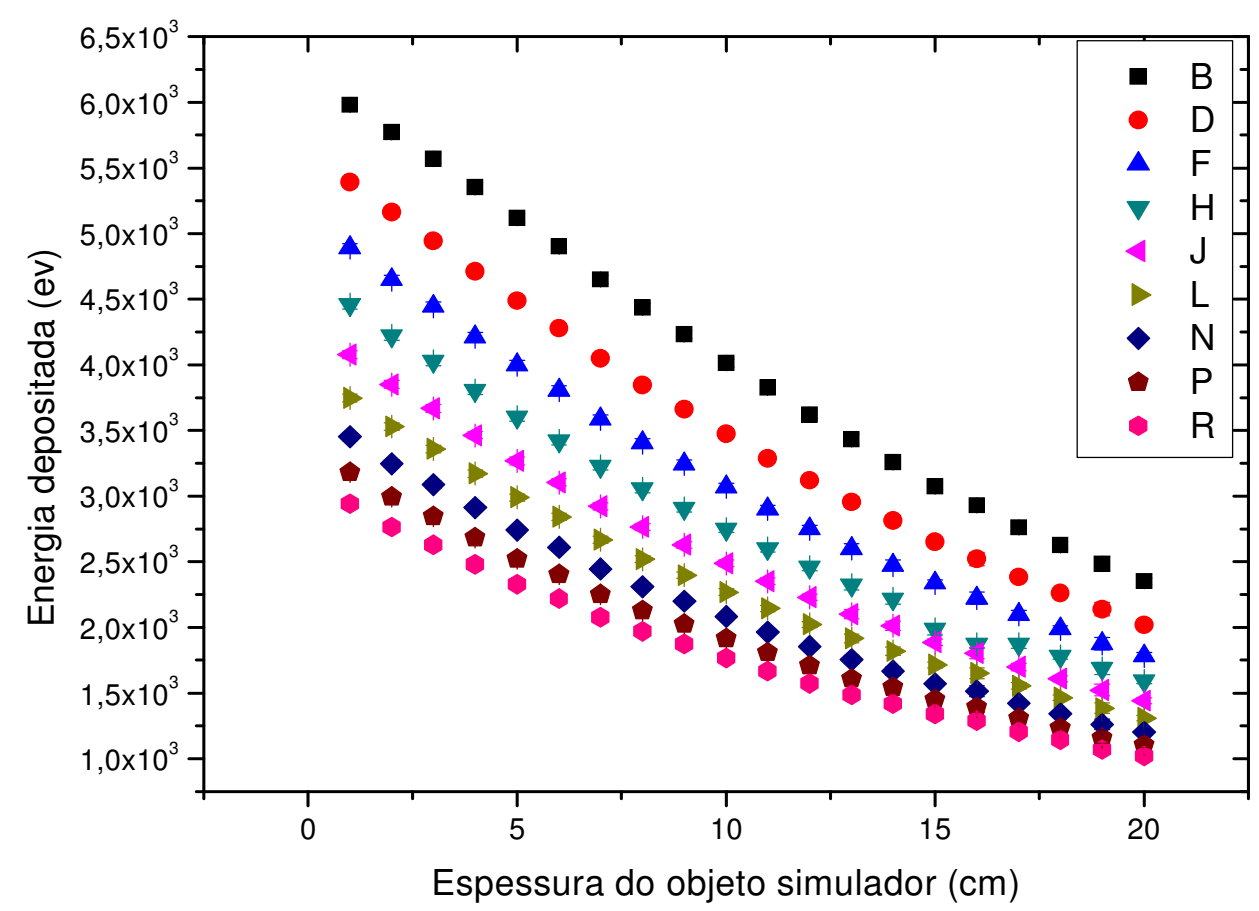

Figura 24 - Energias depositadas em detectores virtuais para diferentes espessuras do objeto simulador.

B- Corresponde ao $1^{\circ}$ detector virtual; D- Corresponde ao $2^{\circ}$ detector virtual;

F- Corresponde ao $3^{\circ}$ detector virtual; $\mathrm{H}$ - Corresponde ao $4^{\circ}$ detector;

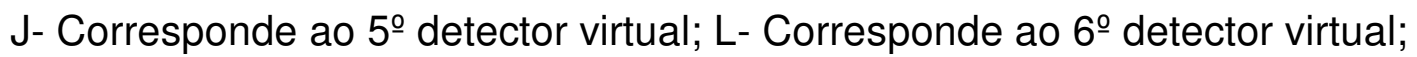

R- Corresponde ao 9o detector. 
Observa-se pelo resultado apresentado no gráfico da figura 23 que a distância que o detector virtual se encontra do objeto simulador é inversamente proporcional à energia depositada. Além disso, é perceptível que as curvas convergem conforme aumenta a distância entre detector virtual e o objeto simulador.

A energia depositada obtida através do arquivo de saída "penmain.dat" para o detector virtual colocado imediatamente abaixo do objeto simulador, denominado ${ }^{\circ}{ }^{\circ}$ detector virtual, apresentou respostas distintas com o aumento da espessura do objeto simulador em questão.

O estudo da dependência da energia depositada em função da espessura do objeto, simulador para os nove detectores virtuais, permite uma visão geral do

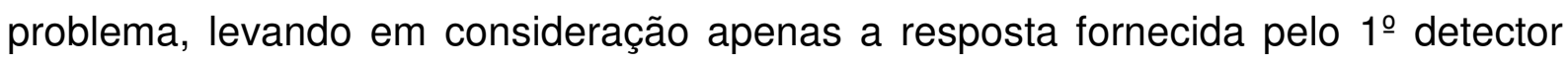
virtual para uma observação mais detalhada, conforme é mostrado no gráfico da figura 25.

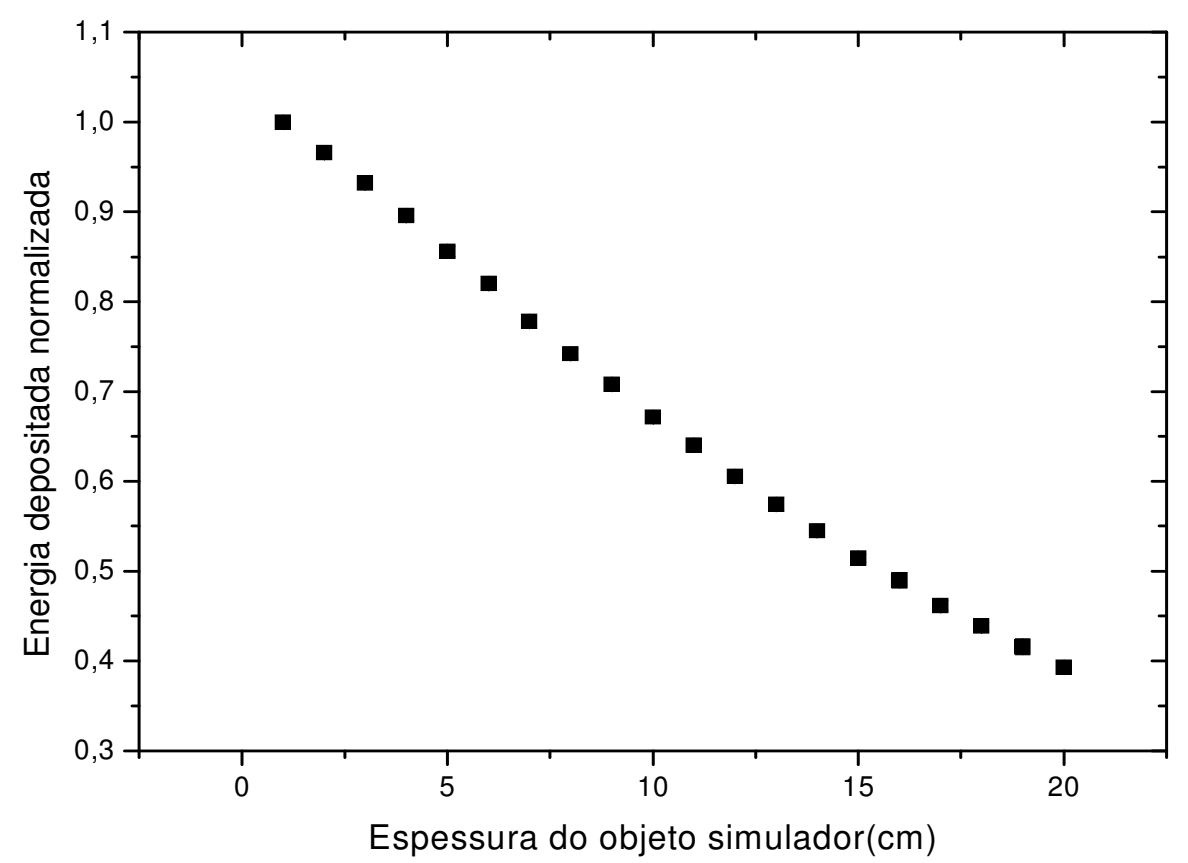

Figura 25 - Energia depositada normalizada em função da espessura do objeto simulador para $01^{\circ}$ detector virtual.

O resultado alcançado mostra que o erro dos resultados é muito pequeno, fato esse que confirma a simulação ter sido feita com um número de partículas primárias adequadas. 
No gráfico da figura 24 pode-se notar que ocorre queda da energia a medida que se aumenta a espessura do objeto simulador, isso mostra que o efeito de atenuação está acontecendo de maneira significativa, visto que a espessura é diretamente proporcional a atenuação sofrida pelo feixe de radiação ao incidir em um determinado material.

Nesse caso considerado a componente primária é a principal responsável pela deposição de energia, pois os fótons espalhados terão uma probabilidade menor de depositar energia.

O comportamento das energias depositadas mostradas no $1^{\circ}$ detector virtual para diferentes espessuras apresentou um comportamento semelhante ao do $4^{\circ}$ detector virtual cuja extremidade superior fica a $9 \mathrm{~cm}$ e a $24 \mathrm{~cm}$ da extremidade inferior do objeto simulador.As figuras 25 e 26 mostram, respectivamente, as energias depositadas normalizadas em função da espessura do objeto simulador para o $4^{\circ}$ e $9^{\circ}$ detector virtual.

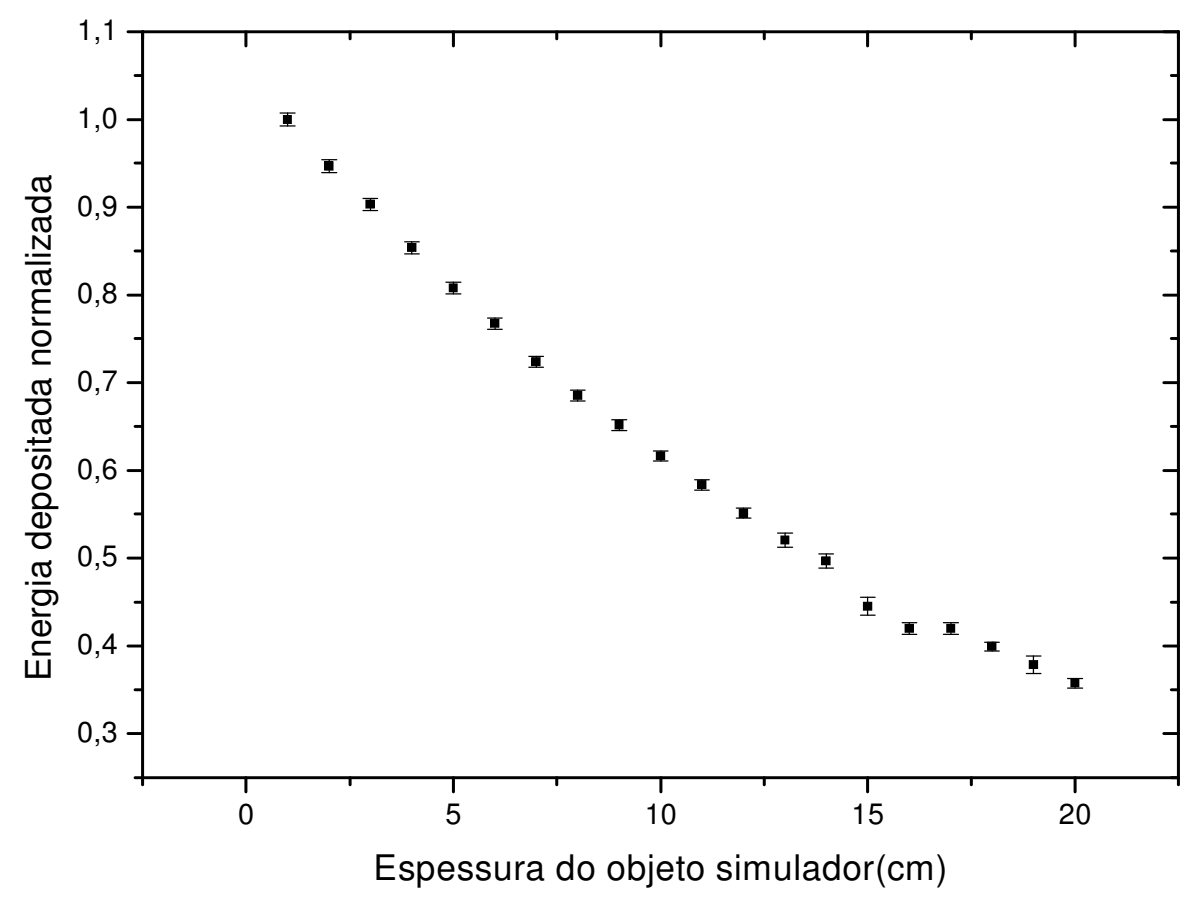

Figura 26 - Energia depositada normalizada em função da espessura do objeto simulador para o $4^{\circ}$ detector virtual. 


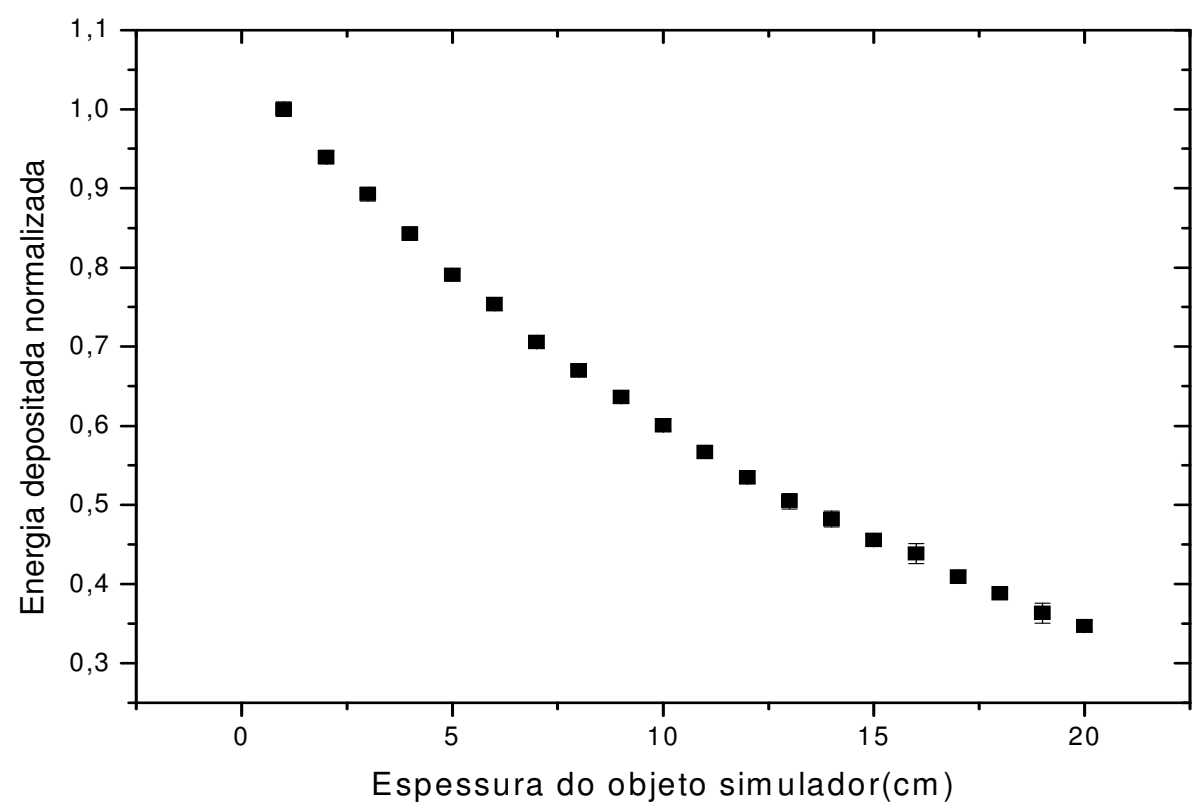

Figura 27 - Energia depositada normalizada em função da espessura do objeto simulador para $09^{\circ}$ detector virtual.

Analisando-se as figuras 25, 26 e 27 fica evidente que os valores obtidos no $4^{\circ}$ detector virtual são menores que no $1^{\circ}$ assim como, no $9^{\circ}$ detector se encontram os menores valores absolutos de todos. Cabe aqui ressaltar que, os gráficos obtidos acima são observados fora do objeto simulador e o build-up é obtido dentro do próprio objeto simulador composto por água, por isso não são observados. A profundidade na qual o build up ocorre para um acelerador linear de $6 \mathrm{MeV}$, em um objeto simulador de água, é igual $1,5 \mathrm{~cm}$.

6.1.3. Estudo das fluências energéticas com a variação das espessuras do objeto simulador

A determinação de espectros experimentalmente é de difícil aquisição, pois a obtenção destes espectros é realizada por meio de um espectrômetro, mas no caso de não se contar com esse tipo dispositivo pode-se utilizar detectores virtuais para determinar a fluência de partículas nas simulações Monte-Carlo e determinar a fluência energética computacionalmente. 
Além do que, a comparação com o espectro primário permite o entender o que ocorre com as partículas primárias ao interagirem dentro do objeto simulador e serem captadas pelos detectores virtuais, por isso foram realizadas diversas situações neste trabalho. Essa observação permite observar em que intervalo de energia estão ocorrendo fenômenos como a atenuação e o espalhamento de partículas primárias.

A figura 28 mostra os espectros primário e de fluência energética secundária mais a transmitida normalizados para um objeto simulador de $1 \mathrm{~cm}$ de espessura .

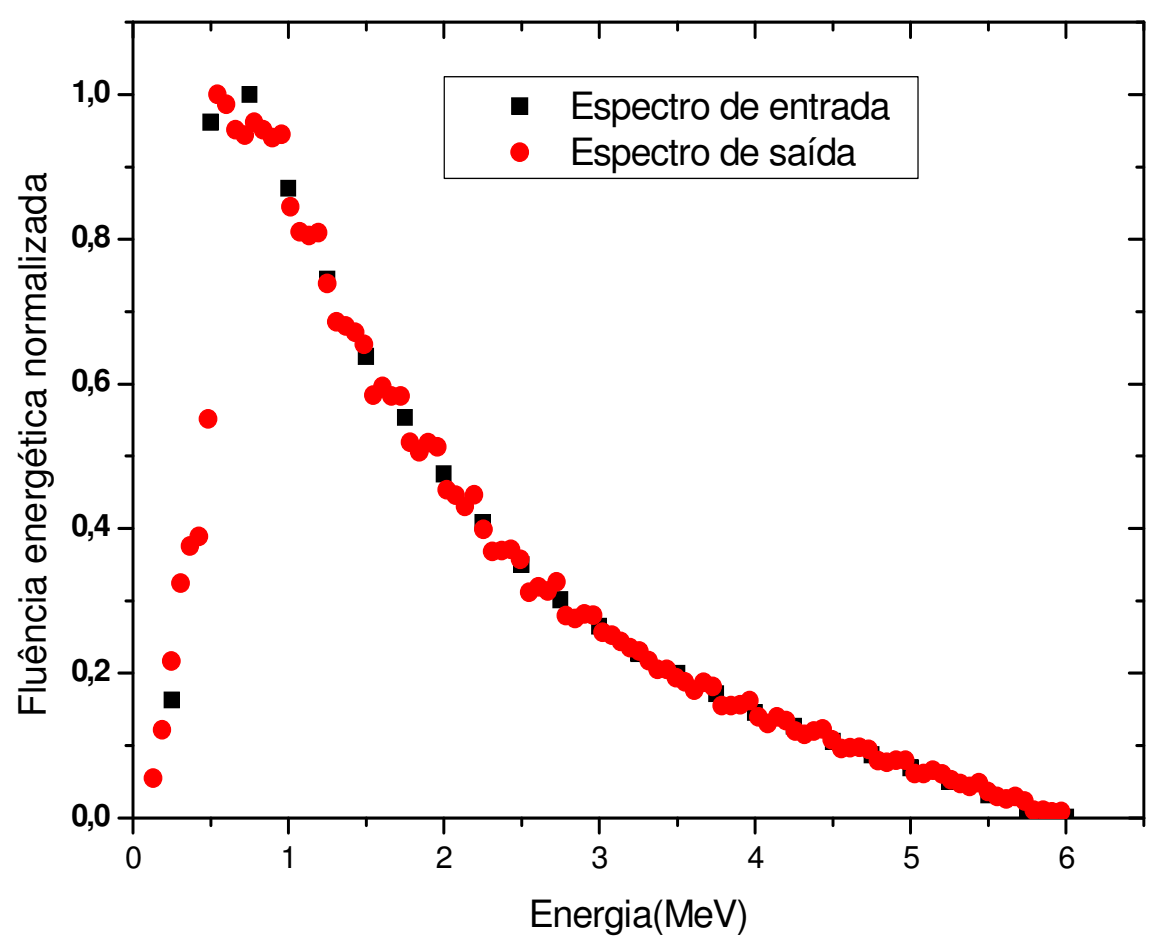

Figura 28 - Espectros de entrada e de saída normalizados para um objeto simulador de $1 \mathrm{~cm}$ de espessura.

No gráfico da figura 28 pode-se observar que a espessura de $1 \mathrm{~cm}$ utilizada na simulação é suficiente para atenuar as componentes de energia abaixo de $1 \mathrm{MeV}$ de maneira significativa, visto que para os pontos acima dessa energia ocorre sobreposição entre os gráficos do espectro primário e do espectro secundário mais o transmitido. 
A figura 29 mostra o espectros primário e de fluência enérgica secundário mais a transmitida e normalizados para um objeto simulador de $5 \mathrm{~cm}$ de espessura.

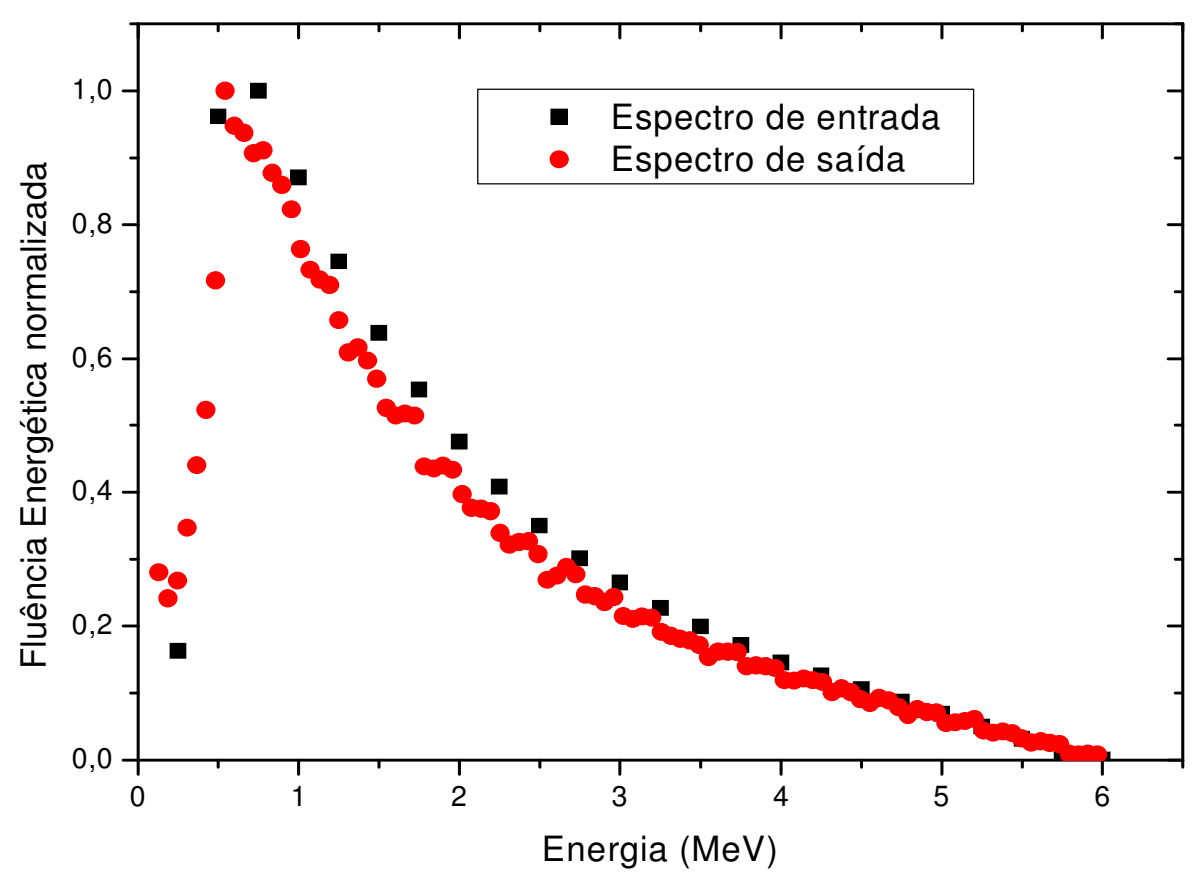

Figura 29 - Espectros de entrada e de saída normalizados para um objeto simulador de $5 \mathrm{~cm}$ de espessura.

No gráfico da figura 29 pode-se observar que uma espessura de $5 \mathrm{~cm}$ é suficiente para atenuar as componentes de energia abaixo de $4 \mathrm{MeV}$ de maneira significativa, pois para os pontos abaixo dessa energia o gráfico do espectro secundário mais o transmitido apresenta valores menores que as componentes primárias.

A figura 30 mostra as fluências energéticas primarias e secundarias da energia depositada e normalizada do objeto simulador de $10 \mathrm{~cm}$ de espessura. 


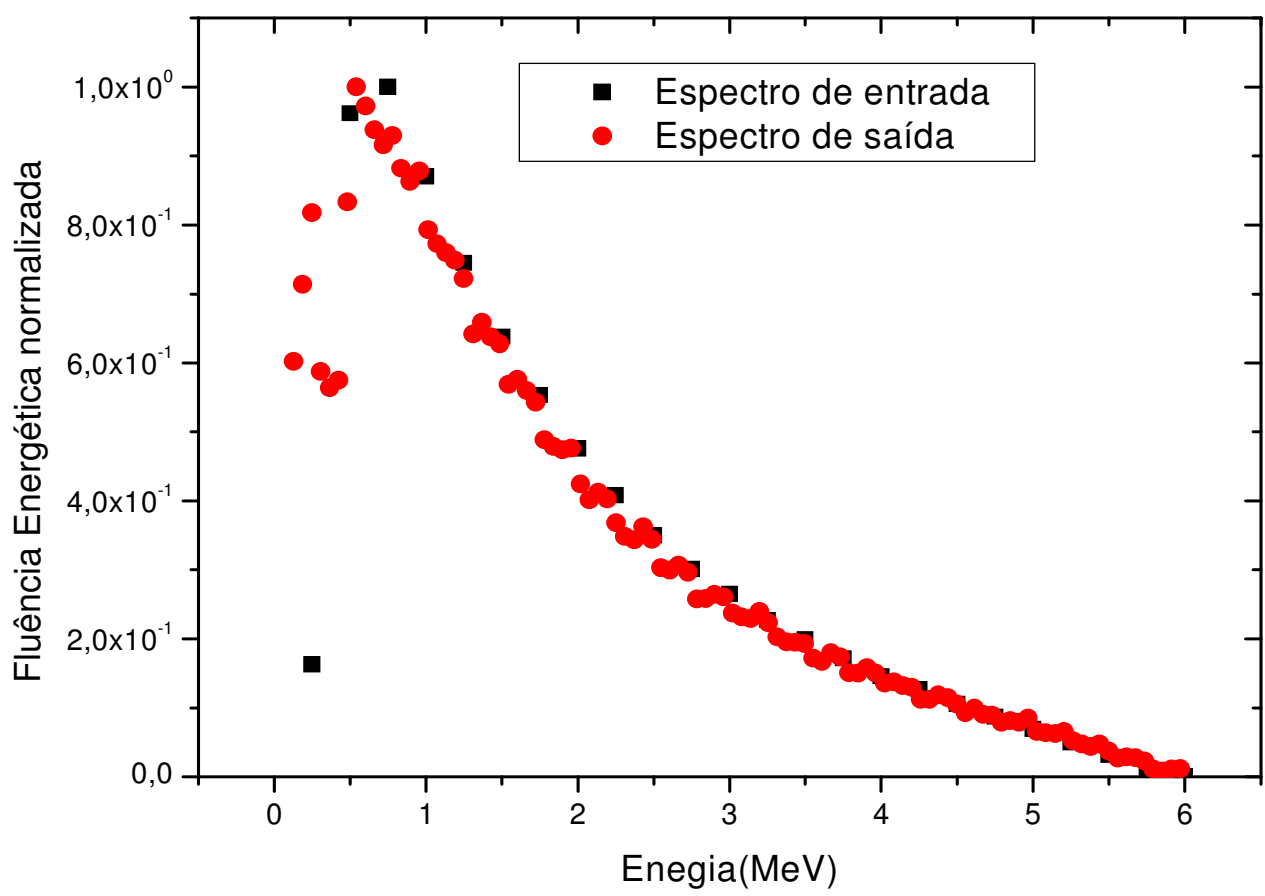

Figura 30 - Espectros de entrada e de saída normalizados para um objeto simulador de $10 \mathrm{~cm}$ de espessura.

O gráfico da figura 30 mostra que o objeto simulador de espessura de $10 \mathrm{~cm}$ atenua energias mais altas do que as que apresentam valor de $4 \mathrm{MeV}$, por isso ocorre uma compensação entre os valores da intensidade da fluência energética normalizada do espectro secundário e transmitido em relação aos valores do espectro primário que apresentam valores próximos.

A figura 31 mostra o espectro primário de fluência energética, secundária mais a transmitida, normalizados para um objeto simulador com $16 \mathrm{~cm}$ de espessura. 


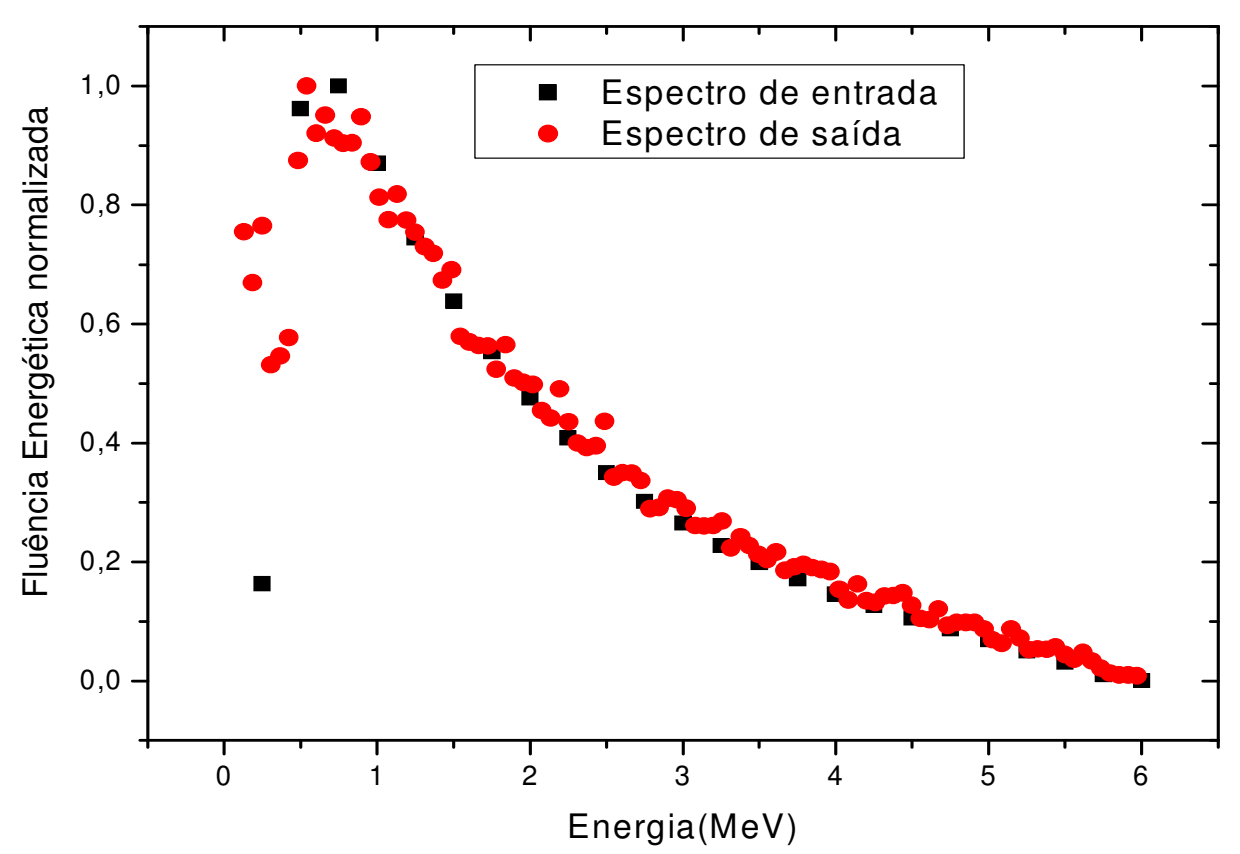

Figura 31 - Espectros de entrada e de saída normalizados, para um objeto simulador de $16 \mathrm{~cm}$ de espessura.

O gráfico da figura 31 no qual o objeto simulador apresenta uma espessura de $16 \mathrm{~cm}$ mostra que a atenuação é ainda maior nas altas energias. O gráfico do espectro secundário e transmitido é formado pelas componentes primárias subtraído das componentes atenuadas do intervalo de energia somada às componentes atenuadas de energia que recaem no intervalo de energia considerado, logo os valores maiores assumidos pela intensidade de fluência energética do espectro secundário e transmitido é maior do que a do espectro primário devido as componentes com energia superior a $4 \mathrm{MeV}$ também serem atenuadas.

A figura 32 mostra as fluências energéticas primaria e secundaria mais a transmitidas normalizadas do objeto simulador com $20 \mathrm{~cm}$ de espessura. 


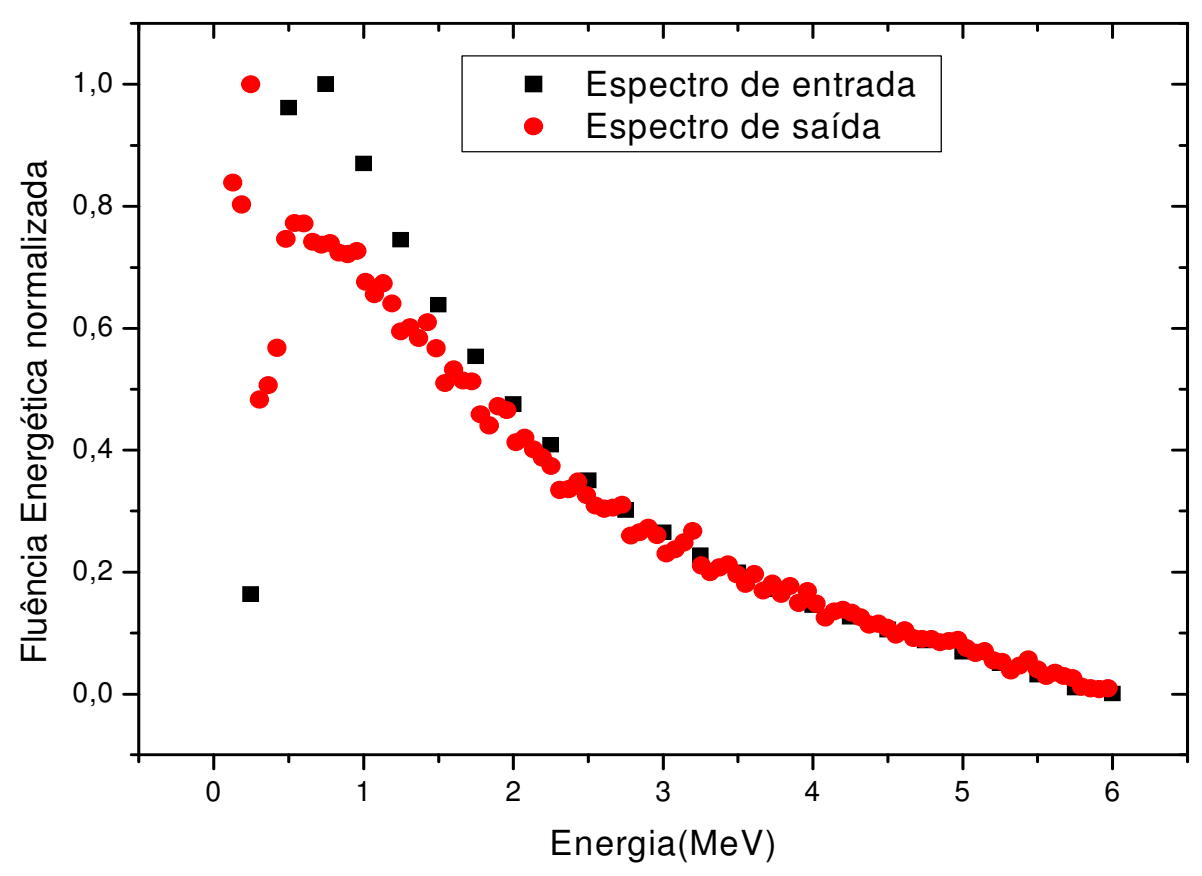

Figura 32 - Espectros de entrada e de saída normalizados para um objeto simulador de $20 \mathrm{~cm}$ de espessura.

Para a espessura do objeto simulador de $20 \mathrm{~cm}$, pode-se notar que fenômenos semelhantes aos observados para a espessura de $16 \mathrm{~cm}$, entretanto ocorre uma brusca redução para as energias abaixo de $2 \mathrm{MeV}$ em virtude dessa espessura ser suficientemente grande para atenuar a maior parte das componentes com essa energia.

Como pode ser observado, nos gráficos anteriores existe um comportamento associado a cada intensidade de fluência energética do espectro secundário mais o transmitido para cada uma das espessuras mostradas acima.

6.1.4. Estudo da energia depositada com a variação do tamanho de campo

O estudo da energia depositada com a variação do tamanho de campo é motivado pelos tratamentos radioterápicos que apresentam diferentes tamanhos de campo para tratar neoplasias de tamanhos distintos, bem como a região em que elas podem disseminar-se. 
A figura 33 mostra uma representação da variação do tamanho de campo em diferentes cores mantendo-se fixos a espessura do objeto simulador com o valor de $20 \mathrm{~cm}$ e a DFS de $100 \mathrm{~cm}$.

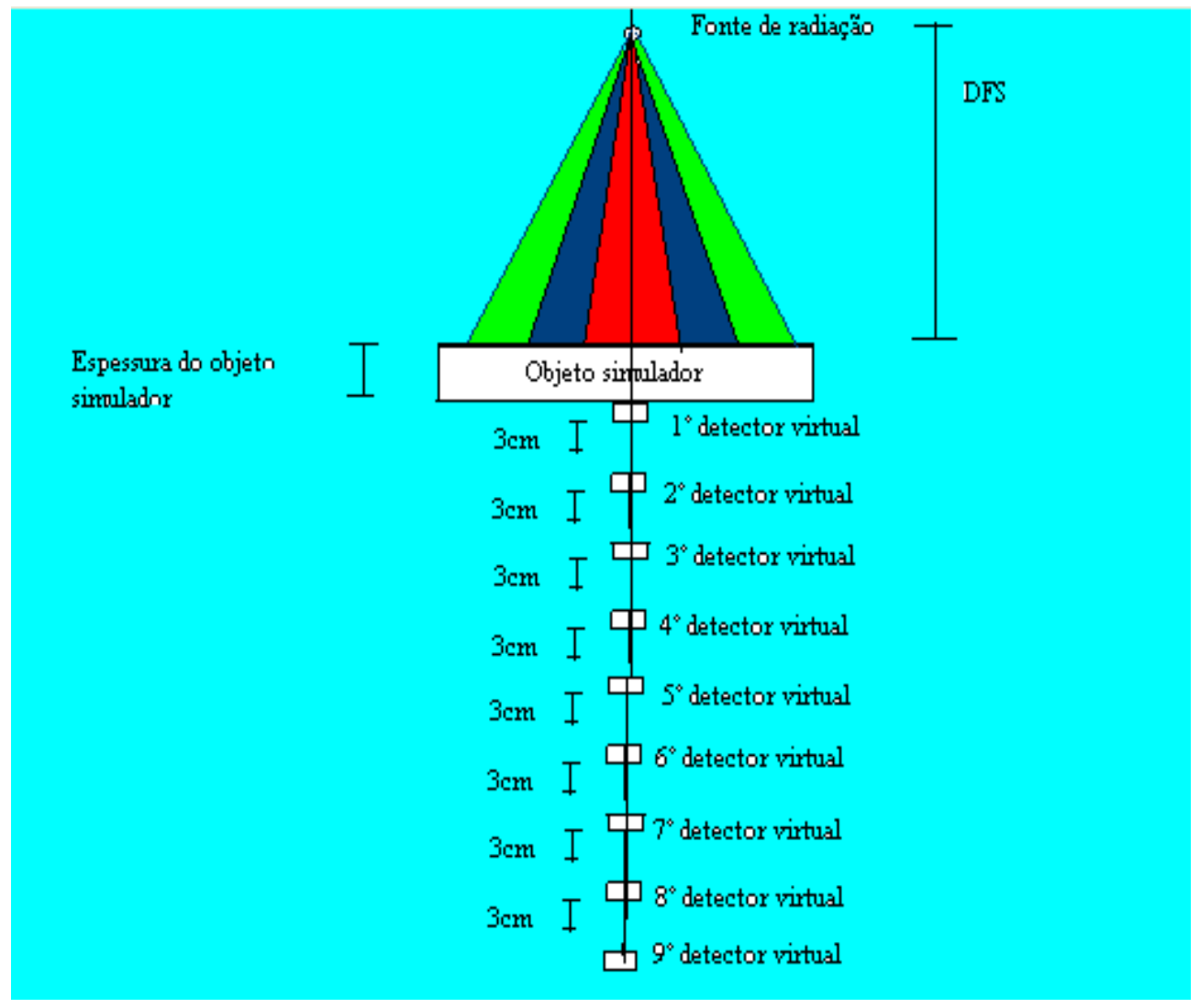

Figura 33 - Apresenta o esquema de diferentes tamanhos de campo mantendo-se fixos a espessura do objeto simulador e a DFS.

A figura 34 apresenta as energias depositadas de todos os detectores virtuais em função do tamanho do campo. 


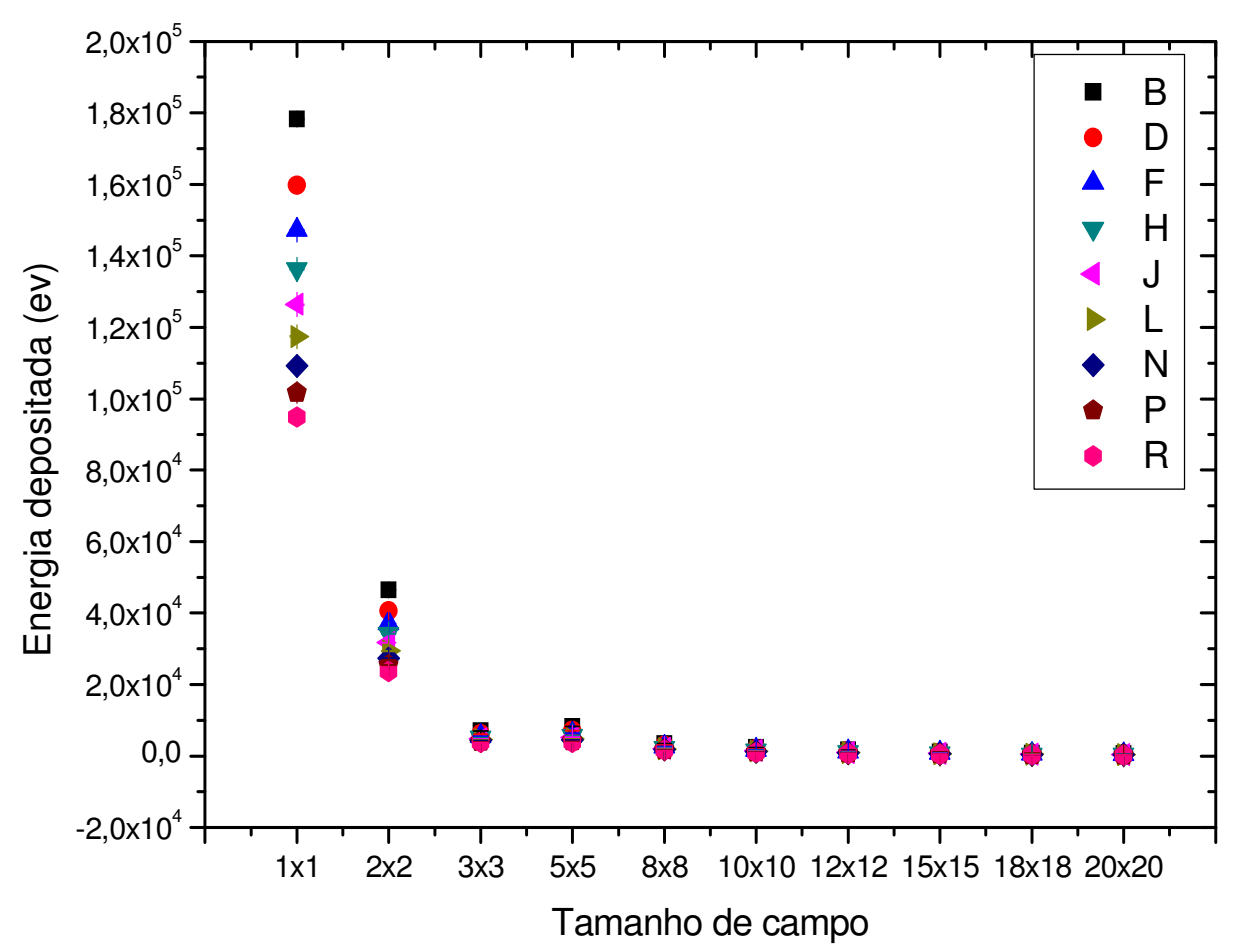

Figura 34 - Energias depositadas de todos os detectores virtuais em função do tamanho do campo.

B- Corresponde ao $1^{\circ}$ - detector virtual; D- Corresponde ao $2^{\circ}$ detector virtual;

F- Corresponde ao $3^{\circ}$ detector virtual; $\mathrm{H}$ - Corresponde ao $4^{\circ}$ detector;

J- Corresponde ao $5^{\circ}$ detector virtual; L- Corresponde ao $6^{\circ}$ detector virtual;

R- Corresponde ao 9o detector.

O gráfico da figura 34 mostra a energia depositada apresentada em todos os detectores utilizados para diferentes tamanhos de campo, considerando-se os nove detectores virtuais apresentados no capítulo anterior. Além disso, observa-se que os comportamentos dos detectores virtuais são os mesmos quando se aumenta o tamanho de campo, sendo que a diferença em questão é de valores absolutos, pois a energia é depositada em maior grau para os detectores virtuais, mais próximos do objeto simulador.

As componentes primárias são as principais responsáveis pela deposição de energia nos detectores virtuais no eixo central do feixe, pois eles estão posicionados no eixo central do feixe de radiação, entretanto o comportamento decrescente da 
energia depositada conforme se aumenta o tamanho de campo é devido ao fato do detector captar uma área do feixe primário cada vez menor quanto maior o campo de tratamento, conforme esquematizado na figura 34 .

É importante ressaltar que não nota-se a barra de erro no gráfico acima que embora tenha sido colocada apresenta um valor muito pequeno em relação ao valor absoluto. O valor máximo do erro referente à energia depositada apresentou valor de 210 ev e foi obtida para o campo $1 \times 1$.

No campo $1 \times 1$ a energia depositada apresentou valor absoluto de $1,7810^{5} \mathrm{eV}$.

A figura 35 apresenta a energia depositada normalizada em função da espessura do objeto simulador para o $1^{\circ}$ detector virtual em função do raio do tamanho do campo.

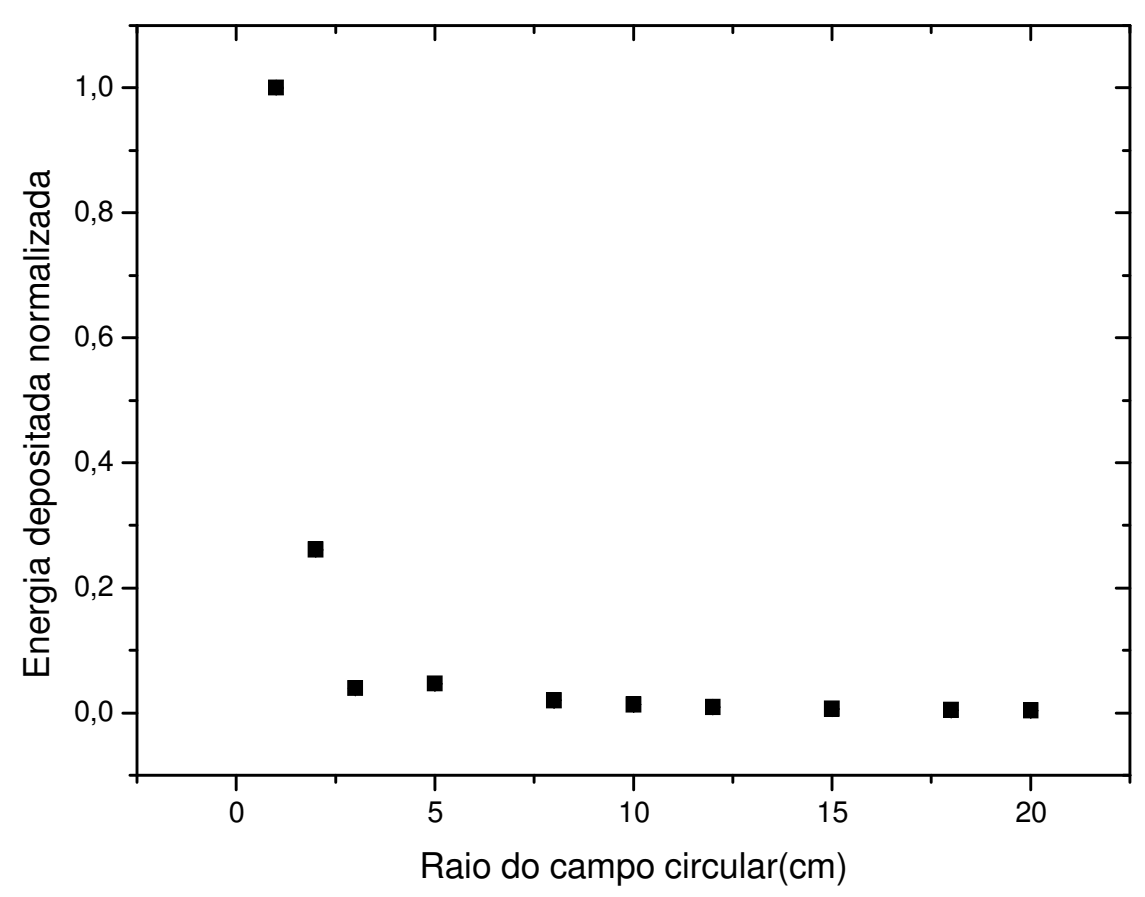

Figura 35 - Energia depositada normalizada em função da espessura do objeto simulador para o $1^{\circ}$ detector virtual em função do raio do tamanho do campo.

No gráfico da figura 35 pode-se notar que conforme o raio do campo circular aumenta houve queda nos valores da energia depositada. Esse fato mostra a importância das componentes primárias nos resultados obtidos, pois conforme a área do campo é aumentada uma área cada vez menor do feixe primário contribui 
para a deposição de energia nos detectores virtuais. Enquanto que, o campo com raio de $5 \mathrm{~cm}$ não segue a mesma tendência devido a uma maximização das componentes secundárias para o campo que apresenta esse tamanho.

Como os valores dos erros associados às medidas são muito pequenos não se consegue visualizá-los no gráfico de forma que o valor obtido para o campo $1 \times 1$ após a normalização para o valor de energia depositada máxima foi de $1,1810^{-3} \mathrm{eV}$.

Na figura 36 é apresentada a energia depositada normalizada em função da espessura do objeto simulador para $04^{0}$ detector virtual em função do raio do tamanho de campo.

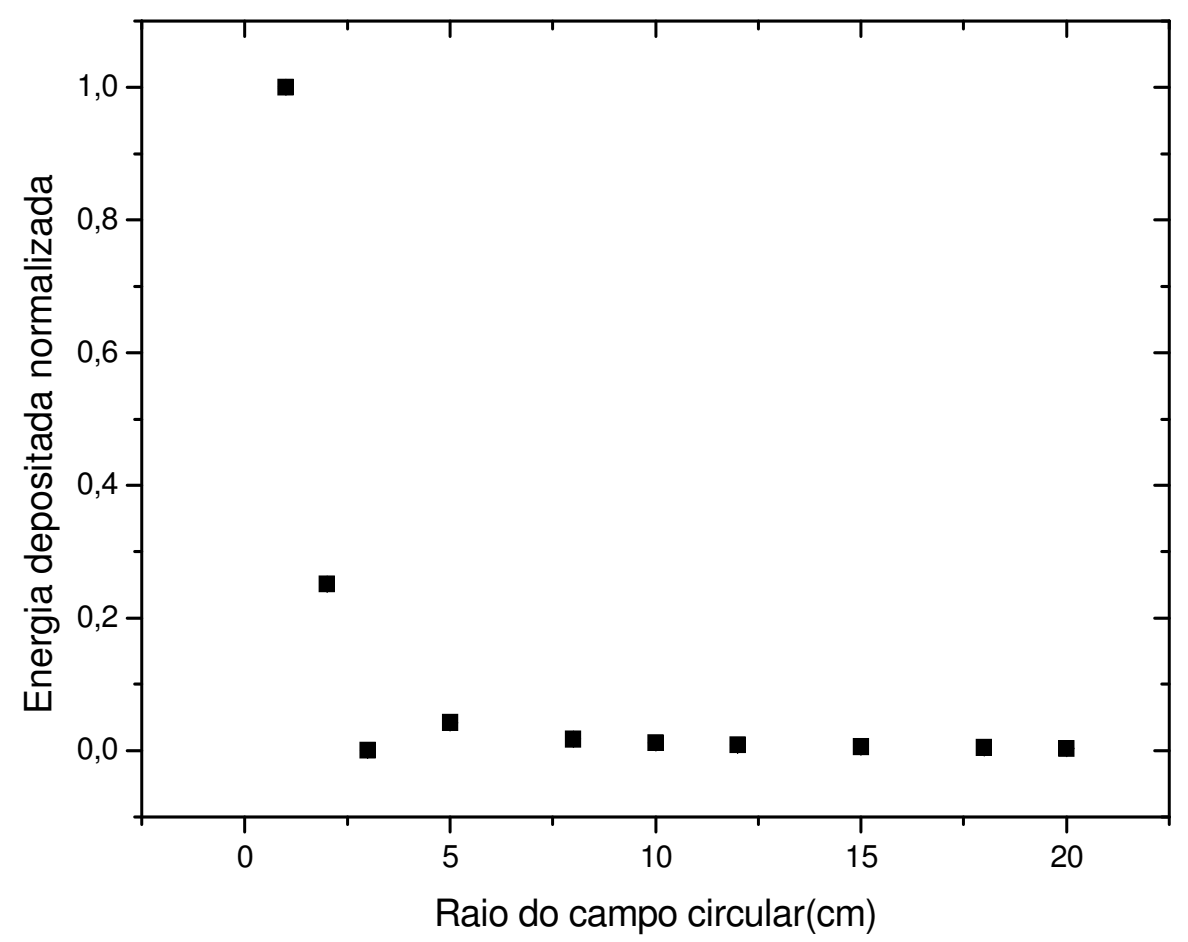

Figura 36 - Energia depositada normalizada em função da espessura do objeto simulador para o 4ํำ detector virtual em função do raio do tamanho de campo.

O gráfico da figura 36 mostra a mesma tendência apresentada pelo $1^{\text {o }}$ detector virtual, ou seja, redução do valor da energia depositada conforme o raio do campo circular cresce com exceção, do campo que apresenta raio de $5 \mathrm{~cm}$.

6.1.5. Estudo da fluência energética com a variação do tamanho de campo 
Essa seção tem por objetivo analisar o comportamento das fluências energéticas para alguns tamanhos de campo e a partir disso conseguir-se extrair informações sobre a perturbação do feixe para cada situação.

$\mathrm{Na}$ figura 37 são apresentadas as fluências energéticas, primária e secundária mais a transmitida, normalizadas para tamanho de campo $1 \times 1 \mathrm{~cm}$.

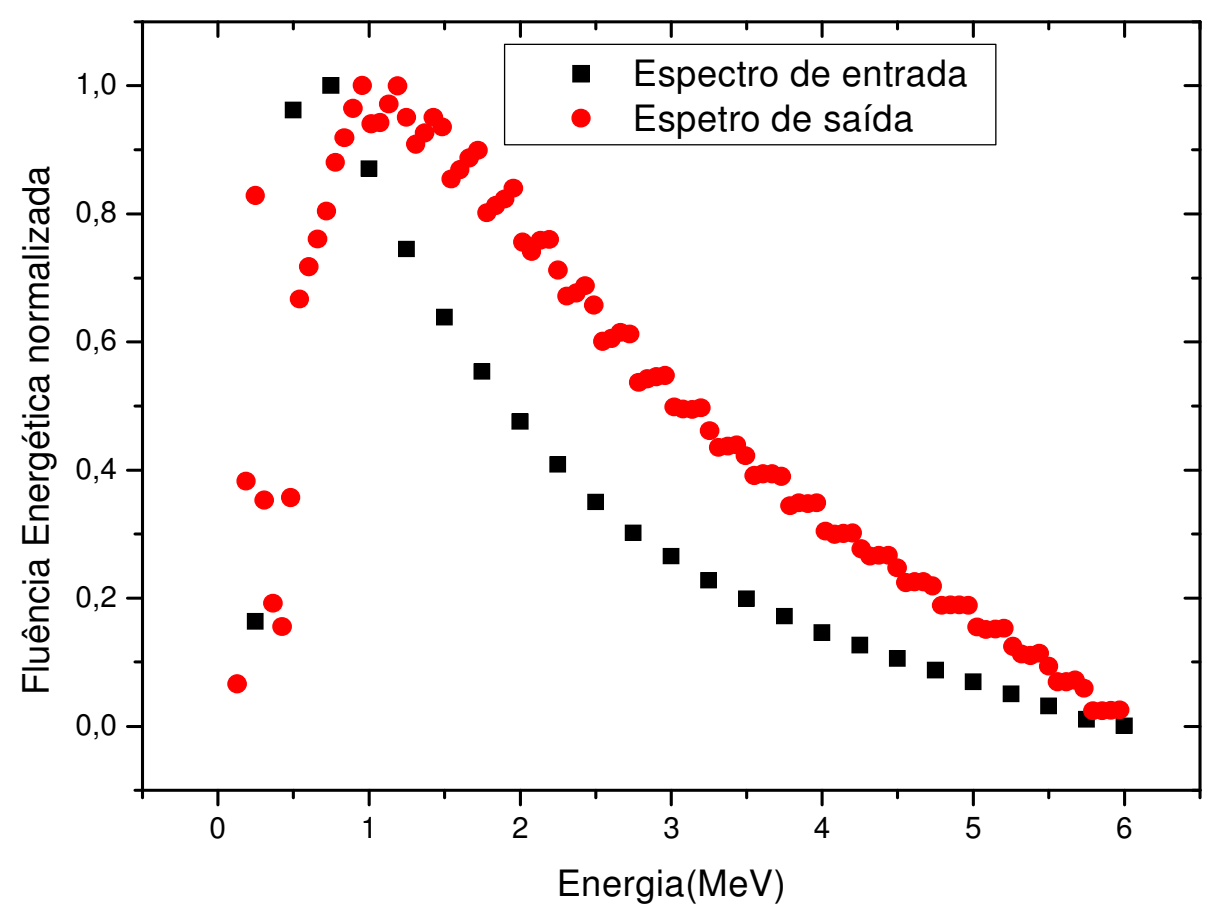

Figura 37 - Espectros de entrada e de saída normalizados para tamanho de campo 1x1 cm.

A resposta da intensidade de fluência energética captada no $1^{0}$ detector virtual, para o tamanho de campo 1x1, está representada na figura 37.

O resultado obtido mostra que as contribuições referentes ao espalhamento são bem superiores às de atenuação, visto que a energia envolvida é uma energia utilizada em radioterapia, da ordem de Megavoltagem, para um feixe estreito, onde 0 detector virtual capta as partículas que seguiram sua trajetória original e as espalhadas lateralmente que estavam localizadas na extremidade e que se dirigiam para o eixo central do feixe.

Portanto, o gráfico do espectro secundário mais o transmitido apresentam valores maiores de intensidade da fluência energética para as energias maiores que 
$1 \mathrm{MeV}$, evidentemente esse resultado pode conter viés devido ao ponto de normalização.

A figura 38 mostra os espectros de entrada e de saída normalizadas para o tamanho de campo $5 \times 5 \mathrm{~cm}$.

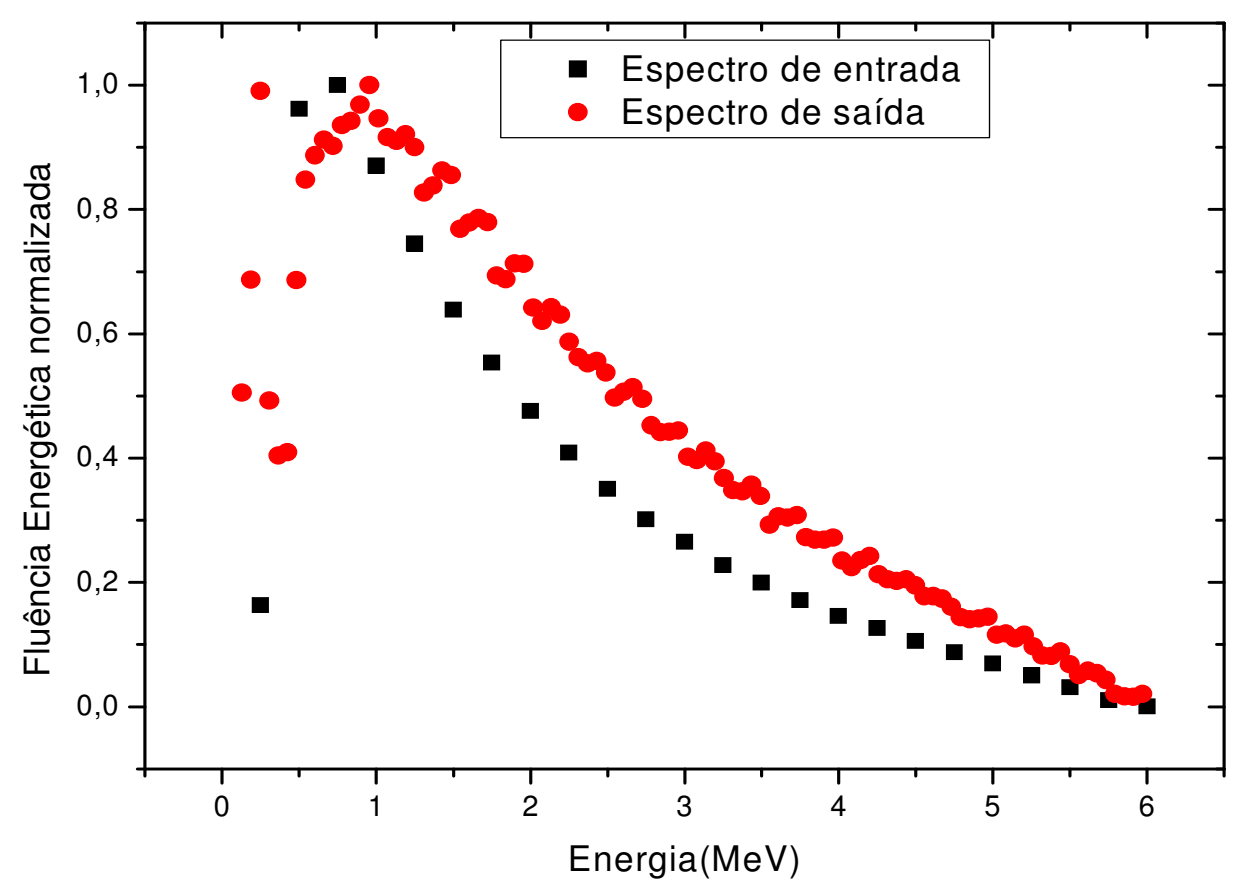

Figura 38 - Espectros de entrada e de saída normalizados para tamanho de campo $5 \times 5 \mathrm{~cm}$.

A resposta da intensidade de fluência energética captada no $1^{0}$ detector virtual para o tamanho de campo $5 \times 5 \mathrm{~cm}$ foi representada no gráfico da figura 38 .

O resultado obtido mostra que o campo $5 \times 5$ proporciona atenuação maior de partículas primárias que no caso do campo $1 \times 1$. Esse fato comprova que a energia efetiva do feixe que chega ao detector de radiação é menor que no caso anterior.

Portanto, as curvas do espectro secundário mais o transmitido apresentam valores maiores de intensidade da fluência energética, para energias maiores que 1 $\mathrm{MeV}$.

$\mathrm{Na}$ figura 39 são apresentados os Espectros primários e de Fluência Energética secundária mais a transmitida, normalizadas para tamanhos de campo $10 \times 10 \mathrm{~cm}$. 


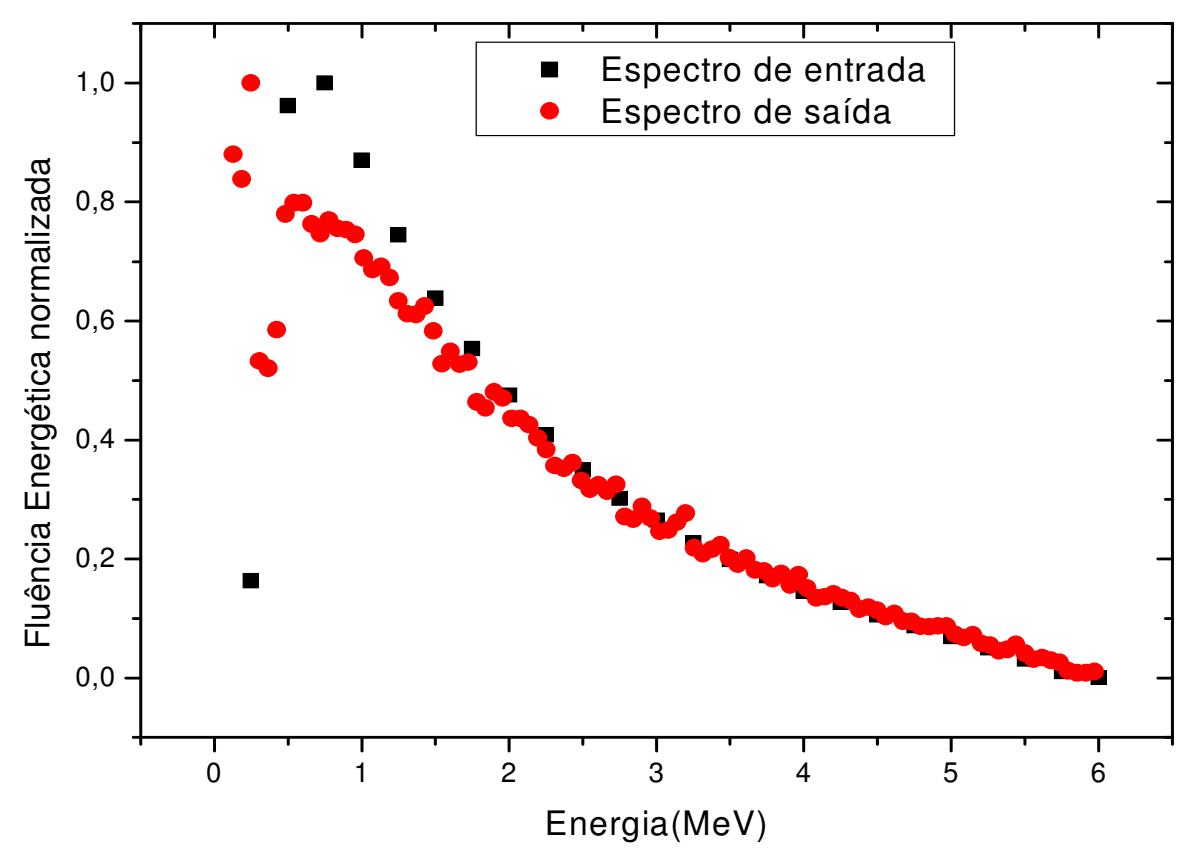

Figura 39 - Espectros de entrada e de saída normalizados para tamanho de campo 10x10.

As curvas da figura 39 apresentam a resposta da intensidade de fluência energética captada no $1^{\circ}$ detector virtual para tamanho de campo $10 \times 10 \mathrm{~cm}$. $\mathrm{O}$ campo 10x10 representa as condições padrão quando se considera a dosimetria realizada em um serviço de radioterapia.

O fator campo apresenta valor igual a 1. Através deste valor corrigi-se 0 espalhamento proveniente de outros campos. A comprovação dessa afirmação decorre pelo fato de que quando se aumenta o tamanho de campo, o espalhamento associado também aumenta, devido a essa relação inversamente proporcional verifica-se no cálculo de quantidade de unidades monitoras a diminuição delas para se chegar à dose prescrita no tratamento. Entretanto, o tratamento não se restringe ao eixo central do feixe, apenas como se propõe nesse trabalho, mas essa análise configura-se como uma importante componente a ser analisada no planejamento do tratamento radioterápico.

$\mathrm{Na}$ figura 39 verifica-se que, as curvas com energias acima de 1,5 MV se sobrepõem, dessa maneira deve ser considerado que os efeitos de atenuação e de espalhamento ocorrem de maneira significativa para as energias abaixo de 1,5 MV. 
Portanto, os espectros secundário mais o transmitido apresentam valores inferiores ao do espectro primário normalizado para as energias abaixo de 1,5 MeV que apresentam atenuação significativa e uma sobreposição para as energias acima de $1,5 \mathrm{MeV}$.

As curvas da figura 40 apresentam as fluências energéticas, primária e secundária, normalizadas para o tamanho de campo $15 \times 15 \mathrm{~cm}$.

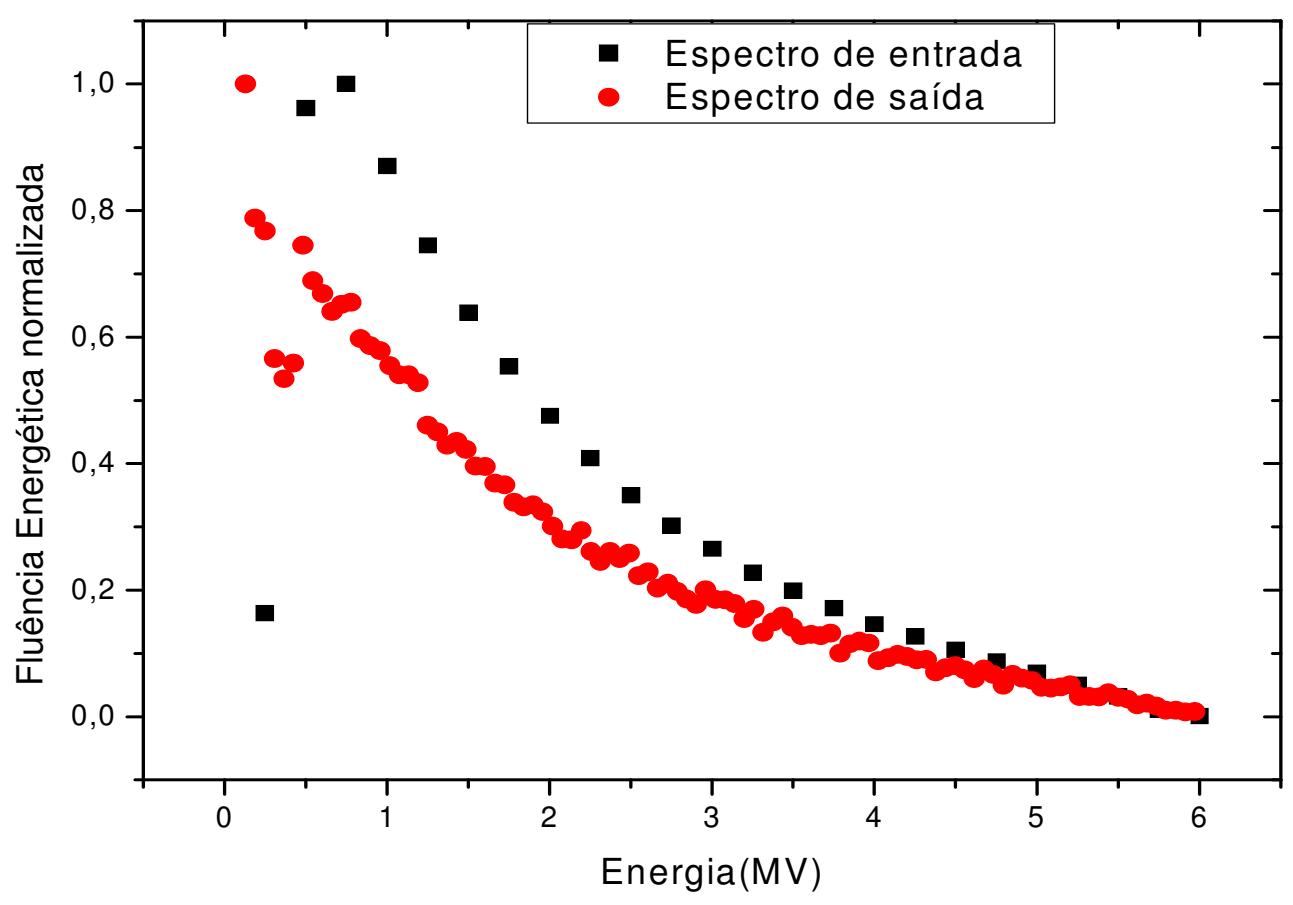

Figura 40 - Espectros de entrada e de saída normalizados para tamanho de campo 15×15.

No gráfico, o espectro secundário mais o transmitido representa a resposta da intensidade de fluência energética captada no $1^{\circ}$ detector virtual para o tamanho de campo $15 \times 15$. Este campo representa um campo que apresenta mais espalhamento do que o campo padrão 10x10 e um fator campo maior que 1 .

O gráfico de intensidade da fluência energética normalizada da componente secundária mais transmitida apresenta valores menores que as componentes do espectro primário normalizado. Vale ressaltar que, para as componentes de baixa energia a atenuação está ocorrendo de maneira mais significativa, portanto existe uma diferença maior entre os valores em questão. 
Portanto o gráfico de fluência energética normalizada para um campo $15 \times 15$ apresenta valores menores que as componentes primárias normalizadas, em especial, para as energias abaixo de $2 \mathrm{MeV}$.

A resposta da intensidade de fluência energética captada no $1^{\circ}$ detector virtual, para o tamanho de campo 20x20 é apresentada na figura 41. Onde o campo $20 \times 20$ representa um campo que apresenta mais espalhamento que o campo padrão 10x10 e um fator campo maior do que 1 , assim como o campo $15 \times 15$.

O comportamento da curva é semelhante ao anterior, entretanto a diferença entre o espectro primário normalizado e a intensidade da fluência energética é ainda maior, indicando uma ocorrência maior na atenuação do que no caso anterior.

As curvas da figura 41 apresentam espectro primário e de fluência energética, secundária mais a transmitida, normalizados para tamanho de campo $20 \times 20 \mathrm{~cm}$.

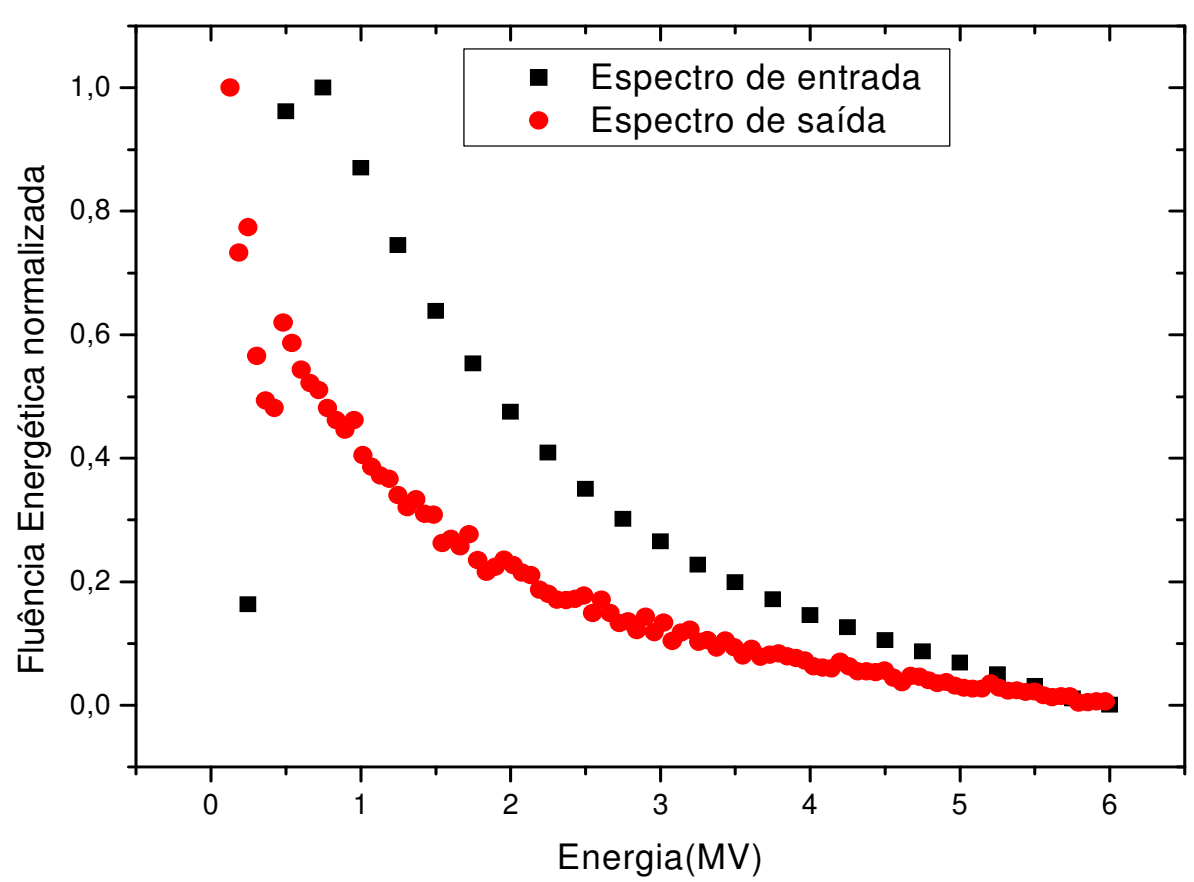

Figura 41 - Espectro de entrada e de saída normalizados para tamanho de campo 20x20.

6.1.6. Estudo da energia depositada com a variação da distância fonte-superfície

Nessa seção foram realizados estudos da resposta dos nove detectores virtuais, para diferentes distâncias fonte-superfície utilizando um objeto simulador 
homogêneo de dimensões 30×30×20 cm e campo de tamanho $10 \times 10 \mathrm{~cm}$ utilizando a técnica dfs. A figura 42 apresenta o esquema utilizado para estudar a resposta de nove detectores virtuais, para as diferentes distâncias fonte-superfície utilizando o objeto simulador homogêneo.

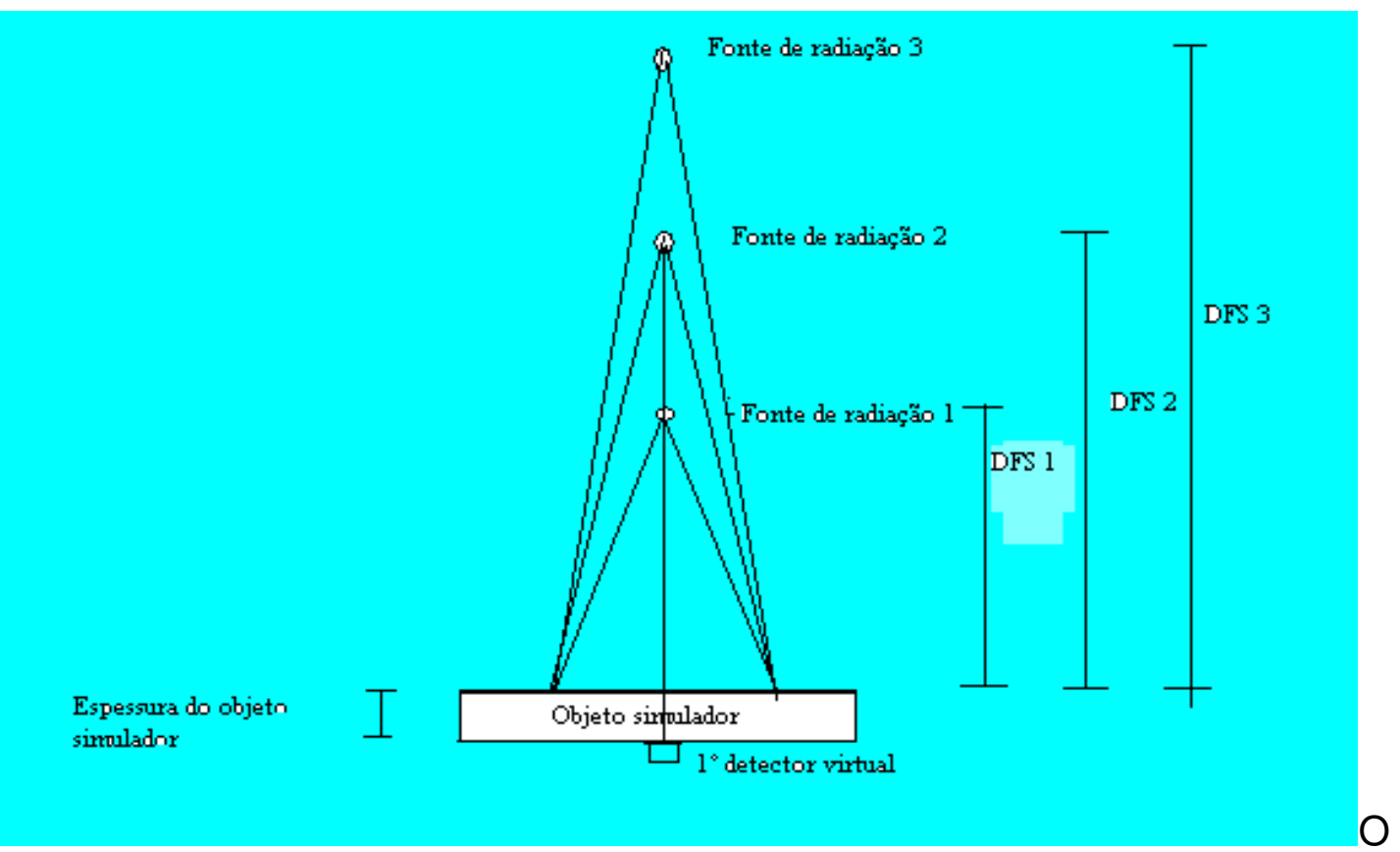

Figura 42 - Esquema de uma fonte de radiação colocada a diferentes DFSs mantendo-se fixos a espessura do objeto simulador e o tamanho de campo.

O esquema da figura 42 evidencia o estreitamento do feixe conforme se aumenta a DFS, portanto a contribuição de componentes primárias (principais responsáveis pela deposição de energia nos detectores virtuais) aumenta com a DFS.

O gráfico da figura 43 mostra a energia depositada nos 9 detectores virtuais para diferentes distâncias fonte-superfície utilizando o objeto simulador homogêneo. 


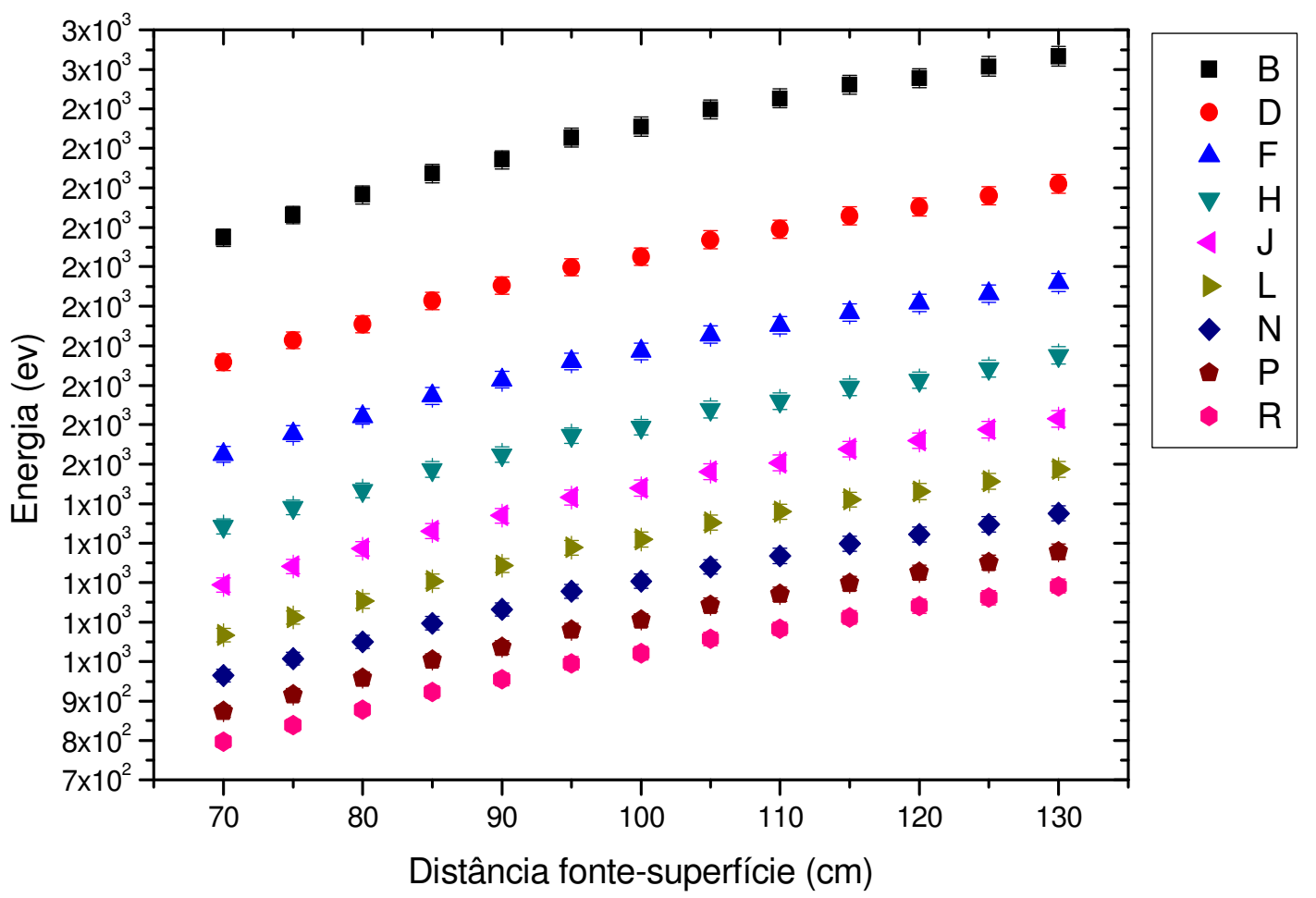

Figura 43 - Apresenta os estudos da resposta de nove detectores virtuais, para diferentes distâncias fonte-superfície utilizando o objeto simulador homogêneo.

O aumento das componentes primárias ocorre devido ao estreitamento do feixe, conforme mostrado na figura anterior.

Os pontos coloridos da figura 43 representam os diferentes detectores virtuais utilizados para determinar a energia depositada no detector virtual conforme representados a seguir: A representação $B$ na cor preta corresponde ao $1^{\circ}$ detector virtual, a letra $\mathrm{D}$ na cor vermelha corresponde ao $2^{\circ}$ detector virtual, a letra $\mathrm{F}$ na cor azul corresponde ao $3^{\circ}$ detector virtual, a cor correspondente a letra $\mathrm{H}$ representa $\mathrm{O}$ $4^{\circ}$ detector virtual, a cor correspondente a letra $\mathrm{J}$ representa o $5^{\circ}$ detector virtual, a cor correspondente a letra $L$ representa o $6^{\circ}$ detector virtual, a cor correspondente a letra $\mathrm{N}$ representa o $7^{\circ}$ detector virtual, a cor correspondente a letra $\mathrm{P}$ representa 0 $8^{\circ}$ detector virtual e a cor correspondente a letra $\mathrm{R}$ representa o 9 detector virtual.

Os erros associados aos valores de energia obtidos por meio da simulação apresentaram valores muito pequenos. Os maiores valores absolutos dos erros foram 25 para o $1^{\text {o }}$ detector virtual para as distâncias fonte-superfície de $125 \mathrm{~cm}$ e $130 \mathrm{~cm}$. 
Pode ser observado que ocorre crescimento da energia depositada no detector virtual conforme se aumenta a dfs em todas as curvas, além disso, percebese que quanto mais distante se localiza o detector virtual menor a resposta obtida considerando-se uma distância fixa.

A figura 44 apresenta o espectro da Energia depositada normalizada em função da espessura dfs para o $1^{\circ}$ - detector virtual.

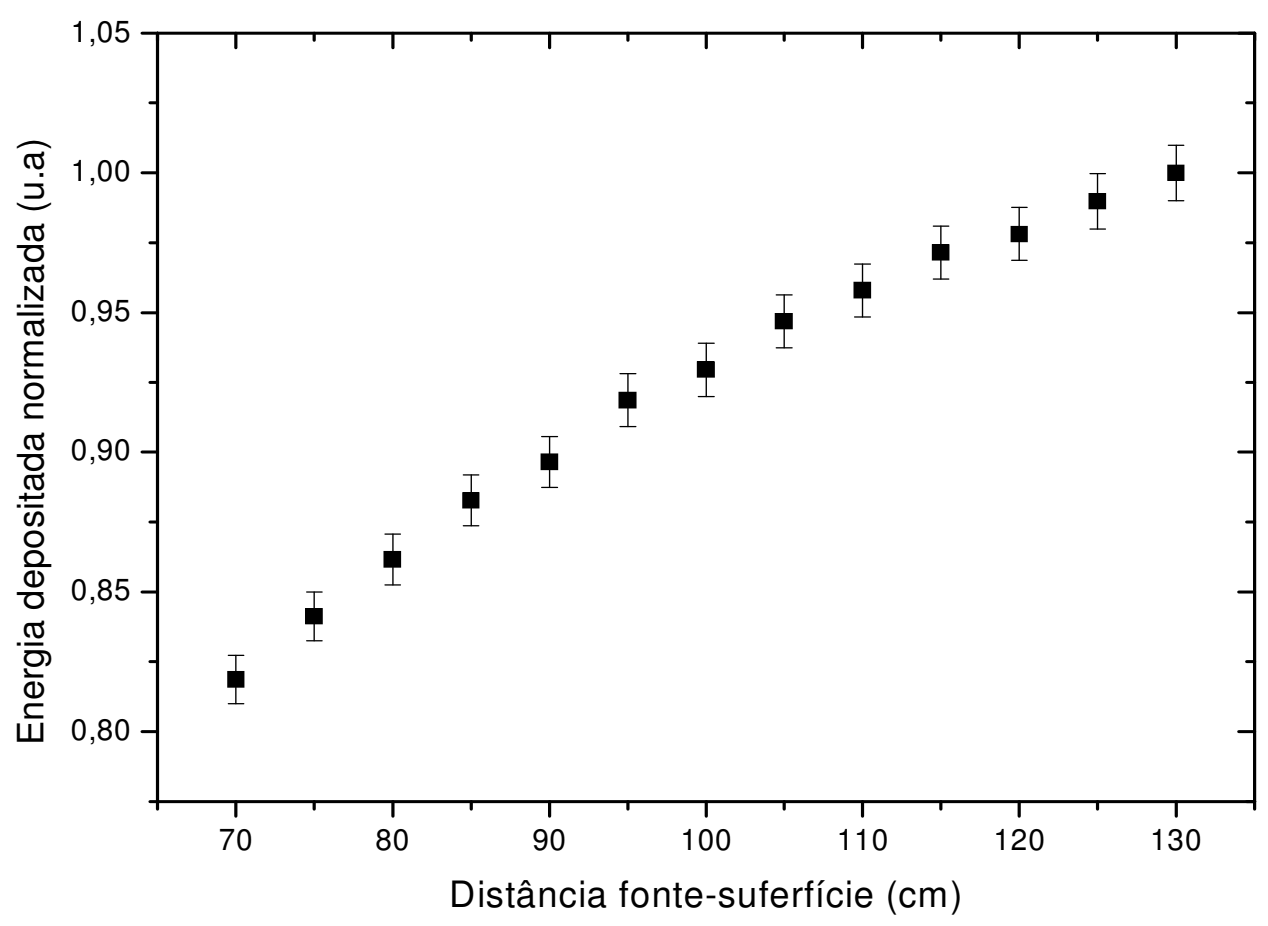

Figura 44 - Energia depositada normalizada em função da espessura dfs para o $1^{\circ}$ detector virtual.

A partir do gráfico da figura 22 pode-se corrigir a dependência com a dfs através, dos pontos presentes no gráfico para um objeto simulador de dimensões $30 \times 30 \times 20 \mathrm{~cm}$ e determinar quanto um valor de um ponto depende do outro, visto que, os pontos estão normalizados pelo ponto de máximo.

A figura 45 e 46 apresentam os espectros da Energia depositada normalizada

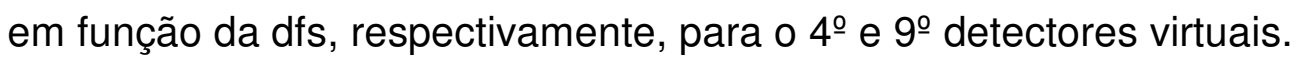




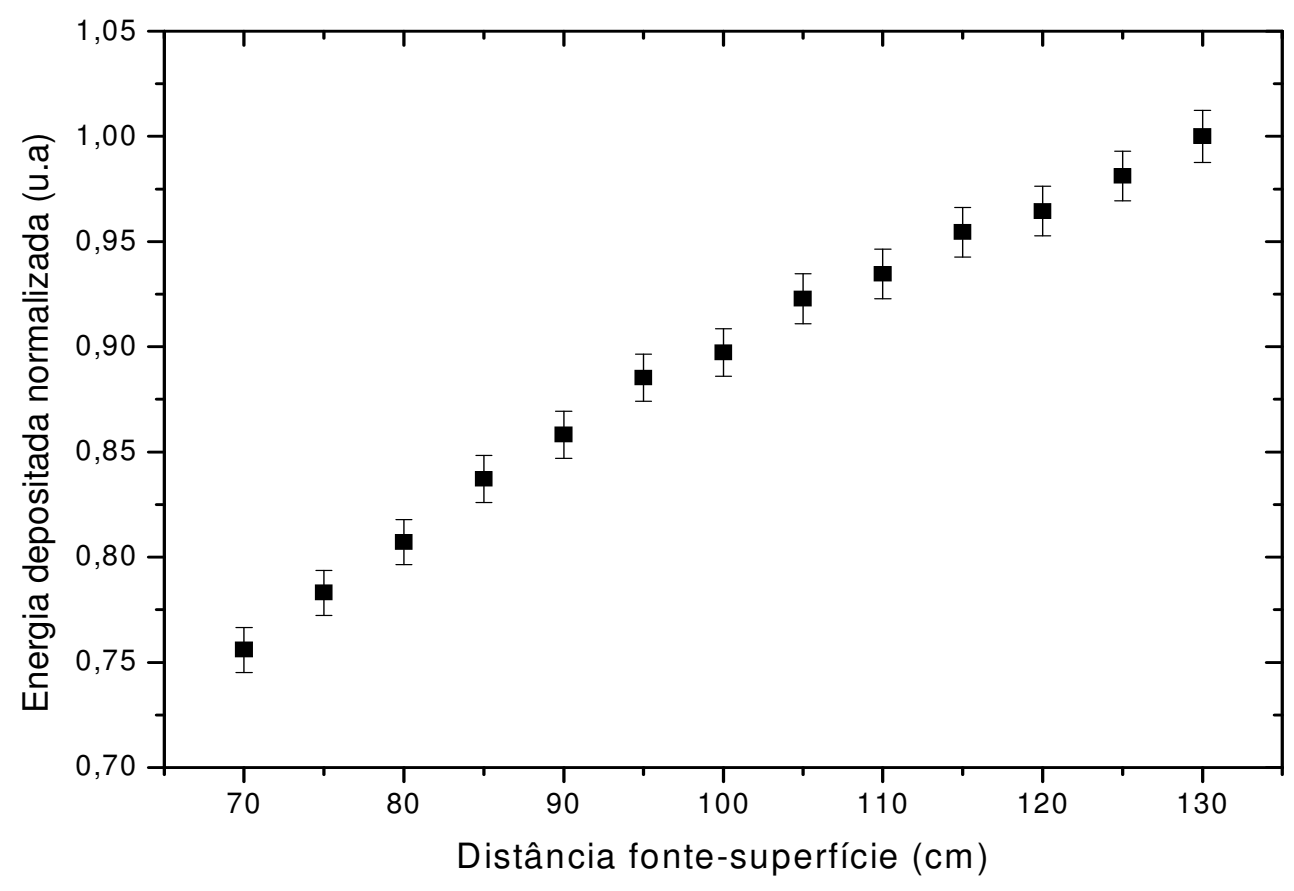

Figura 45 - Energia depositada normalizada em função da dfs para o $4^{0}$ detector virtual.

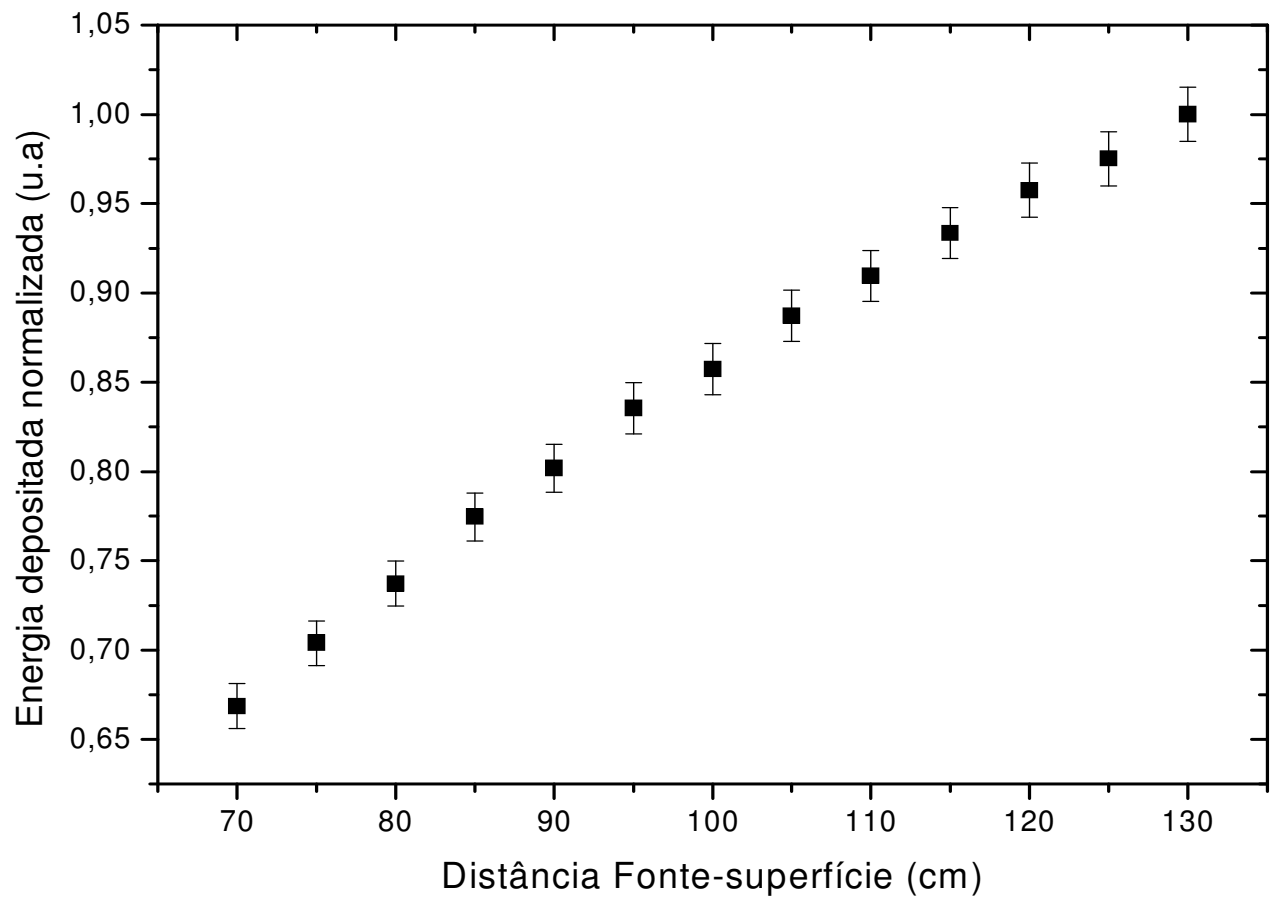

Figura 46 - Energia depositada normalizada em função da espessura dfs para o 9 ำ detector virtual. 
Os valores obtidos apresentam importância clínica para os tratamentos em que existem problemas de colisão do gantry com a mesa, quando for necessário um afastamento maior do paciente, tornando necessária uma correção no cálculo de unidades monitoras para que, a dose prescrita em uma determinada distância seja a mesma para outra distância.

6.1.7. Estudo da fluência energética com a variação da distância fonte superfície

As figuras 47, 48, 49 e 50 apresentam a comparação entre o espectro primário e a fluência energética do espectro, secundário mais o transmitido, normalizados, respectivamente, para as DFS iguais a 70, 90, 110 e $130 \mathrm{~cm}$.

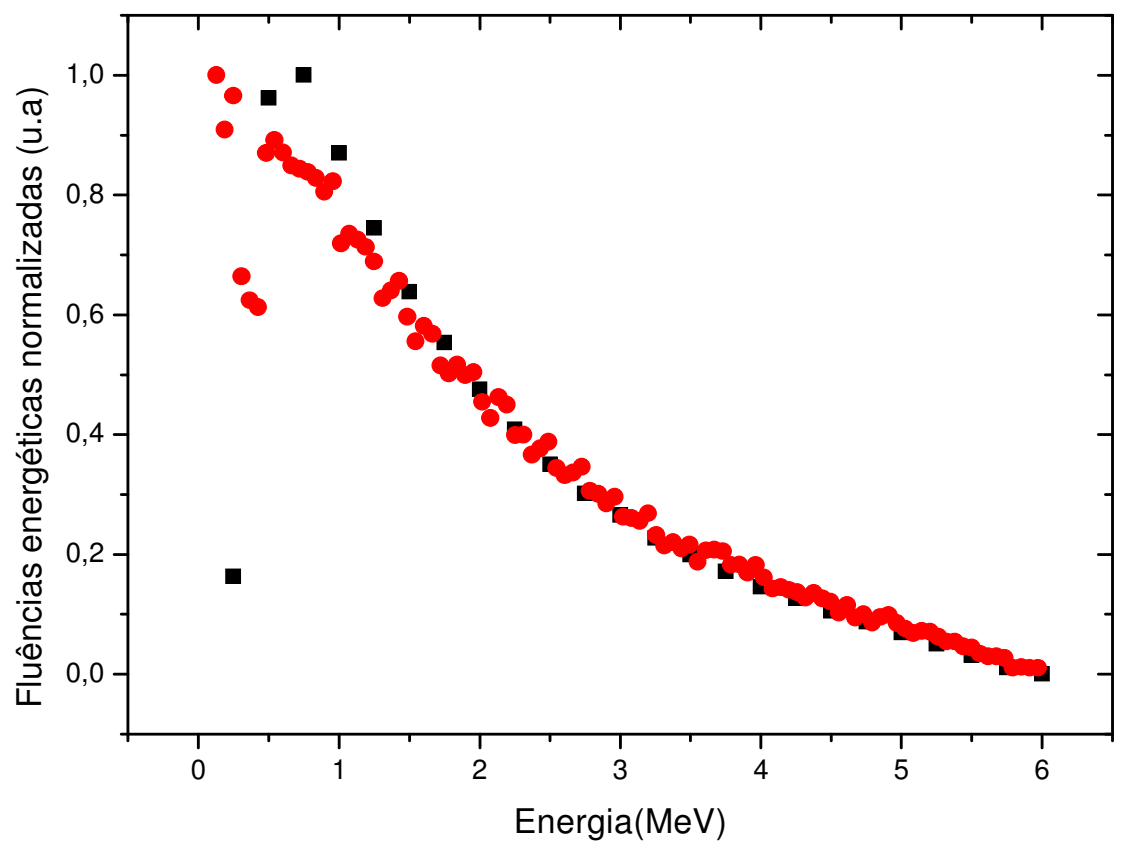

Figura 47 - Espectros de entrada e de saída normalizados para uma DFS $=70 \mathrm{~cm}$.

$\mathrm{Na}$ figura 47 pode-se observar que no espectro primário as principais perturbações ocorrem para as energias abaixo de $1 \mathrm{MeV}$. Em geral, existe a predominância de efeito Compton na maior parte do intervalo de energia adotado, mas considerando-se que existem componentes de 0,25 MeV até 0,75 MeV podese perceber a possibilidade de haver interação por meio de efeito fotoelétrico, pois o espectro secundário mais o transmitido apresenta valores inferiores aos espectros 
primários. Esse fato pode ter decorrido devido a absorção de fótons com energia cinética, abaixo do valor da função trabalho.

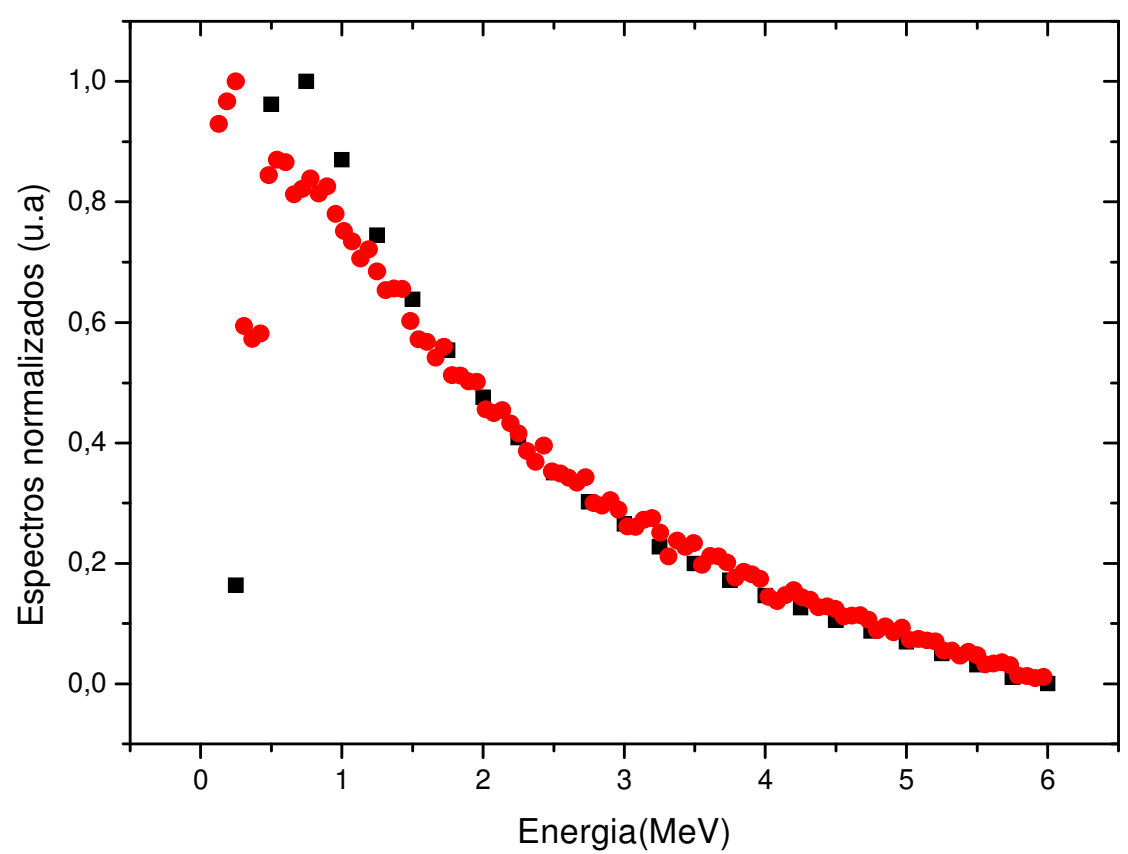

Figura 48 - Comparação entre o espectro primário e a fluência energética do espectro, secundário mais o transmitido, normalizados para uma DFS $=90 \mathrm{~cm}$.

O comportamento da curva primária no gráfico da figura 47 é semelhante a do gráfico 48 considerando-se as baixas energias, mas é possível perceber que o espectro secundário mais o transmitido apresenta valores maiores que o espectro primário, para o intervalo de energia entre 3 e $4 \mathrm{MeV}$, isso decorre devido ao fato das componentes com energias maiores que $4 \mathrm{MeV}$ serem atenuadas. Portanto, $\mathrm{o}$ espectro secundário mais o transmitido terão essas componentes de energia contabilizadas nessa energia inferior, após o processo de atenuação. 


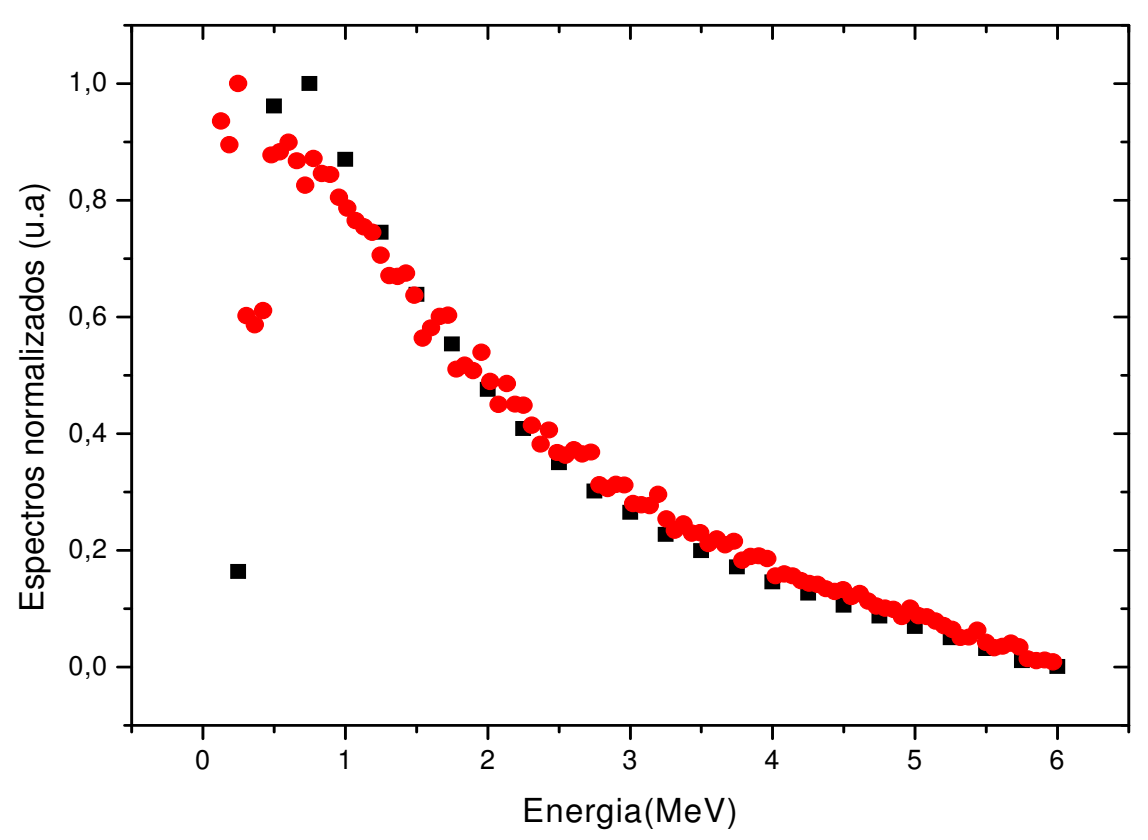

Figura 49 - Comparação entre o espectro primário e a fluência energética do espectro secundário e transmitido normalizados para uma DFS $=110 \mathrm{~cm}$.

No gráfico da figura 49 os valores da fluência energética normalizada do espectro secundário mais o transmitido praticamente se sobrepõem ao espectro primário normalizado, entretanto esse comportamento não é evidenciado para as energias abaixo de $1 \mathrm{MeV}$.

O gráfico da figura 50 mostra uma comparação entre o espectro primário e a fluência energética do espectro secundário mais o transmitido, normalizados para uma DFS $=130 \mathrm{~cm}$. 


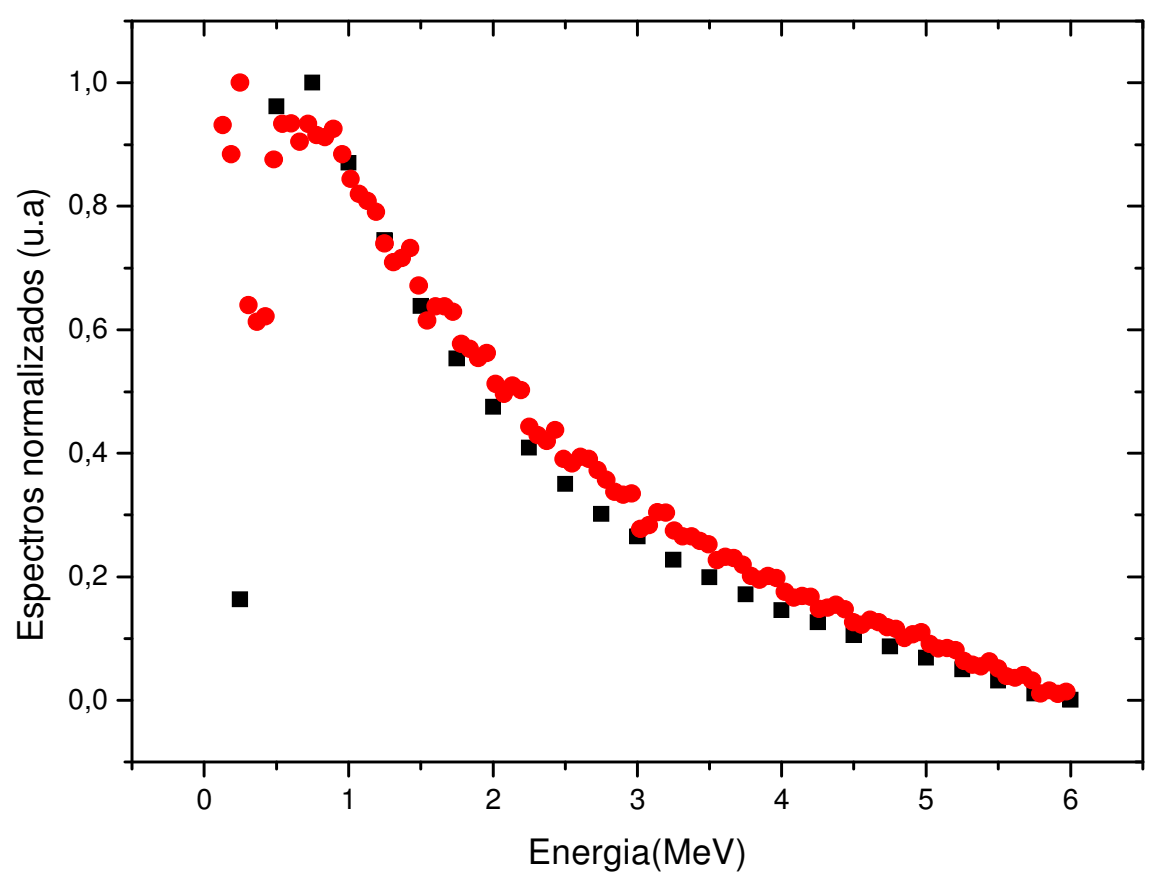

Figura 50- Comparação entre o espectro primário e a fluência a energética do espectro secundário mais o transmitido normalizados para uma $\mathrm{DFS}=130 \mathrm{~cm}$.

No gráfico da figura 50 observa-se que os valores associados ao espectro de fluência energética do espectro secundário mais o transmitido normalizados apresentam valores maiores que o espectro primário normalizado no intervalo de energia entre 2 e $4 \mathrm{MeV}$. Esse fato indica que as energias maiores que $4 \mathrm{MeV}$ foram atenuadas para essa dfs.

\subsection{Medidas realizadas com câmara de ionização}

Essa seção destina-se a mostrar como se comporta a resposta de uma câmara de ionização quando se varia a espessura do objeto simulador, o tamanho de campo e a distância fonte superfície.

Além disso, se propõe a obter fatores de conversão $f_{c}$ que relacionem o valor da carga coletada com o valor da energia depositada obtido por meio das simulações utilizando o método Monte Carlo. 
A figura 51 apresenta a resposta da carga obtida em $\mathrm{nC}$ obtida utilizando uma câmara de ionização, em função da espessura do objeto simulador, seguindo a metodologia apresentada no capítulo anterior.

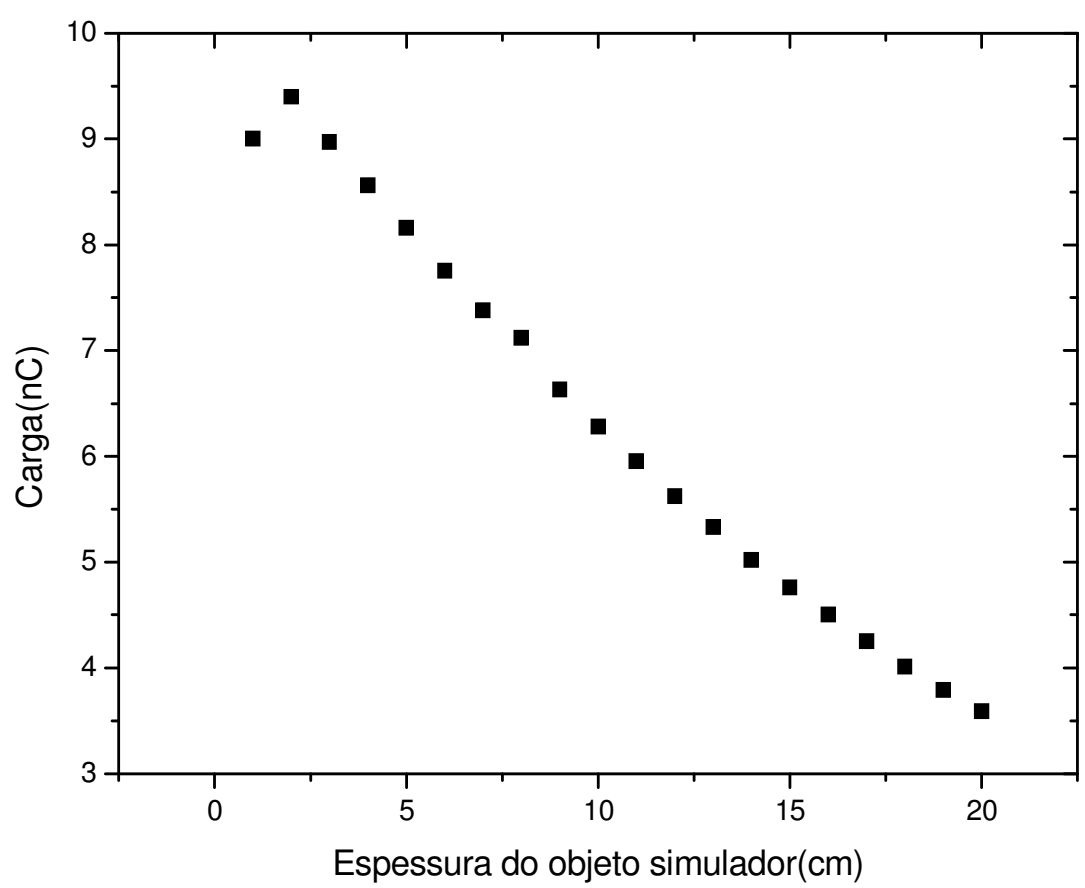

Figura 51 - Resposta da carga em nC obtida com a câmara de ionização colocada dentro do objeto simulador de água sólida em função da sua espessura.

Os resultados apresentados mostram simplesmente uma porcentagem de dose profunda em função da espessura. Para a determinação da carga nas diferentes espessuras do objeto simulador, composto de água sólida, a câmara foi colocada em um orifício apropriado para diferentes espessuras do objeto simulador que estavam no intervalo de 1 a $20 \mathrm{~cm}$ com incremento de $1 \mathrm{~cm}$ entre elas.

A figura 52 mostra os valores dos fatores de conversão calculados para as 20 espessuras do objeto simulador, levando em consideração os nove detectores virtuais. 


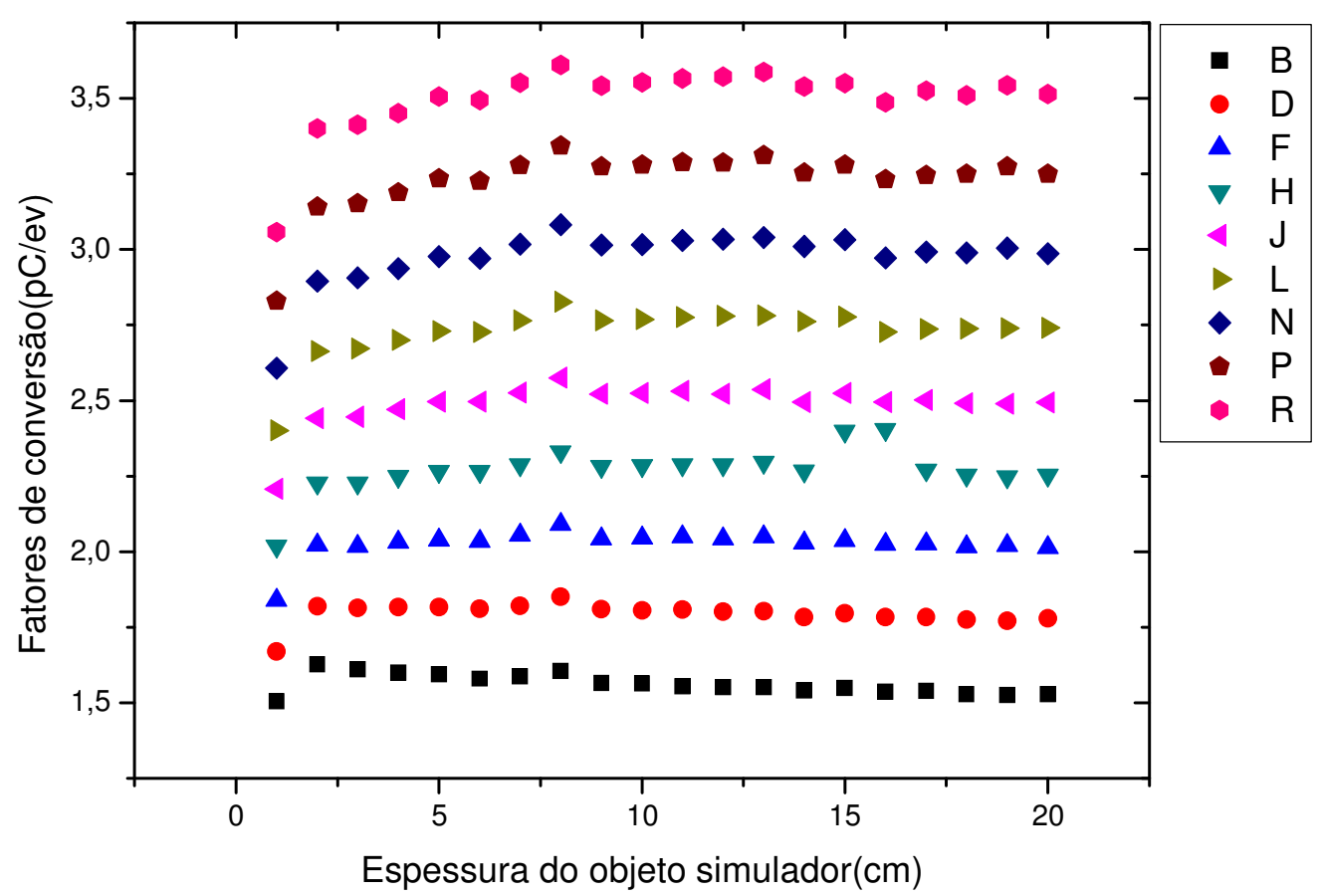

Figura 52 - Fator de conversão da espessura do objeto simulador.

Avaliando as curvas apresentadas na figura 52 nota-se que os fatores de conversão apresentam um caráter quase linear. Esse fato ocorre porque, tanto o gráfico da porcentagem de dose profunda, quanto o gráfico de resposta dos detectores virtuais apresentam queda, a partir de uma determinada profundidade.

As regiões em que ocorre crescimento são devido ao fato do termo $E_{d_{S M C}}$ decrescer mais do que $Q_{c}$. Por outro lado, as regiões em que ocorre decrescimento são devido ao fato da $Q_{c}$ decrescer mais rápido do que $E_{d_{S M C}}$.

Entretanto, vale ressaltar que a porcentagem de dose profunda apresenta crescimento antes da região de build-up, ou seja, um crescimento no numerador da expressão:

$$
f_{c}=\frac{Q_{c}}{E_{d_{S M C}}} .
$$

Além disso, decresce em todo intervalo considerado, conforme é evidenciado pela curva da figura 52. Portanto, o fator de conversão dos nove detectores virtuais 
considerados para a espessura de $1 \mathrm{~cm}$ apresentam um valor diferenciado em relação aos demais.

A figura 53 mostra a resposta obtida para diferentes tamanhos de campo, obtida em nC, com a câmara de ionização, em função do tamanho de campo.

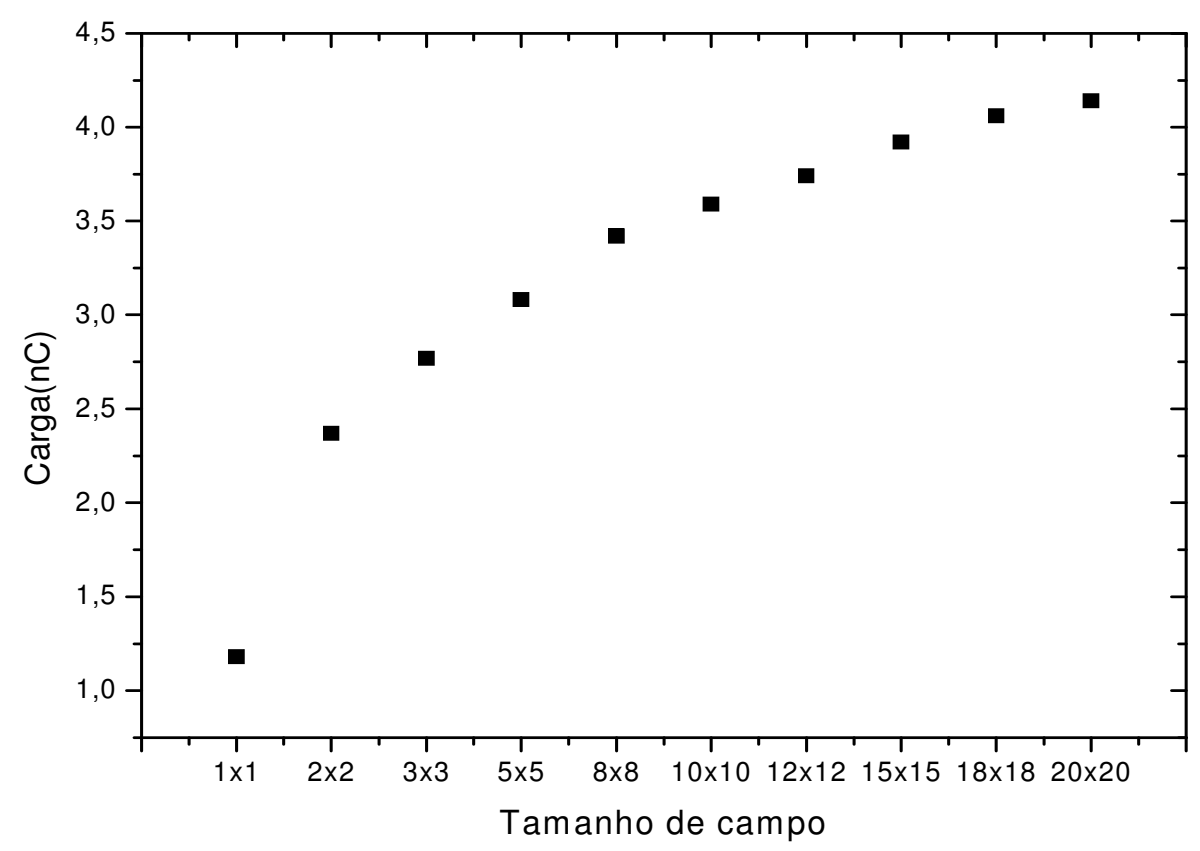

Figura 53 - Resposta da carga em nC obtida com a câmara de ionização colocada dentro do objeto simulador de água sólida em função do tamanho de campo.

Pela distribuição de carga apresentada na figura 53 nota-se que a resposta obtida pela câmara de ionização, em nano coulomb, para os diferentes tamanhos de campo aumenta com o tamanho de campo, devido ao fato de haver mais espalhamento. Nota-se que, o crescimento da carga ocorre de maneira mais suave com o aumento do tamanho do campo com tendência de se tornar constante, conforme era de se esperar.

A figura 54 apresenta o fatores de conversão em $\mathrm{pC} / \mathrm{eV}$ em função do tamanho de campo, obtida em $\mathrm{nC}$, com a câmara de ionização, para os nove detectores estudados. 


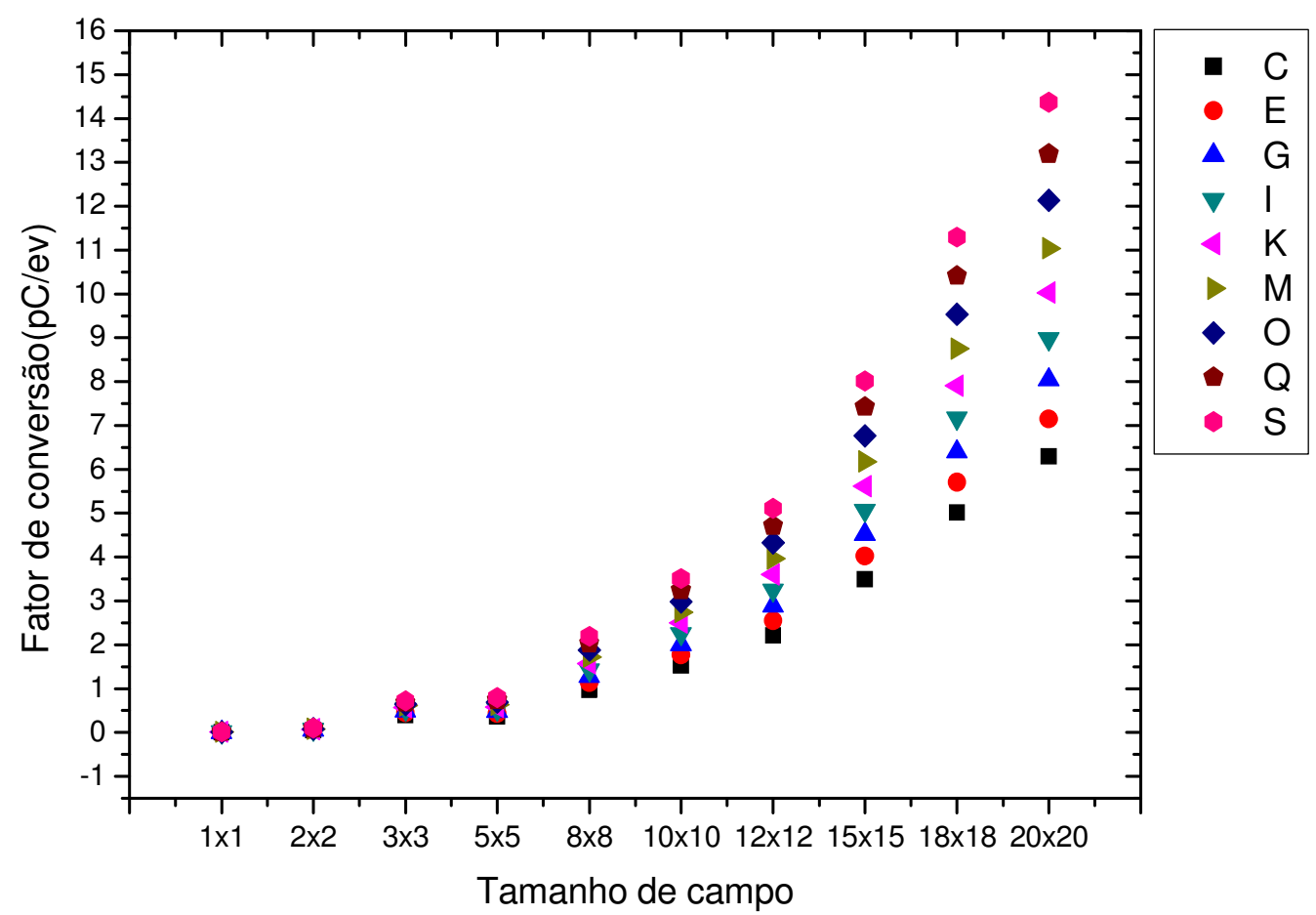

Figura 54 - Resposta obtida em nC, utilizando a câmara de ionização, em função do tamanho de campo, para os nove detectores estudados.

$\mathrm{O}$ as curvas da figura 53 mostram que o fator de conversão é diretamente proporcional ao tamanho de campo para quase todo o intervalo de tamanhos de campo considerado. Esse comportamento se deve a dois fatores decorrentes da expressão:

$$
f_{c}=\frac{Q_{c}}{E_{d_{S M C}}}
$$

O primeiro é que $Q_{c}$ é diretamente proporcional ao aumento do tamanho de campo, e o segundo, $E_{d_{S M C}}$ é inversamente proporcional ao aumento do tamanho de campo. Esses dois fatores combinados fazem com que a expressão cresça rapidamente.

A exceção observada ocorre para o campo $5 \times 5$ em que a função apresenta um comportamento diferenciado, ou seja, decresce em relação ao campo 3×3.

O gráfico da figura 55 mostra que a carga coletada por uma câmara de ionização responde, a diferentes distâncias fonte superfície dentro de um objeto simulador com $20 \mathrm{~cm}$ de espessura conforme é apresentado na figura. 


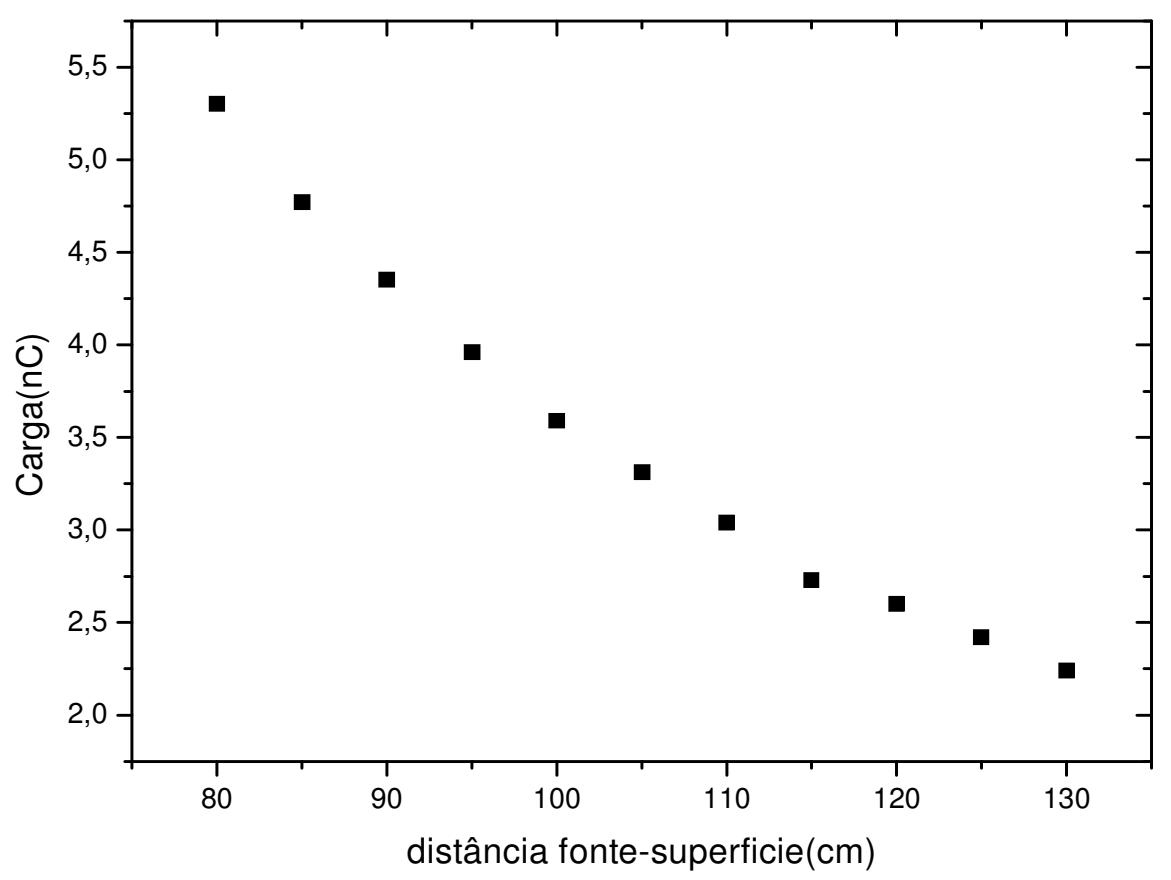

Figura 55 - Resposta obtida da carga em nC em função da dfs, com a câmara de ionização.

Os resultados encontrados com a câmara de ionização mostram a resposta da carga coletada pelo eletrômetro em valores absolutos, onde fica comprovado que, a carga coletada é inversamente proporcional a distância, entre a fonte de radiação e a superfície do objeto simulador.

Na figura 56 são apresentadas as curvas do fator de conversão em pC/eV em função da distância em cm, da fonte-superfície. 


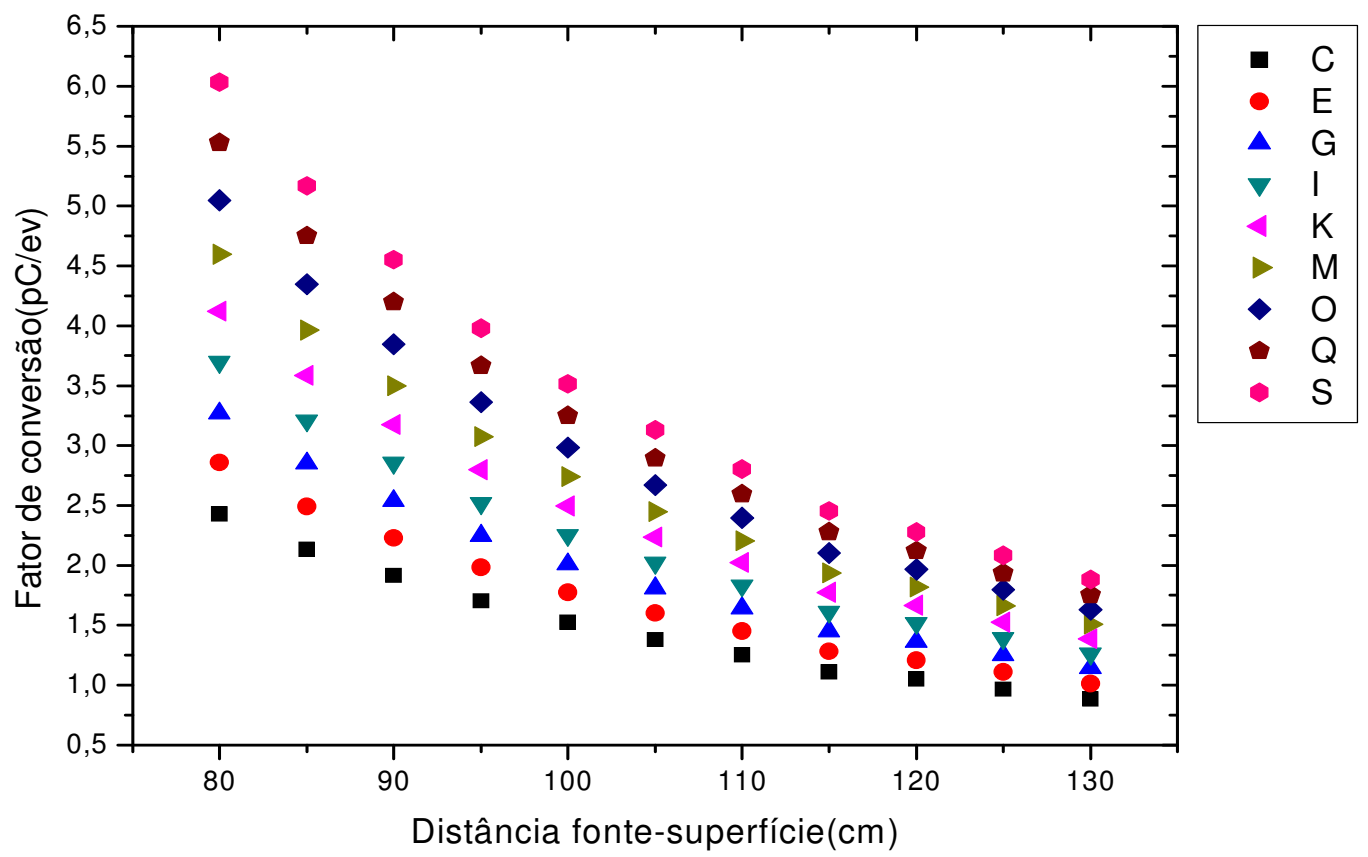

Figura 56 - Fator de conversão em pC/eV em função da distância fonte-superfície.

As curvas da figura 56 mostram que o fator de conversão é inversamente proporcional à distância fonte-superfície. Esse fato se deve a dois motivos que são o fato do termo $E_{d_{S M C}}$ ser diretamente proporcional à distância e o termo $Q_{c}$ ser inversamente proporcional.

\subsection{Medidas utilizando objeto simulador antropomórfico}

O câncer de pulmão é o mais comum no mundo que vem sofrendo redução devido à diminuição do tabagismo. Os fatores de risco associados a essa neoplasia são o tabagismo que é responsável por $90 \%$ dos casos aumentando o risco da doença em 20 vezes, radioterapia, tabagismo passivo, asbesto, radônio, metais cromo e níquel, radiação ionizante, hidrocarbonos aromáticos policíclicos, fibrose pulmonar, HIV e os efeitos genéticos.

A motivação desse estudo deu-se devido à magnitude dessa neoplasia no contexto mundial e a diferença de heterogeneidade existente nesse órgão que possui tecido na parte externa e ar na parte interna. 
6.3.1. Variação da energia depositada em função do tamanho de campo

A descrição da energia depositada em função do tamanho de campo para os nove detectores virtuais colocados atrás do objeto simulador está representada na figura 56.

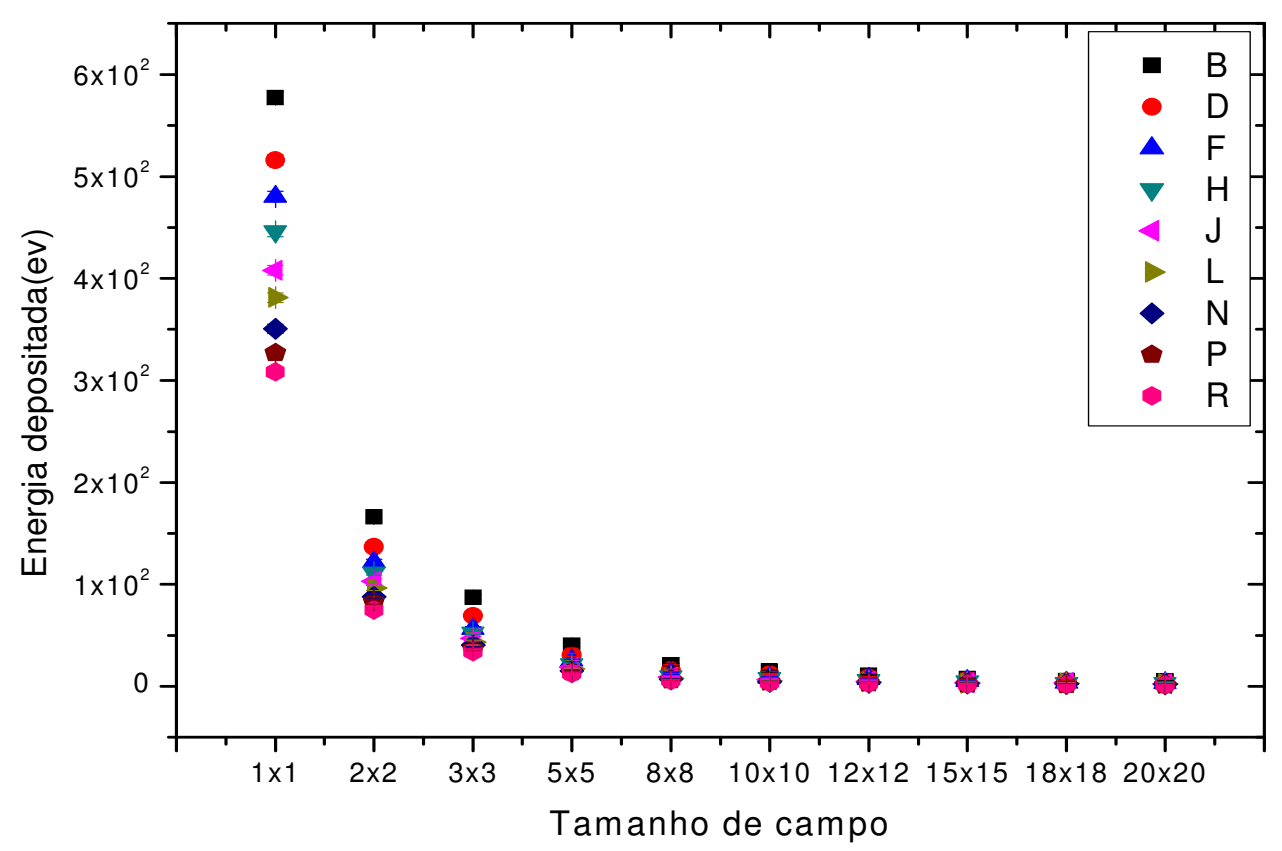

Figura 56 - Energias depositadas para os 9 diferentes detectores virtuais em função do tamanho do campo de exposição.

O gráfico da figura 56 mostra o decrescimento da energia depositada em função do tamanho de campo. Esse decrescimento se deve ao fato dos campos grandes captarem uma pequena parte das componentes primárias incidentes do feixe de radiação. Deve-se ressaltar que o mesmo comportamento foi observado para os nove detectores virtuais, além disso, nota-se que na situação considerada, na qual o órgão irradiado é o pulmão que possui uma heterogeneidade associada a ele, os resultados indicam que as componentes primárias são as principais responsáveis pela deposição de energia no processo.

O gráfico da figura 57 apresenta a resposta das energias depositadas normalizadas para o $1^{\circ}$ detector virtual na qual, os valores foram divididos pelo valor da resposta máxima, ou seja, a resposta associada ao campo $1 \times 1$. 


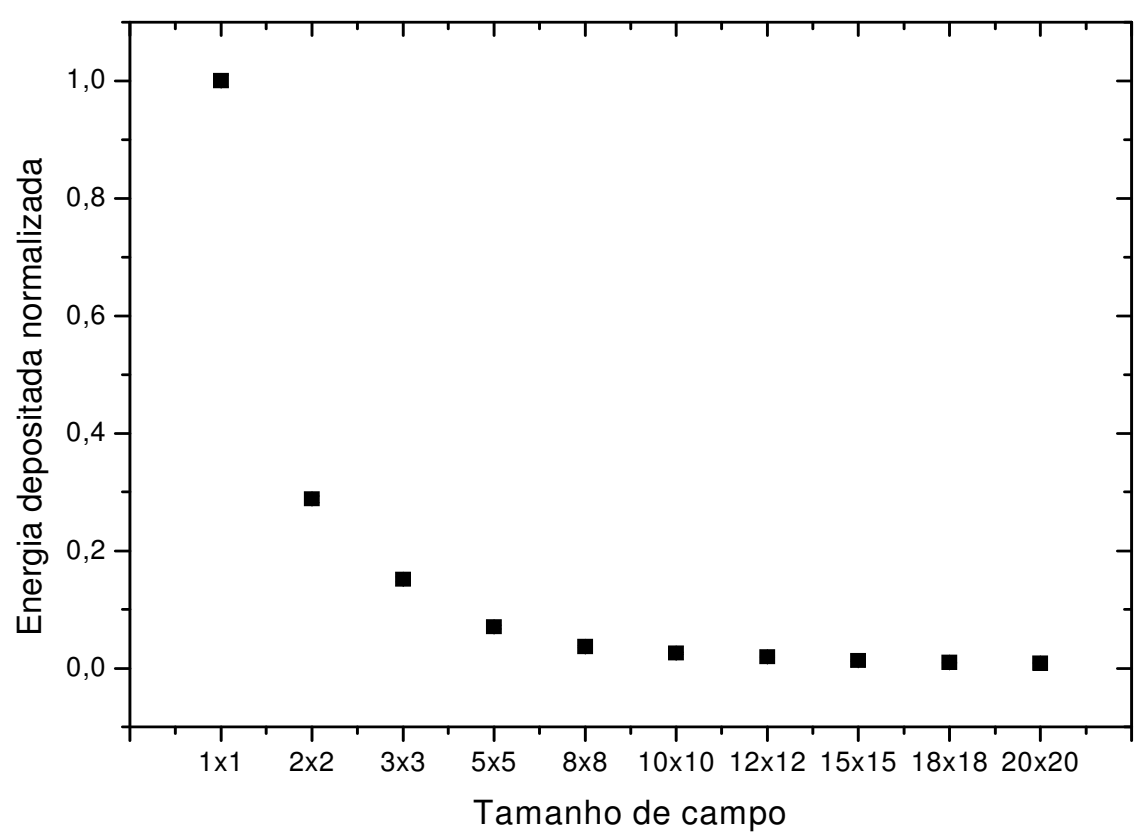

Figura 57 - Energias depositadas normalizadas para o $1^{\circ}$ detector virtual para diferentes tamanhos de campo.

Os valores apresentados mostram os valores relativos das energias depositadas. A curva da figura 57 mostra que o valor da energia depositada associada ao campo $2 \times 2$ corresponde aproximadamente a $30 \%$ do valor correspondente ao campo $1 \times 1$. Portanto, a variação de campos pequenos tem maior influência no gradiente de energia depositada, do que a variação de campos grandes.

Esse estudo poderia ser extrapolado para outras regiões do corpo, em especial naquelas em que a dosimetria de campos pequenos é de fundamental importância.

O gráfico da figura 58 apresenta a resposta das energias depositadas normalizadas, para o $4^{\circ}$ detector virtual para os diferentes tamanho de campo. 


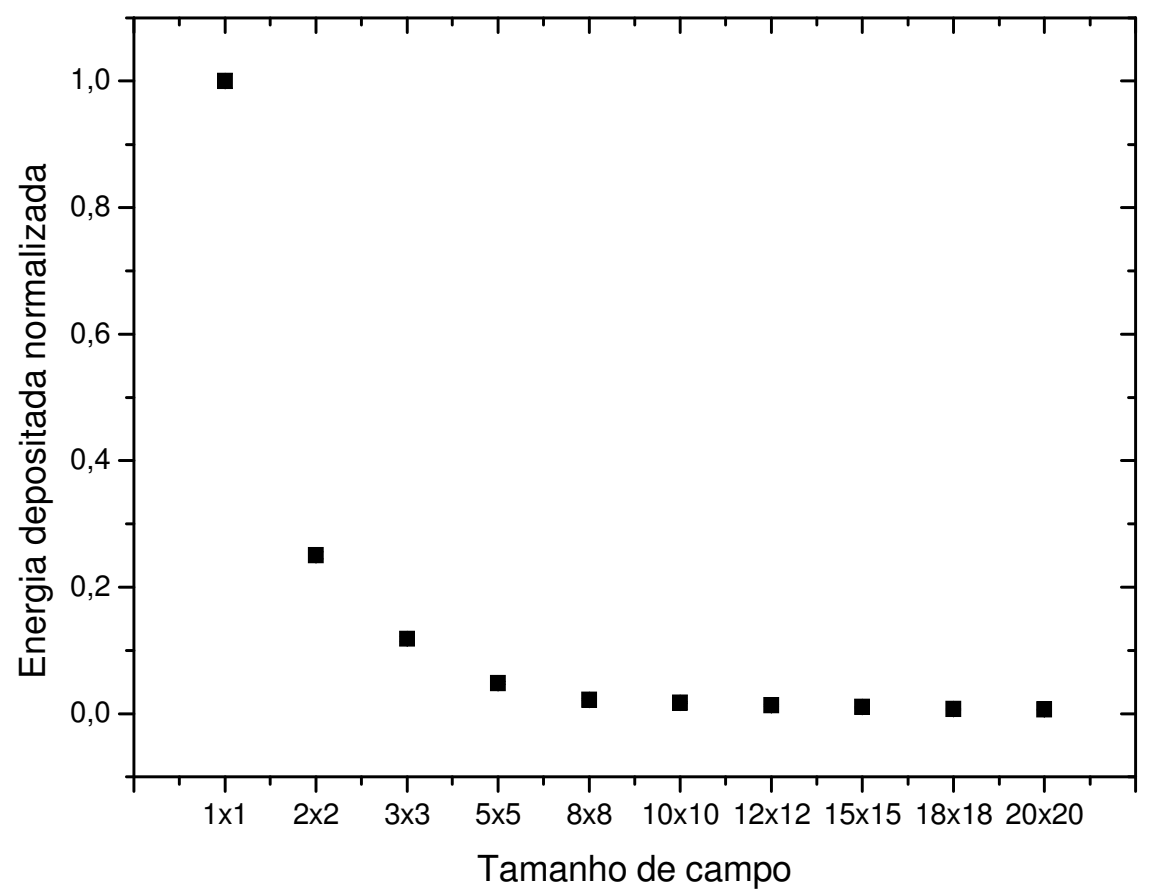

Figura 58 - Energias depositadas normalizadas para o $4^{\circ}$ detector virtual para diferentes tamanhos de campo.

O gráfico da figura 59 apresenta a resposta das energias depositadas normalizadas, para o 9 detector virtual para os diferentes tamanhos de campo em que o objeto simulador antropomórfico é exposto. 


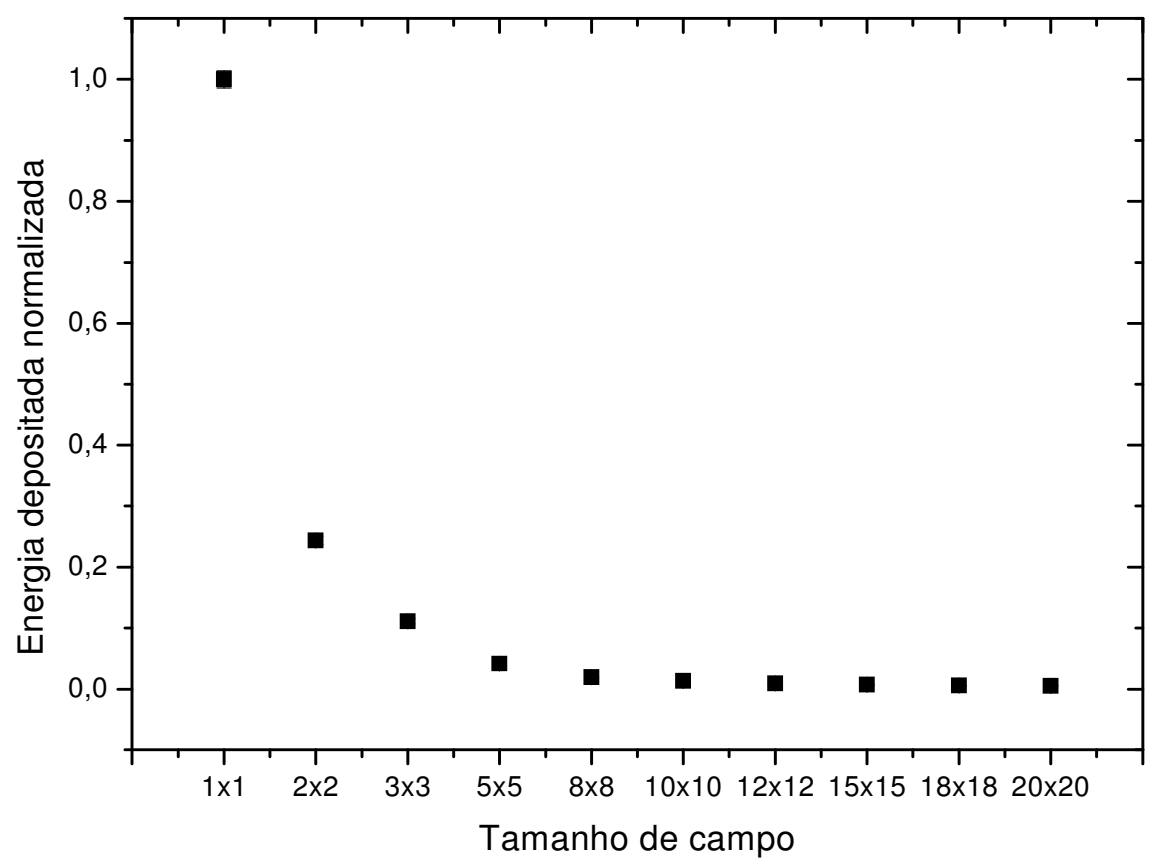

Figura 59 - Energias depositadas normalizadas para o 9 detector virtual para diferentes tamanhos de campo em que o objeto simulador antropomórfico é exposto.

A resposta obtida com esta simulação mostra variações semelhantes àquela obtida pelo $4^{\circ}$ detector virtual em termos relativos.

6.3.2. Variação da fluência energética em função do tamanho de campo

O gráfico da figura 60 apresenta o espectro normalizado em função da energia em eV da fluência energética primaria e secundária obtida para um campo 1x1 em que, o detector virtual está localizado imediatamente atrás do objeto simulador. 


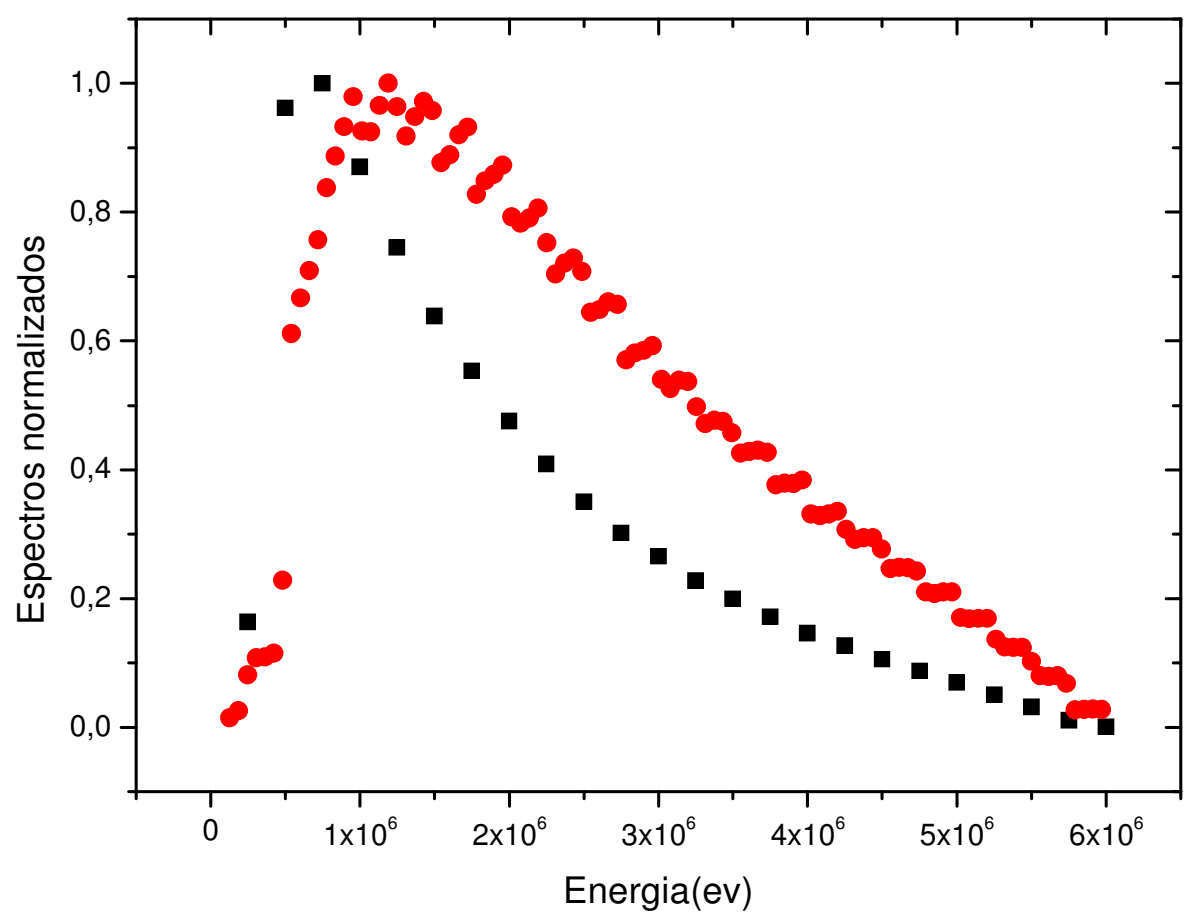

Figura 60 - Comparação entre os espectros de entrada e de saída normalizados para o tamanho de campo $1 \times 1$ utilizando objeto simulador antropomórfico.

Esse resultado mostra que na região de predominância de efeito Compton, ou seja, para as energias de $10^{6}$ até $6.10^{6} \mathrm{eV}$ as partículas primárias são espalhadas e algumas destas mudam a direção inicial, para incidir no eixo central do feixe. Esse fenômeno é predominante em relação à atenuação total, provocada pelo objeto simulador e por isso, o espectro das fluências secundárias mais as transmitidas apresentam valores maiores que, o espectro de energia primário normalizado nesse intervalo de energia.

O gráfico da figura 61 apresenta a comparação entre os espectros de entrada e de saída normalizados para o tamanho de campo 5x5 utilizando objeto simulador antropomórfico. 


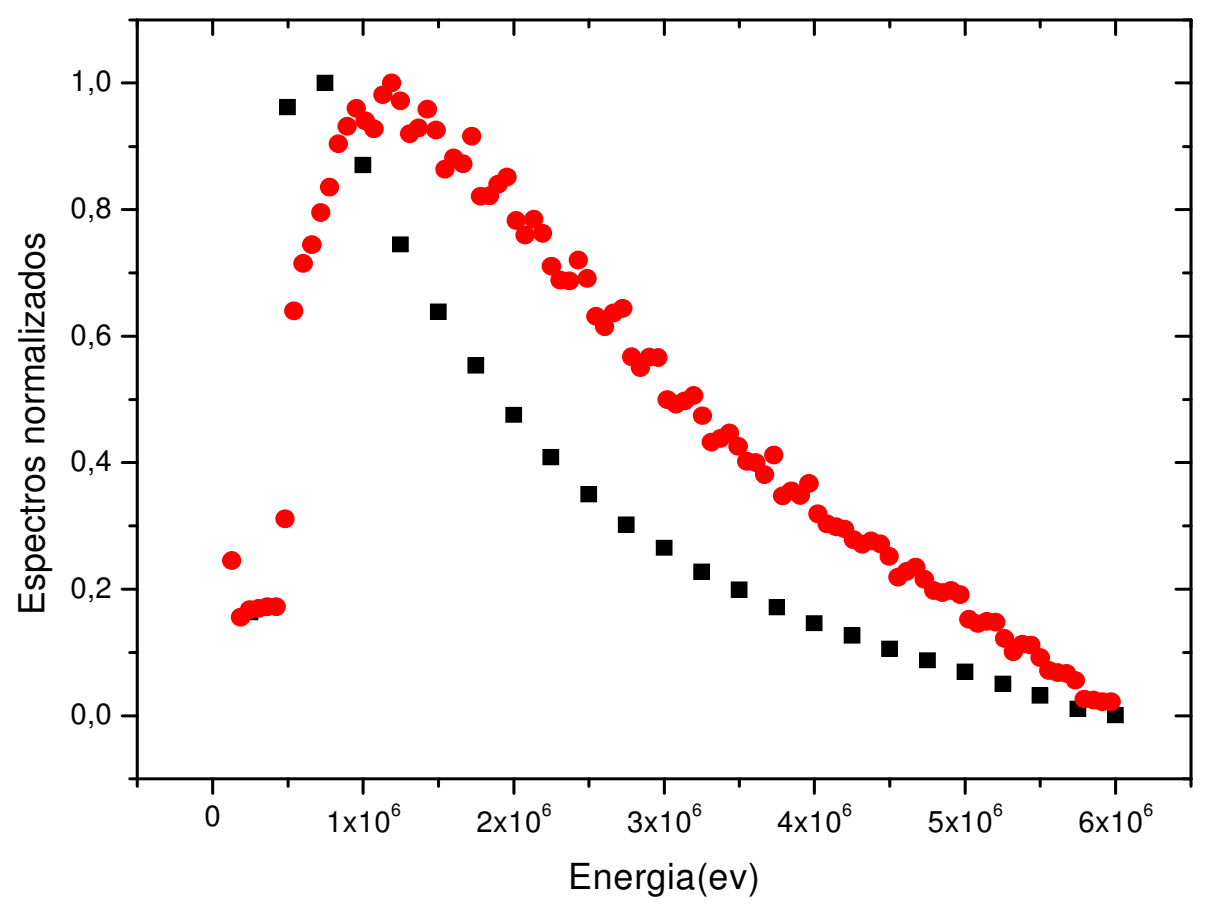

Figura 61 - Comparação entre os espectros de entrada e de saída normalizados para o tamanho de campo 5x5 utilizando objeto simulador antropomórfico.

O resultado das fluências energéticas apresentadas no gráfico da figura 61 apresentam comportamento semelhante ao anterior para as energias acima de 1 $\mathrm{MeV}$, embora detecte-se mais partículas espalhadas no eixo central do feixe enquanto que, o número de partículas primárias captadas decresce.

Desse resultado verifica-se que o espectro secundário mais o transmitido é menor do que o do campo $1 \times 1$, e além disso o decréscimo da incidência de partículas primárias é predominante em relação ao aumento de espalhamento, portanto a maior dependência observada das partículas primárias, para o eixo central do feixe, observada nos resultados para a explicar os espectros captados, após a radiação interagir com objetos simuladores homogêneos também é valida para os objetos simuladores antropomórficos.

O gráfico da figura 62 apresenta a fluência energética obtida para um campo 10x10 em que, o detector virtual está localizado imediatamente atrás do objeto simulador. 


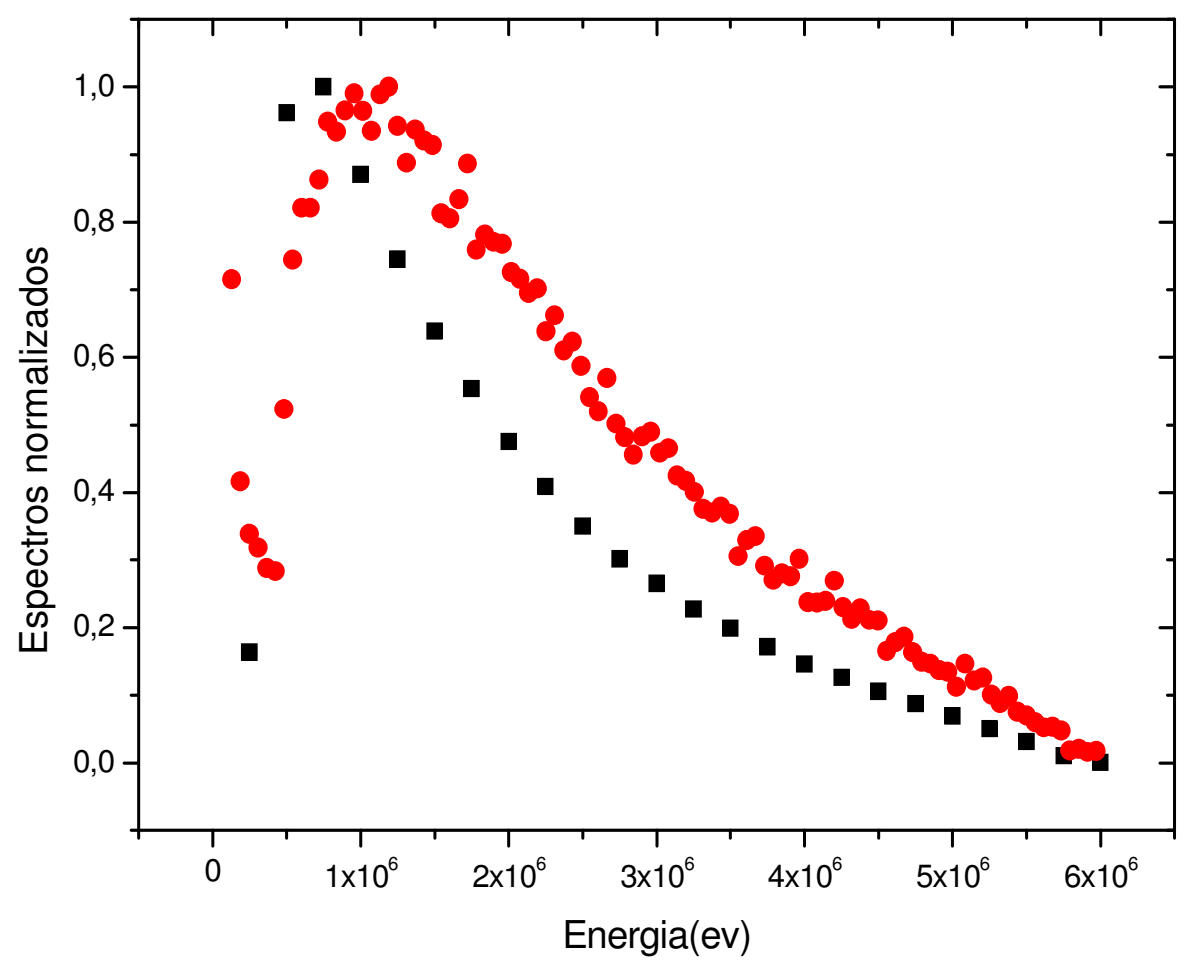

Figura 62 - Comparação entre os espectros de entrada e de saída normalizados para o tamanho de campo 10x10 utilizando objeto simulador antropomórfico.

O espectro de saída normalizado e associado ao campo 10×10 apresenta valores maiores que o espectro primário, embora no campo $5 \times 5$ a elevação observada seja maior.

Além disso, observa-se que nas componentes com energia abaixo de $1 \mathrm{MeV}$ na qual, o efeito fotoelétrico é predominante existe um comportamento de decrescimento da intensidade da fluência energética do espectro secundário, até a energia de $3,9510^{5} \mathrm{eV}$ na qual a fluência energética apresenta um valor mínimo percentual de $28,74 \%$.

Entretanto a partir desse ponto de mínimo observa-se um aumento na função que descreve a intensidade de fluência energética.

O gráfico da figura 63 apresenta a fluência energética obtida para um campo $15 \times 15$ em que, o detector virtual está localizado imediatamente atrás do objeto simulador. 


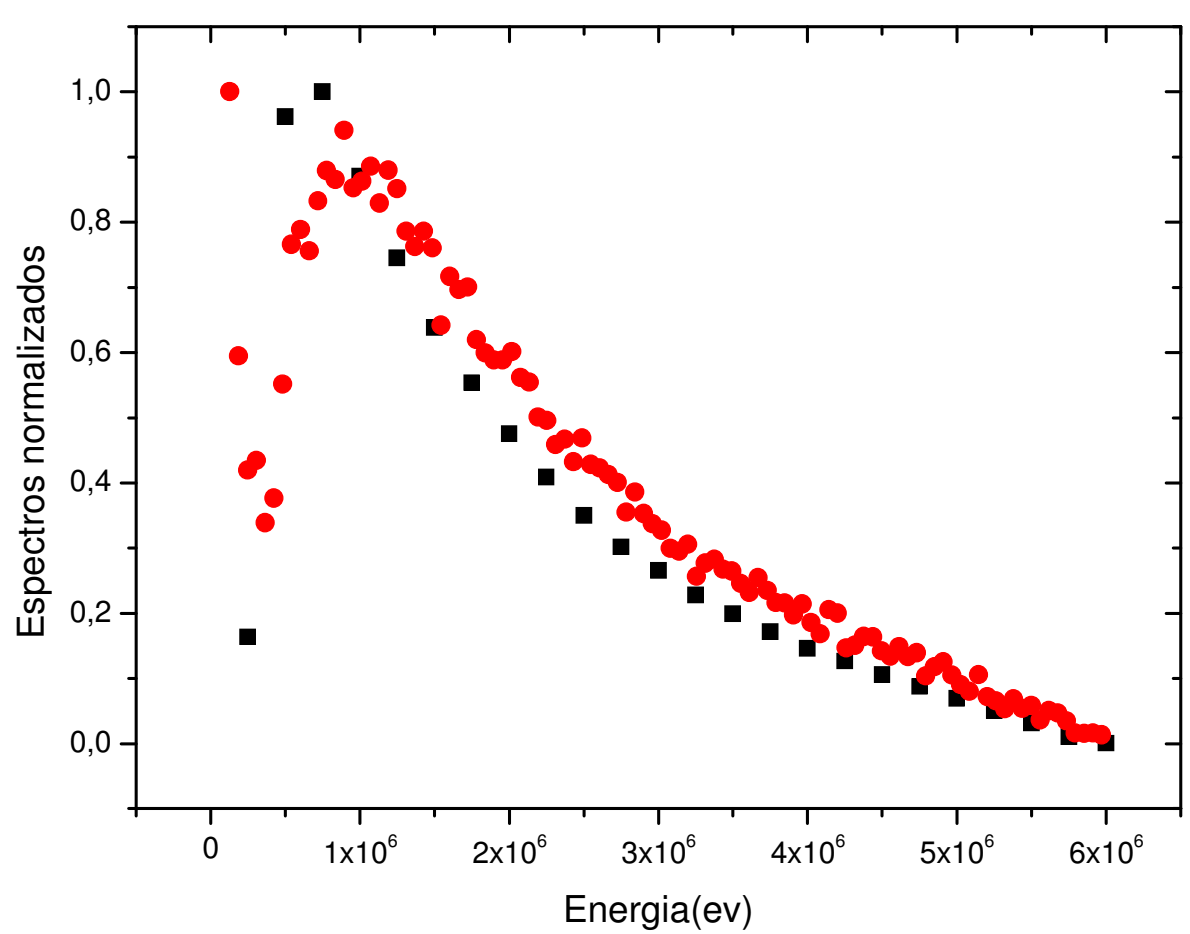

Figura 63 - Comparação entre os espectros de entrada e de saída normalizados para o tamanho de campo 15x15 utilizando objeto simulador antropomórfico.

O espectro de saída normalizado associado ao campo $15 \times 15$ apresenta valores maiores que o espectro primário, embora nos campos $5 \times 5$ e $10 \times 10$ as elevações observadas sejam maiores.

Esse fenômeno ocorre devido à atenuação que aumenta conforme cresce o tamanho de campo para o eixo central do feixe.

Além disso, observa-se que nas componentes com energia abaixo de $1 \mathrm{MeV}$, na qual o efeito fotoelétrico é predominante, existe um comportamento de decrescimento da intensidade da fluência energética do espectro secundário até a energia de $3,57.10^{5} \mathrm{eV}$ na qual, a fluência energética apresenta um valor mínimo percentual de $33,93 \%$. Entretanto, a partir desse ponto de mínimo observa-se um aumento na função que descreve a intensidade de fluência energética. Esse fenômeno ficou evidenciado no gráfico para o tamanho de campo 10×10.

O gráfico da figura 64 apresenta a comparação entre o espectro primário e a fluência energética do espectro secundário mais o transmitido normalizado para o 
tamanho de campo 20x20 utilizando objeto simulador antropomórfico, em que o detector virtual está localizado imediatamente atrás do objeto simulador.

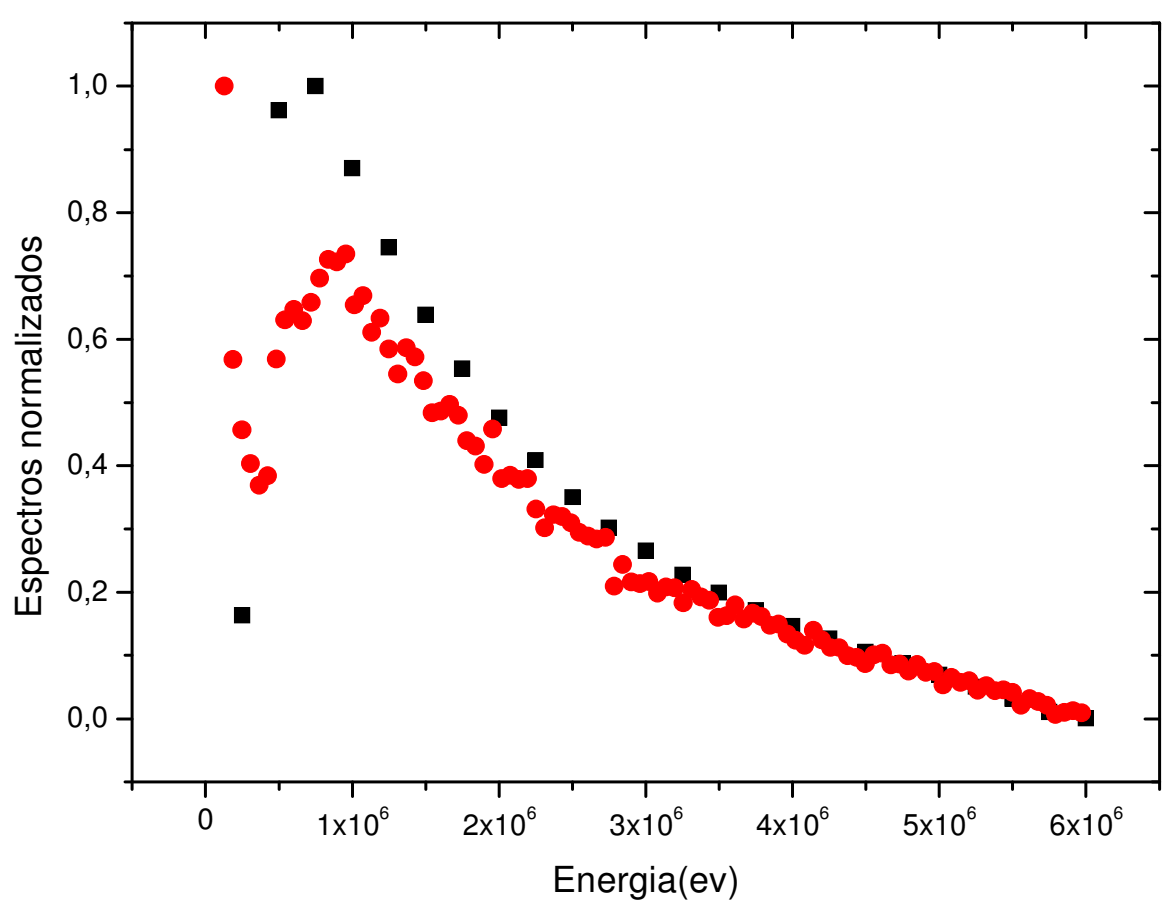

Figura 64 - Comparação entre os espectros de entrada e de saída normalizados para o tamanho de campo 20x20 utilizando objeto simulador antropomórfico.

O resultado obtido pelas curvas da figura 64 confirma a tendência de que a atenuação cresce com o aumento do tamanho de campo para o eixo central do feixe, pois a intensidade do espectro de saída normalizado é menor que o espectro de entrada normalizado no intervalo de energia que, ocorre predominância do efeito Compton no intervalo de energia de $10^{6} \mathrm{eV}$ até $6.10^{6} \mathrm{eV}$. Além disso, observa-se que nas componentes com energia abaixo de $1 \mathrm{MeV}$, na qual o efeito fotoelétrico é predominante, existe um comportamento de decrescimento da intensidade da fluência energética do espectro secundário até a energia de 3,71.105 eV na qual, a fluência energética apresenta um valor mínimo percentual de $36,62 \%$. Entretanto a partir desse ponto de mínimo observa-se aumento na função que descreve a intensidade de fluência energética.

Outro ponto, que deve ser observado é que o ponto de máximo, contido na região de predominância do efeito fotoelétrico, é bem maior que o $2^{0}$ ponto da função de intensidade de fluência energética que, apresenta $57 \%$ do seu valor. 
6.3.3. Variação da energia depositada em função da distância fonte-superfície

O gráfico da figura 65 apresenta os valores de energias depositadas captadas em valores absolutos pelos nove detectores virtuais utilizados nas simulações.

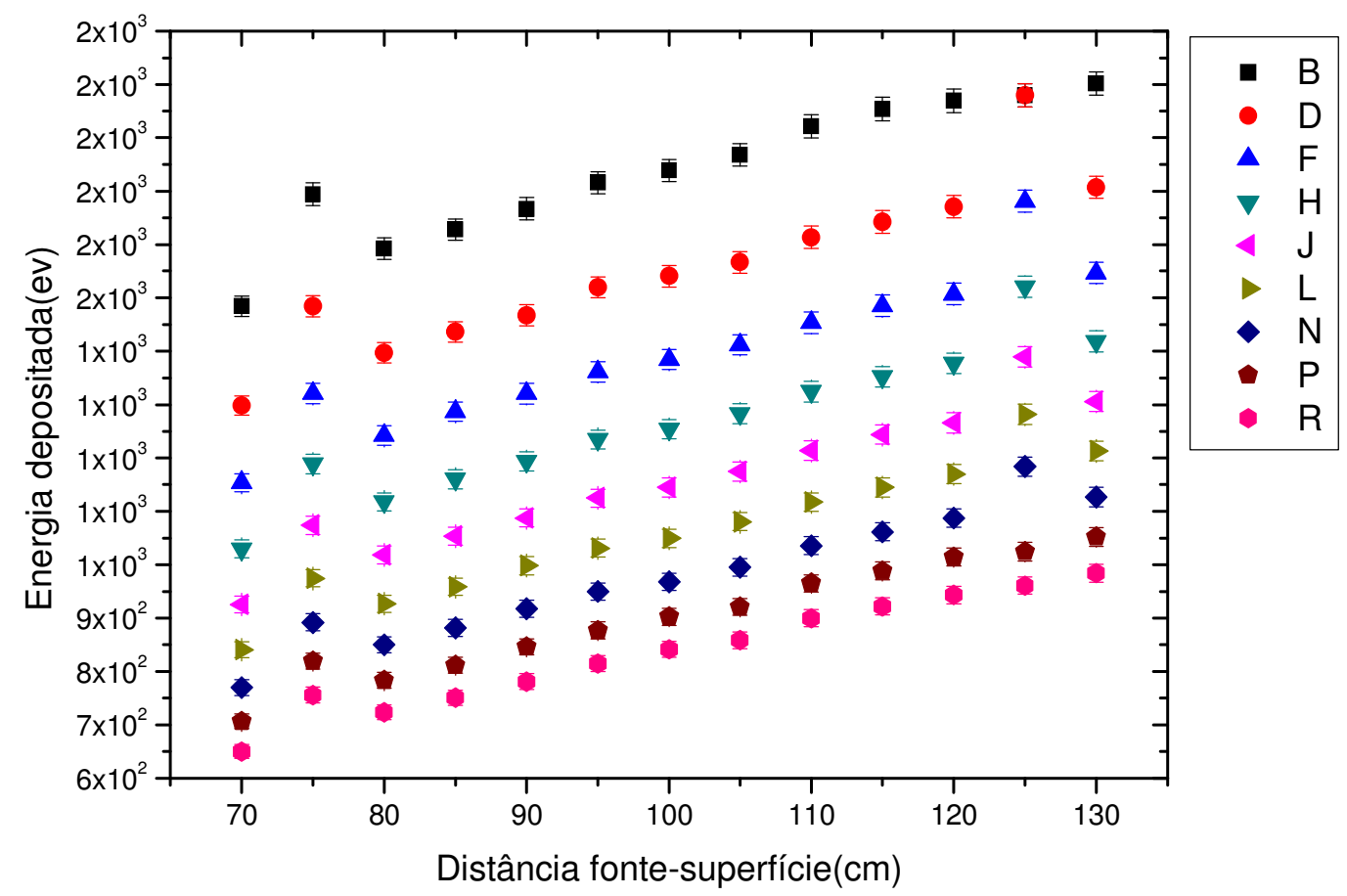

Figura 65 - Energias depositadas em detectores virtuais para diferentes dfs.

O resultado obtido mostra que a energia depositada em todos os nove detectores virtuais é diretamente proporcional à distância da fonte de radiação a superfície do objeto simulador antropomórfico.

A explicação desse fenômeno é devido ao fato, do feixe que está mais distante, apresentar uma maior divergência, portanto capta um menor número de partículas primárias conforme se aumenta a distância.

Vale ressaltar que a tendência de crescimento também foi observada nos resultados utilizando objetos simuladores homogêneos, mostrando que para o eixo central do feixe a dependência das componentes primárias é maior que a dependência das componentes espalhadas. 
As figuras 66, 67, 68 apresentam as energias normalizadas em função da distância fonte superfície, respectivamente, para os $1^{\circ}$, $4^{\circ}$ e $9^{\circ}$ detectores virtuais.

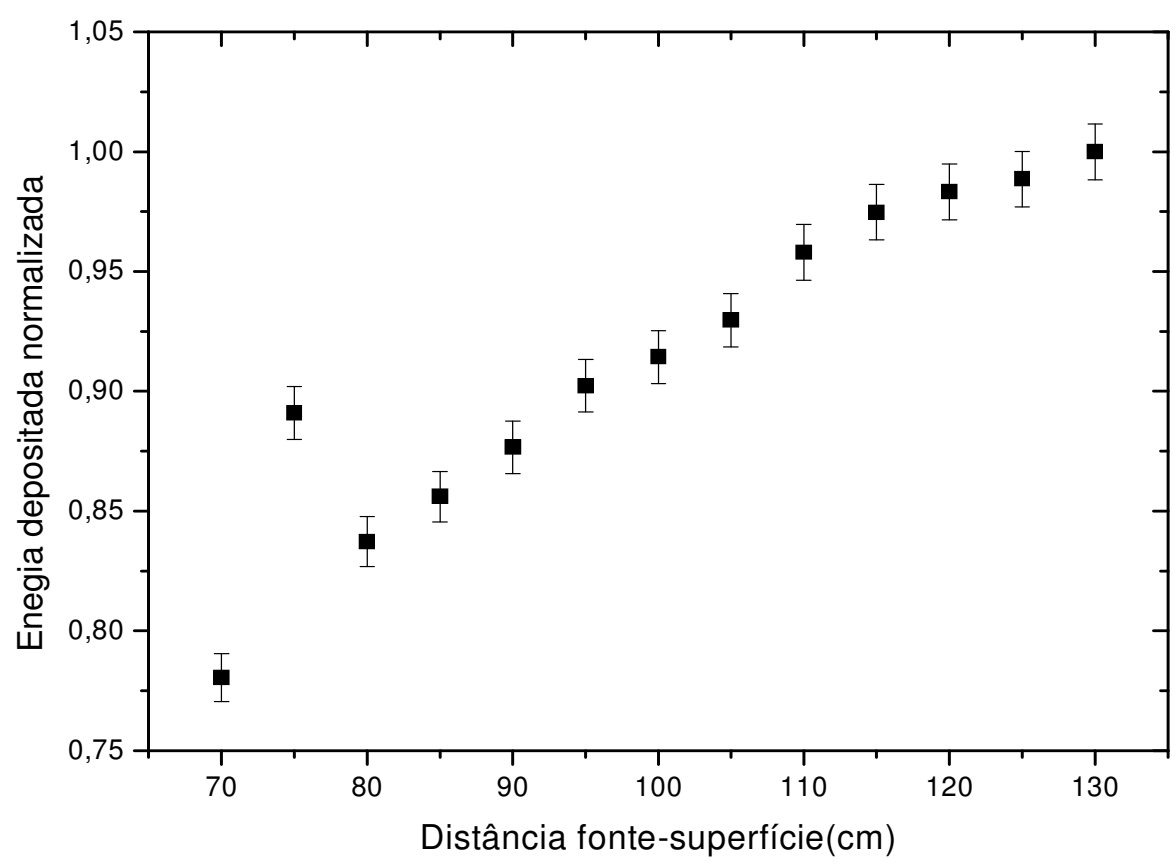

Figura 66 - Energias depositadas no $1^{\circ}$ detector virtual para diferentes dfs.

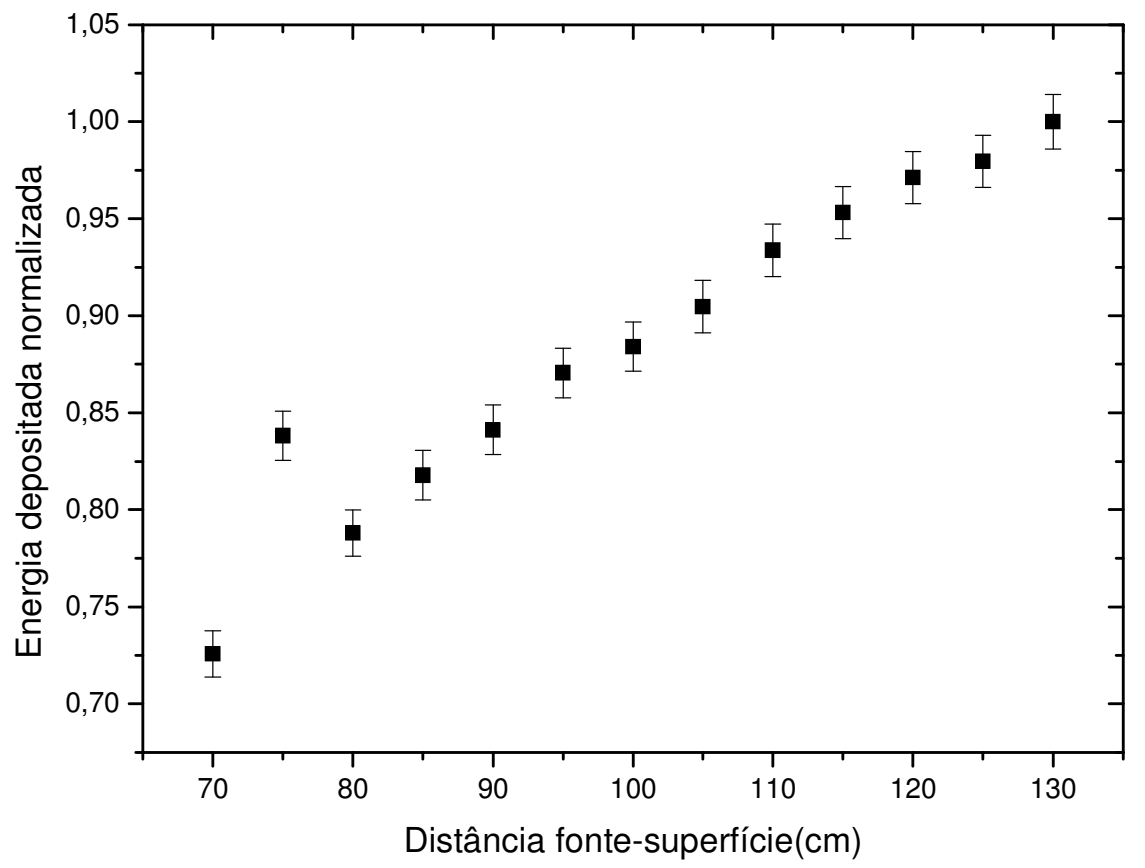

Figura 67 - Energias depositadas no $4^{\circ}$ detector virtual para diferentes dfs. 


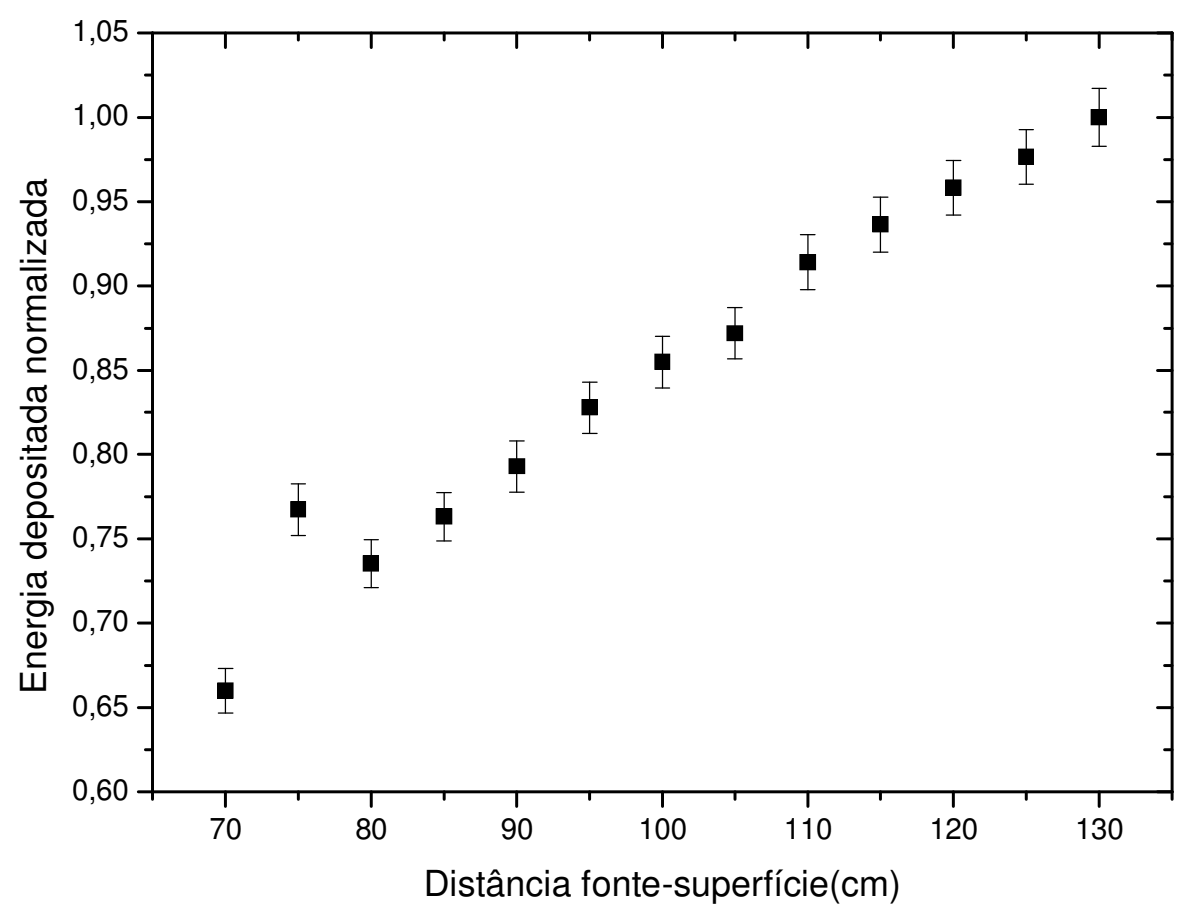

Figura 68 - Energias depositadas no $99^{\circ}$ detector virtual para diferentes dfs. 
6.3.4. Variação da fluência energética em função da dfs

A figura 69 mostra a intensidade do espectro de saída normalizado sobreposto ao espectro de entrada normalizado para a $\mathrm{dfs}=70 \mathrm{~cm}$ utilizando um objeto simulador antropomórfico, vejamos:

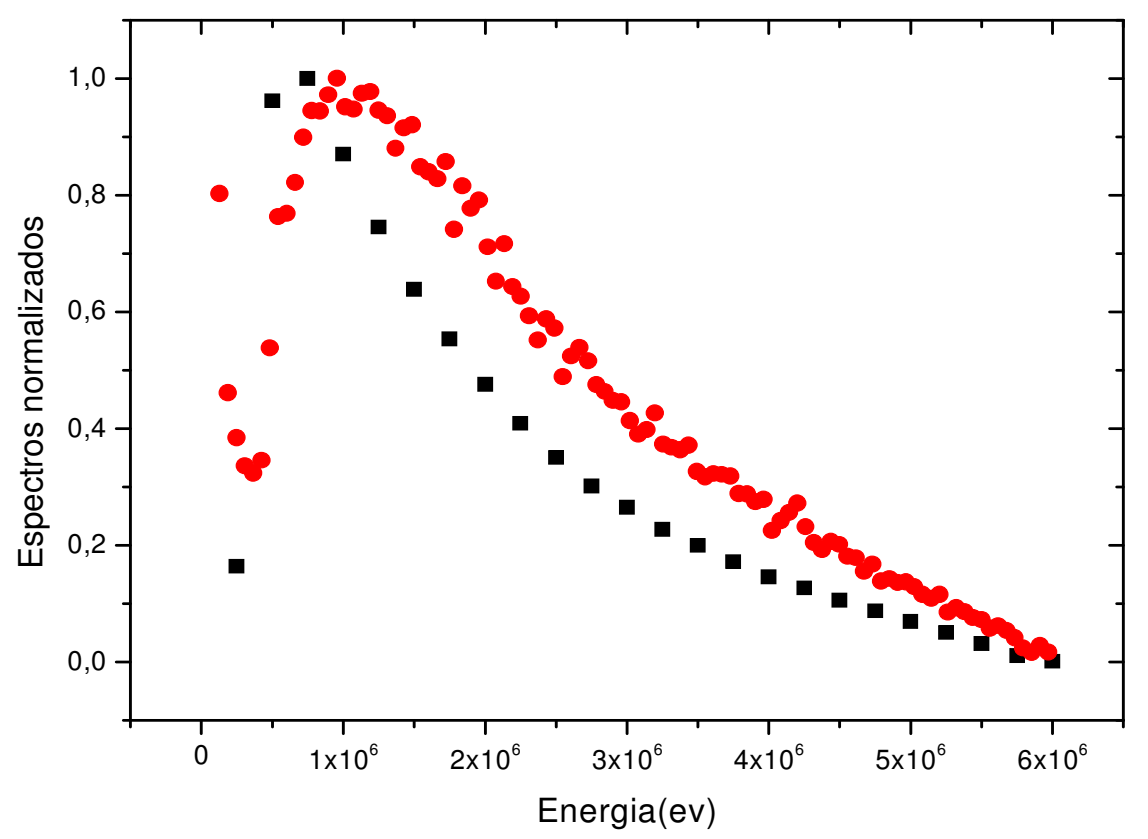

Figura 69 - Comparação entre o espectro primário e a fluência energética do espectro secundário mais o transmitido, normalizados para uma DFS $=70 \mathrm{~cm}$.

Comparação entre os espectros de entrada e de saída normalizados para o tamanho de campo $O$ resultado da intensidade de fluência energética mostrada no gráfico da figura 69 revela que para as energias acima de $10^{6} \mathrm{eV}$, onde existe a predominância do espalhamento Compton, o espectro de saída normalizado apresenta valores superiores ao do espectro de entrada normalizado.

Entretanto, na região das energias abaixo de $10^{6} \mathrm{eV}$ existe uma predominância de efeito fotoelétrico, o qual precisa de um limiar de energia para remover os elétrons do material absorvedor, que no caso é o próprio objeto simulador.

Esses elétrons removidos e eventualmente detectados apresentarão energias inferiores à energia dos fótons incidentes, por isso existe uma queda na intensidade 
da fluência energética até um valor que representa um ponto crítico de mínimo que nesse caso corresponde a 0,32 que ocorre na energia de 3,54.105. Entretanto, a partir desse valor, a resposta de intensidade da fluência energética volta a crescer até um valor máximo.

A figura 70 mostra a intensidade de fluência energética secundária, mais a transmitida normalizada sobreposta ao espectro primário normalizado, para a dfs igual $90 \mathrm{~cm}$, utilizando um objeto simulador antropomórfico.

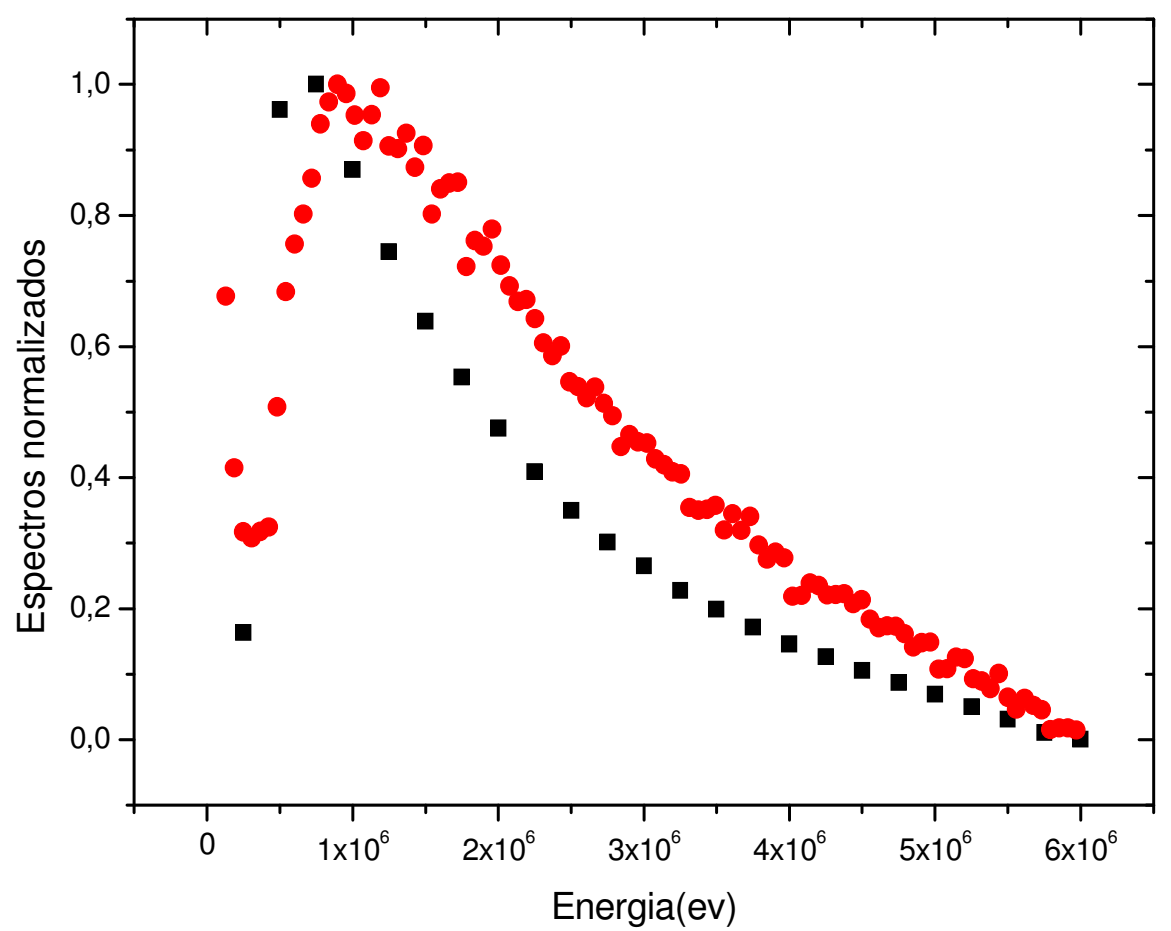

Figura 70 - Comparação entre os espectros de entrada e de saída normalizados para uma $\mathrm{DFS}=90 \mathrm{~cm}$.

O resultado da intensidade de fluência energética mostrada no gráfico da figura 70 revela que, para as energias acima de $10^{6} \mathrm{eV}$, onde existe a predominância do espalhamento Compton, o espectro de saída normalizado apresenta valores superiores ao do espectro de entrada normalizado.

As observações e comentários para o resultado encontrados para a dfs $=70$ $\mathrm{cm}$, também são válidas para os resultados alcançados para a dfs igual a $90 \mathrm{~cm}$.

Entretanto o valor de mínimo encontrado foi de 0,3 para a energia de 2,89 $10^{5}$ eV. 
A figura 71 mostra a intensidade de fluência energética secundária, mais a transmitida normalizada sobreposta ao espectro primário normalizado, para a dfs igual a $110 \mathrm{~cm}$, utilizando um objeto simulador antropomórfico.

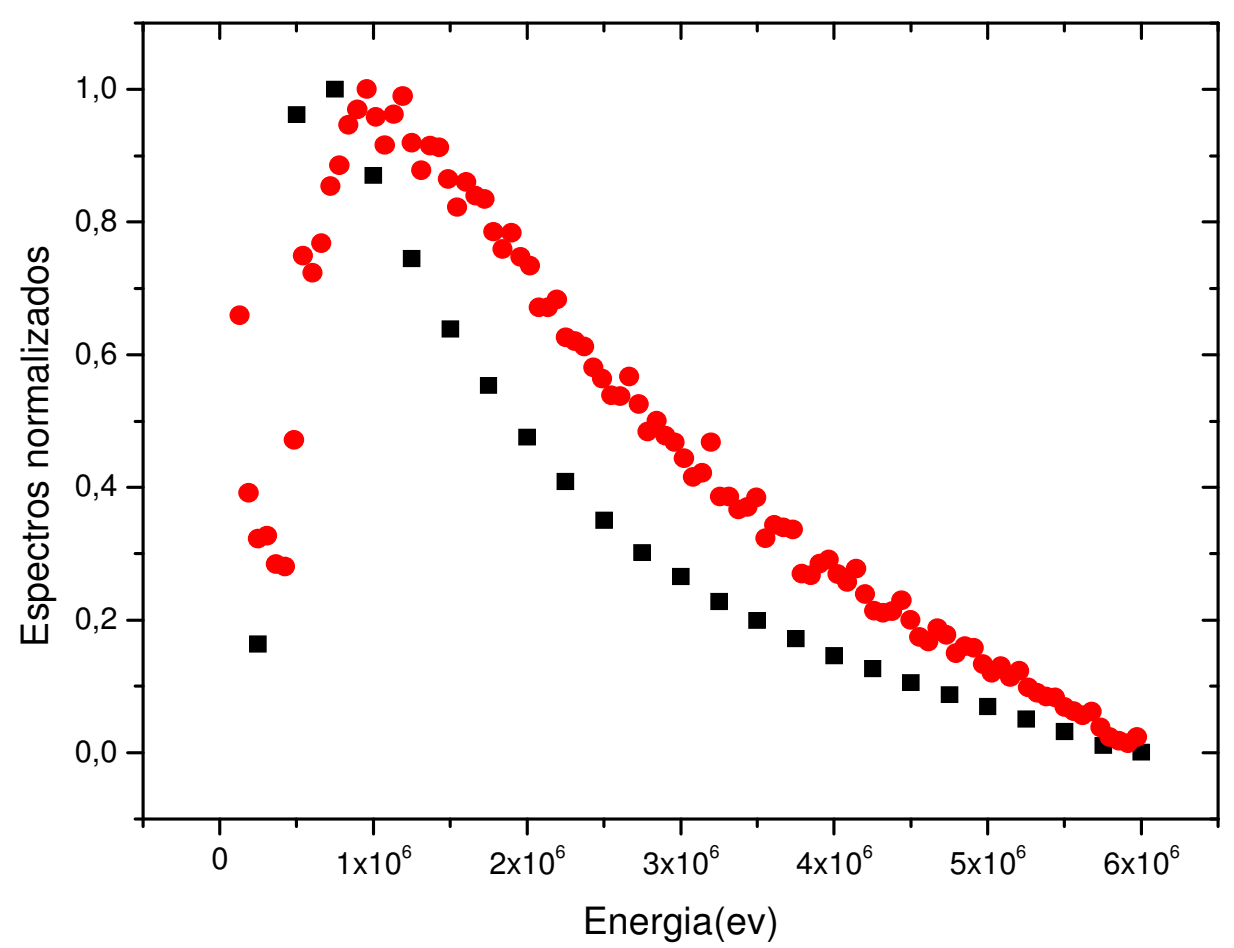

Figura 71 - Comparação entre os espectros de entrada e de saída normalizados para uma DFS $=110 \mathrm{~cm}$.

O resultado da intensidade de fluência energética mostrada no gráfico da figura 69 revela que, para as energias acima de $10^{6} \mathrm{eV}$, onde existe a predominância do espalhamento Compton, o espectro secundário mais o transmitido normalizado apresenta valores superiores ao do espectro primário normalizado.

As observações realizadas para o gráfico da dfs $=7 \mathrm{~cm}$, também são válidas para esse.

Entretanto o valor obtido foi de 0,28 para a energia de $4,1810^{5} \mathrm{eV}$.

A figura 72 mostra a intensidade do espectro de saída normalizado sobreposto ao espectro de entrada normalizado, para a dfs igual $130 \mathrm{~cm}$, utilizando um objeto simulador antropomórfico. 


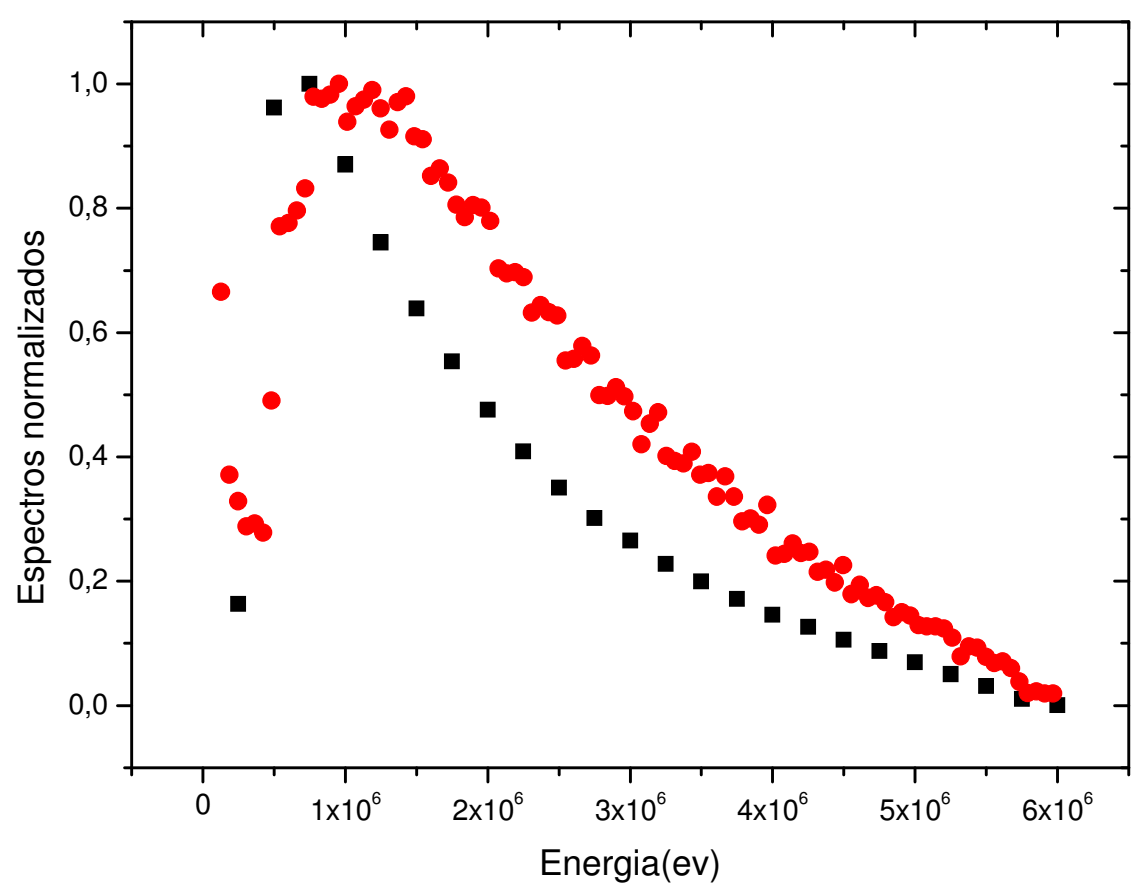

Figura 72 - Comparação entre o espectro de entrada e do espectro de saída normalizados para uma DFS $=130 \mathrm{~cm}$.

O resultado da intensidade de fluência energética mostrada no gráfico da figura 72 revela que para as energias acima de $10^{6} \mathrm{eV}$, onde existe a predominância do espalhamento Compton, o espectro de saída normalizado apresenta valores superiores, ao do espectro primário normalizado.

As observações realizadas para o gráfico da dfs $=70 \mathrm{~cm}$, também são válidas para esse.

Entretanto o valor obtido foi de 0,28 para a energia de $4.10^{5} \mathrm{eV}$. 


\section{CONCLUSÕES}

As variações de resposta para parâmetros clínicos, através do método monte Carlo podem ser utilizadas em trabalhos posteriores no desenvolvimento de algoritmos de transformação da resposta de imagem em dose, devido à obtenção da perturbação que um determinado objeto produz na fluência energética, que entra no corpo devido à interação da radiação com a matéria.

Vale ressaltar que o método monte Carlo consegue determinar a fluência total em um determinado corpo, a qual tem relação com a imagem. Além disso, pode ser utilizado para o estabelecimento de métodos de controle da qualidade baseados em testes que utilize a fluência total como grandeza física de referência.

Esse trabalho constatou o comportamento das fluências energéticas e das energias depositadas em diferentes condições de irradiação, com isso consegue-se entender melhor como um feixe de radiação pode ser perturbado por objetos simuladores e quanto dessa energia é depositada nos detectores externos ao objeto simulador.

Esse trabalho pode ser importante para auxiliar no entendimento de dados controversos obtidos em comissionamento de aceleradores lineares, principalmente para campos pequenos circulares utilizados para aplicações em radiocirurgia.

Com base nos resultados obtidos confirma-se a necessidade de se realizar mais testes, referentes ao controle da qualidade em radioterapia para regiões contidas fora do eixo central do feixe, em virtude da infinidade de fenômenos concomitantes que ocorreram para o eixo central do feixe, que seria uma proposta para realização de futuras aplicações dosimétricas. 


\section{REFERÊNCIAS BIBLIOGRÁFICAS}

World Health Organization. Disponível em: <http://www.who.int/mediacentre/ factsheets/fs297/en/index.html>acesso em 30 de agosto de 2012.

Instituto Nacional do câncer. Incidência de câncer no Brasil. Disponível em:<http://www.inca.gov.br/estimativa/2012/> acesso em 28 de agosto de 2012.

KHAN, F. M. The physics of radiation therapy,3 ed. Philadelphia, 2003.

International Commission on Radiation and Measurements-ICRU. Prescribing, Recording and Reporting Photon Beam Therapy, ICRU 62, Washington DC, 1999.

IAEA, TRS 398. INTERNATIONAL ATOMIC ENERGY AGENCY(IAEA): Absorbed Dose Detrmination in External Beam Radiotherapy: An International Code of Pratice for Dosimetry based on Standards of Absorbed Dose to Water. International Atomic Energy Agency(IAEA). Technical Report Series 398, 2001.

Berdaky, M. F.; Caldas, L. V. E. Implementação de um programa de controle de qualidade de um acelerador linear de 6MV de fótons. Radiol Bras, v. 34, p.281-284, 2001.

Sabet, M. (Sabet, Mahsheed) ${ }^{1,2,3}$; Rowshanfarzad, P ( Rowshanfarzad, Pejman) ${ }^{1}$; Vial, P (Vial, Philip) ${ }^{4,5}$; Menk, FW (Menk, Frederick W. $)^{1}$; Greer, PB (Greer, Peter B. $)^{1,2,3}$. Transit Dosimetry in IMRT with an a-Si EPID in direct detection configuration. PHYSICS IN MEDICINE AND BIOLOGY, v.57, p.N295-N306, 2012.

PENELOPE-2008: A Code System for Monte Carlo Simulation of Electron and Photon Transport. Salvat, F. Fernández-Varzea, J.M., \& Sempau, J, Barcelona.

Handbook of radiotherapy physics, P Mayles, A Nahum, J C Rosenwald, 2007.

TAHUATA, SALATI, DI PRONZIO, Radioproteção e dosimetria, Instituto de Radioproteção e dosimetria, Cnen, Rio de Janeiro, 2003.

KHAN, F. M., The physics of radiation therapy, 3 ed. Philadelphia, 2003.

ATTIX, F. H., Introduction to Radiological Physics and Radiation Dosimetry, Wiley, New York, 1986.

JOHNS, H.E., and CUNNINGHAM, J.R.The Physics of Radiology. Springfield USA: Charles C Thomas Publisher, 1983.

Burman C, Chui CS, Kutcher G, Leibel S, Zelefsky M, LoSasso T, Spirou S, Wu Q, Yang J, Stein J, Mohan R, Fuks Z, Ling CC. Planning, delivery, and quality 
assurance of intensity-modulated radiotherapy using dynamic multileaf collimator: a strategy for large-scale implementation for the treatment of carcinoma of the prostate.

Tissue Substitutes in Radiation Dosimetry and measurement (Report 44), 1989.

Salvat, F., Fernández-Varzea, J.M., \& Sempau, J. A. Code system for Monte Carlo Simulation of Electron and Photon transport, Barcelona, 2005.

Daryoush Sheikh-Bagheriand D. W. O. Rogers. Monte Carlo calculation of nine megavoltage photon beam spectra using the BEAM code, SHEIKH-BAGHERI E ROGERS, 2002

International Atomic Energy Agency, IAEA, 2000, TRS-398, Absorbed Dose Determination in External Beam Radiotherapy: An International Code of Practice for Dosimetry Based on Standards of Absorbed Dose to Water. Vienna. 
